\title{
The Behavioural Ecology of Social Associations in Fishes
}

\author{
by \\ Stacey Sui Yee Lee-Jenkins
}

A thesis submitted to the Faculty of Graduate and Postdoctoral Affairs in partial fulfillment of the requirements for the degree of

\author{
Doctor of Philosophy \\ in \\ Biology \\ Carleton University \\ Ottawa, Ontario
}

(C) 2012

Stacey Sui Yee Lee-Jenkins 
Library and Archives

Canada

Published Heritage

Branch

395 Wellington Street

Ottawa ON K1A ON4

Canada
Bibliothèque et

Archives Canada

Direction du

Patrimoine de l'édition

395 , rue Wellington

Ottawa ON K1A ON4

Canada
Your file Votre référence

ISBN: 978-0-494-93686-3

Our file Notre référence

ISBN: $978-0-494-93686-3$
NOTICE:

The author has granted a nonexclusive license allowing Library and Archives Canada to reproduce, publish, archive, preserve, conserve, communicate to the public by telecommunication or on the Internet, loan, distrbute and sell theses worldwide, for commercial or noncommercial purposes, in microform, paper, electronic and/or any other formats.

The author retains copyright ownership and moral rights in this thesis. Neither the thesis nor substantial extracts from it may be printed or otherwise reproduced without the author's permission.
AVIS:

L'auteur a accordé une licence non exclusive permettant à la Bibliothèque et Archives Canada de reproduire, publier, archiver, sauvegarder, conserver, transmettre au public par télécommunication ou par l'Internet, prêter, distribuer et vendre des thèses partout dans le monde, à des fins commerciales ou autres, sur support microforme, papier, électronique et/ou autres formats.

L'auteur conserve la propriété du droit d'auteur et des droits moraux qui protege cette thèse. $\mathrm{Ni}$ la thèse ni des extraits substantiels de celle-ci ne doivent être imprimés ou autrement reproduits sans son autorisation.
In compliance with the Canadian Privacy Act some supporting forms may have been removed from this thesis.

While these forms may be included in the document page count, their removal does not represent any loss of content from the thesis.
Conformément à la loi canadienne sur la protection de la vie privée, quelques formulaires secondaires ont été enlevés de cette thèse.

Bien que ces formulaires aient inclus dans la pagination, il n'y aura aucun contenu manquant. 


\begin{abstract}
My thesis focuses on the behavioural ecology of social associations using fishes as a study system. The first part of the thesis examined the influence of social familiarity on shoaling behaviour in the banded killifish (Fundulus diaphanus) in the laboratory and the field. Killifish preferred familiar shoal mates and this preference occurred in the form of cliques in the social network of a wild population. These social cliques were assorted by body size and furthermore individuals with apparent key roles in the network were larger than others.
\end{abstract}

The second part of the thesis examined how brood-mixing events shape and influence social associations based on familiarity and kinship during early ontogeny in the convict cichlid (Amatitlania siquia). First, I optimised microsatellite markers for this species to determine if brood mixing occurs in wild broods (in the Rio Cabuyo). I genotyped 50 wild broods and categorized them into sibsets. My data indicated that $78 \%$ of the broods were mixed (contained foreign young). Potentially $26 \%$ of broods contained young from extra-pair copulations. Given the mixed kinship in broods, I performed a four-way choice experiment where I disentangled the effects of social familiarity and kinship on social partner choice in cichlid young (= fry) at varying developmental stages. Smaller fry did not have a shoal preference, whereas larger fry preferred to associate with familiar kin. Lastly, given that fry become separated from their parents and brood mates ( $=$ family) during predation encounters in nature and that some fry have a preference for familiar kin, I performed a 'homing' experiment in both the field and laboratory to determine if fry that were experimentally displaced from their family would successfully 
return to it. Displacement distance influenced the likelihood and time displaced fry took to return to their family in both the field and laboratory, and in the laboratory trials, this relationship was influenced by a fry's body length. The body length of the fish affected the outcome of the field trials; larger fry were more likely to refuge than return to the brood, and smaller fry were more likely to be eaten than to refuge. 


\section{PREFACE}

\section{Co-authorship Statement for Chapters 3, 7 and 9}

Of the six data chapters included in this thesis, Chapter 3 and Chapter 7 are currently published in peer-reviewed articles and Chapter 9 is currently under review.

For Chapter 3 and 9, Dr. Jean-Guy Godin and I collaboratively developed the experimental projects (the questions, logistics, experimental design and analyses). I performed all of the methods, data collections and analyses and wrote up the first draft of the manuscript for these chapters. Dr. Godin provided editorial suggestions and comments which improved these manuscripts.

For Chapter 7, the initial development of this project was in collaboration between Dr. Godin, Dr. Myron Smith and I. The collection of convict cichlid fry in Costa Rica was performed by Dr. Godin and I. I performed all of the microsatellite optimisation procedures (DNA extraction, PCR, fragment analyses) and subsequent data analysis (allele binning and sibset identification). Adam Densmore was instrumental in the further refinement of the DNA extraction and PCR optimisation which was necessary for the future analysis of this large dataset. Dr. Smith provided me with the genetic technique training required to complete this project and provided lab space and equipment to do so. He also provided insights into the analysis of these data. I wrote up the first draft of this manuscript and all three co-authors provided editorial comments and suggestions for revision. 
I have received permission from all co-authors to include our collaborative manuscripts in my doctoral thesis (see Appendices). Moreover, I have permission from each publisher (Chapters $3 \& 7$ ) to reproduce these published manuscripts in my thesis.

To cite this thesis as a whole document or any of the unpublished chapters I recommend the following citation:

Lee-Jenkins, S.S.Y. 2012. The Behavioural Ecology of Social Associations in Fishes. PhD Thesis, Carleton University, Ottawa, Ontario, Canada.

The following citations are the published manuscripts (Chapters $3 \& 7$ ) reproduced herein and the submitted manuscript currently under peer-review (Chapter 9) at the time of thesis submission:

\section{Chapter 3:}

Lee-Jenkins, S.S.Y. \& Godin, J.-G.J. 2010. Social familiarity and shoal formation in juvenile fishes. Journal of Fish Biology, 76, 580-590. Publisher: Wiley-Blackwell.

\section{Chapter 7:}

Lee-Jenkins, S.S.Y., Densmore, A.M., Godin, J.-G.J. \& Smith, M.L. 2011.

Polymorphic microsatellite loci optimised for studies on the convict cichlid fish (Amatitlania siquia). Environmental Biology of Fishes, 92, 261-266. Publisher: Springer.

\section{Chapter 9:}

Lee-Jenkins, S.S.Y. \& Godin, J.-G.J. Concurrent effects of familiarity and kinship on social affiliations in convict cichlid (Amatitlania siquia) young. Behaviour [under review: MS\# BES-S-12-00095] 


\section{ACKNOWLEDGEMENTS}

This thesis is the result of an academic 'journey' and represents a few tangents from my original thesis research proposal. During my time as a graduate student, I have learned so much about adapting to current circumstances, both the good and the bad! This entire process has been both challenging and rewarding for me, and I have many people to thank.

First, I would like to thank my thesis supervisor, Dr. Jean-Guy Godin. Thank you for your guidance, patience and support throughout my graduate career. You have provided me with so many amazing opportunities: field work in Costa Rica and Trinidad, presenting at a large variety of conferences, mentoring students, and moreover you have always encouraged me to expand my professional development (be involved!) and to further develop my skills as a researcher and teacher. I've enjoyed our chats about work/life balance and the many lab dinners at the Godins' (Thank you Heather Godin for the delicious food!). I have learned so much about science during my time in the Godin Lab, thank you for a rewarding and unforgettable experience.

My thesis advisory committee (Drs. Gabriel Blouin-Demers and Mark Forbes, and my supervisor) has provided many helpful suggestions during my committee meetings, for which I am grateful. Additionally, thank you Mark for adopting me into your lab when I first arrived and for the use of your microscope!

Thank you to my friends (many of whom I met in grad school) who have been supportive throughout this process: Stacey Robinson, Colin Henein, Jen Schellinck, Kim Hair, Tonia Robb, Ryan Chlebak, Michelle Zanuttig, Amanda Goth, Katie Lucas, Jen 
McAllister, Andrea Main, Devon Metcalf, and Lara Annett. I have particularly enjoyed being involved in the Biology Department with Stacey Robinson; it has been fun being the 'Staceys' together! Moreover, I would also like to thank my past and present labmates, many of you have become my close friends: Adam, Alex, Sarah, Kim, Pat, Heather, Pierre-Luc, Kat, Rich, Rebecca, Alisa, Amelia, Steph, Shawn, Megan and Keegan. You have been the most amazing lab mates who have kept me laughing and sane! I've enjoyed my many discussions about science with Sarah, Pat and Heather. I would particularly like to thank Adam, Alex, Rebecca and Sarah who contributed directly to my thesis research.

Dr. Brian Wisenden has been a very enthusiastic collaborator on the convict cichlid work. I would like to thank him for sharing his convict cichlid knowledge, introducing me to the Rio Cabuyo and Rio Potrero field sites in Costa Rica and for commenting on portions of my thesis research. I would also like to thank Drs. Grant Brown, Jen Snekser and Murray Itzkowitz who provided some breeding convict cichlids for the Godin Lab cichlid population, which made this thesis work possible. Dr. Tom Sherratt has provided me with a lot of statistical advice throughout this thesis; thank you for always having an open door!

A major portion of my time was spent on the molecular aspects of this thesis. A better part of one year was spent just learning the necessary molecular techniques and trying to find and optimize appropriate microsatellite primers and DNA extraction techniques for convict cichlids. As I initially had no formal molecular training, my genotyping work would not have been possible without the guidance of Dr. Myron Smith 
and with the help of the Smith Lab. To the Smith Lab; Melissa Begin, Rob Smith, Isabel Cruz, Denis Lafontaine, and Kristin Duval, thank you so much for your undying patience and for training me! I would like to particularly thank Isabel for keeping the ABI genetic analyser going and Kristin for teaching me so many different techniques! Myron, thank you for always having an open door, your patience, your enthusiasm and for making me feel like a part of the Smith Lab! The actual sample processing and data collection would not have been feasible without the help of Adam Densmore. Thank you Adam for your DNA extracting genius and helping me PCR, and "ABI" the 1921 samples X 4 loci... eek!

Some of the most rewarding experiences have been the teaching opportunities I have had while doing my doctoral degree. Many thanks to Joan Mallett, Nigel Waltho, Jussi Helava, Mike Weber, Roxanne Ross, Marlene Haley and Joe Lipsett. I would particularly like to thank Joan, for her friendship and support throughout graduate school and for making the Animal Form and Function course such a joy to TA!

I am most appreciative for the funding and scholarships I received throughout my graduate student career from the Natural Sciences and Engineering Research Council of Canada (NSERC), the Ontario Graduate Scholarship Program and Carleton University.

Lastly, thank you to my family for your encouragement, support and love. I am so lucky to have two extremely supportive families. To the Densmores and Bradleys, thank you for your love and support, and especially to my mother and father in-law, Al and Lisa Densmore, thank you for always being there to celebrate my successes, and for being okay with me taking your son away to Ottawa! To my parents, Liz and Alan, thank you for always encouraging me to push myself and for your love and support during my 
continuing education. My siblings, Justin, Claire and Noam: thanks for always taking an interest in what I was doing, and many thanks to my grandparents, Millie and Jim, who supported me in so many ways throughout my education. I love you all, and can't thank you enough.

Lastly, and most of all, I thank my husband Adam. In so many different ways this thesis would not have been possible without you. Thank you for your never-ending support, encouragement, understanding, patience and love. I love you xo. 
To Adam- my husband and 'shoal mate'

and

to our future brood 


\section{TABLE OF CONTENTS}

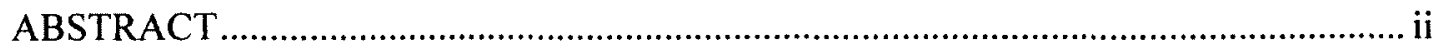

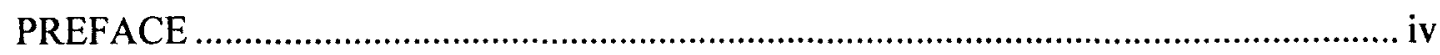

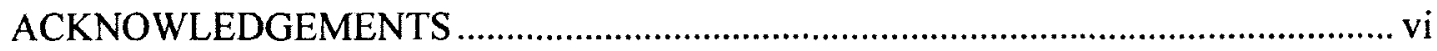

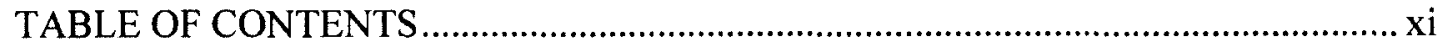

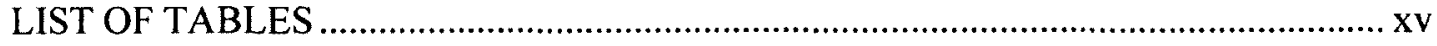

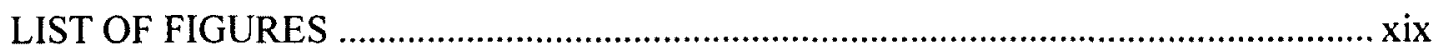

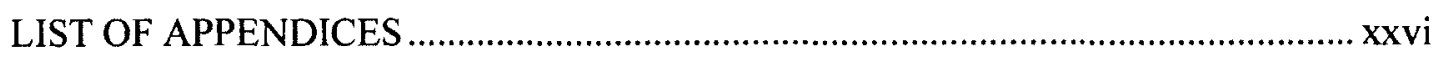

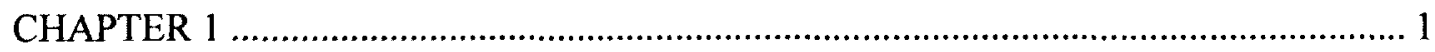

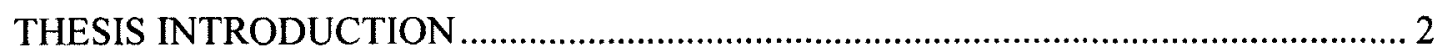

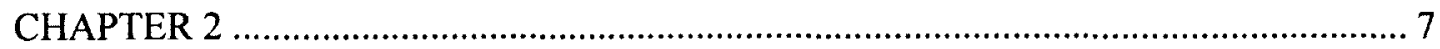

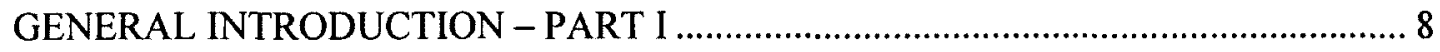

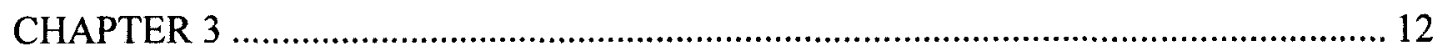

Social familiarity and shoal formation in juvenile fishes

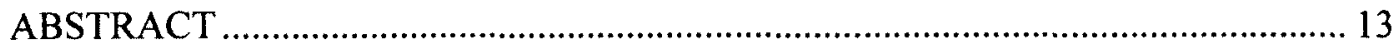

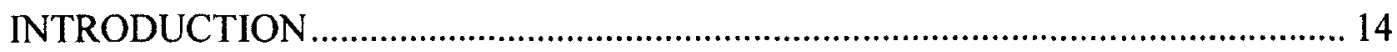

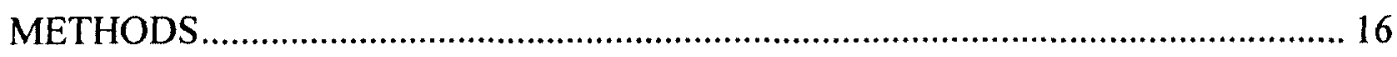

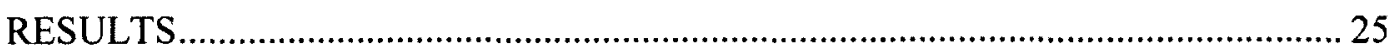

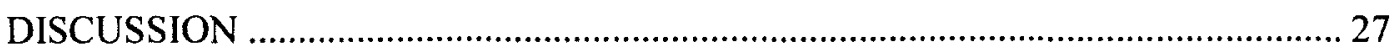


Using social network analysis to examine preferred social associations in wild banded killifish (Fundulus diaphanus)

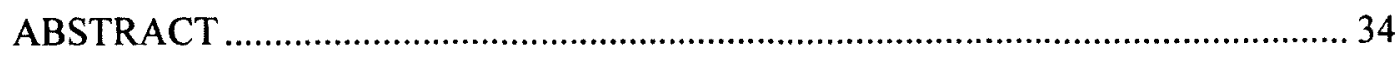

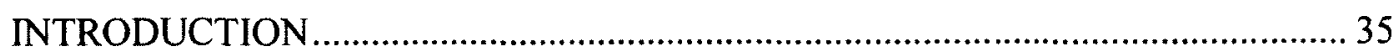

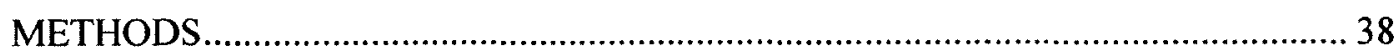

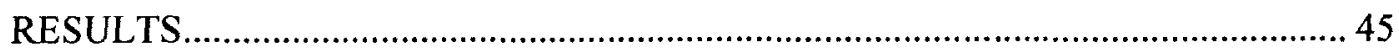

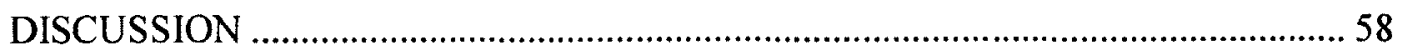

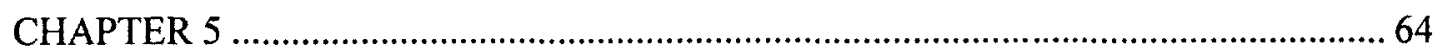

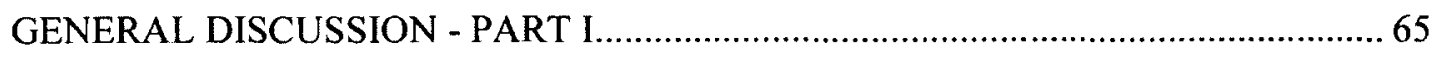

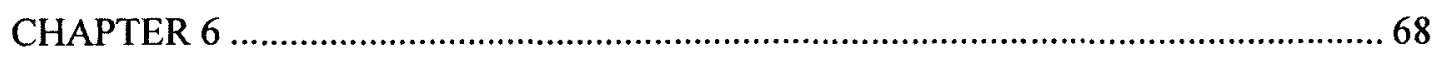

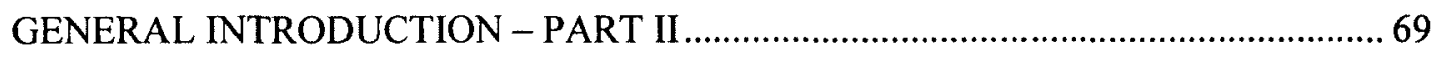

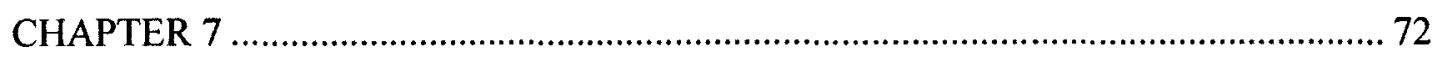

Polymorphic microsatellite loci optimised for studies on the convict cichlid fish

(Amatitlania siquia)

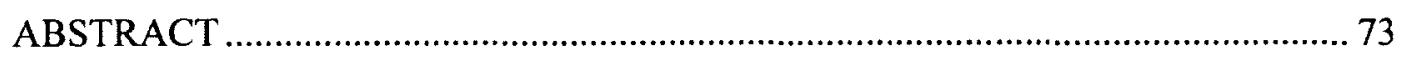

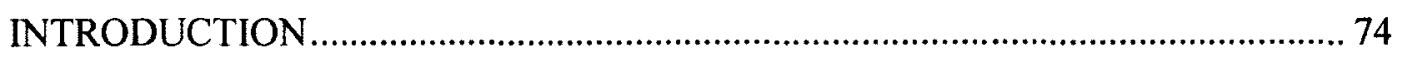

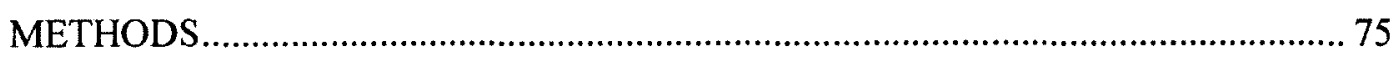

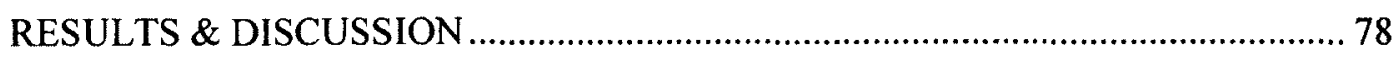


Genetic evidence for brood mixing and alloparental care in the convict cichlid fish (Amatitlania siquia) in nature

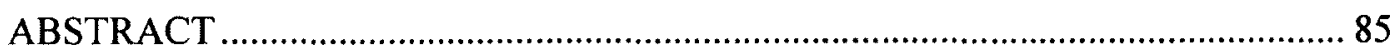

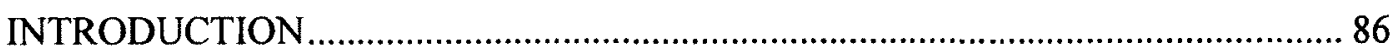

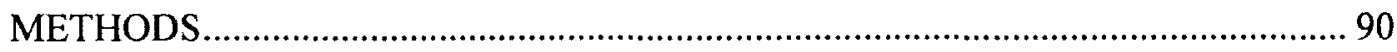

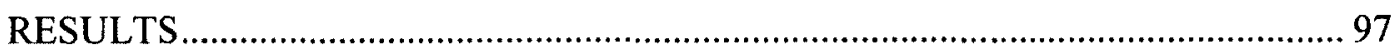

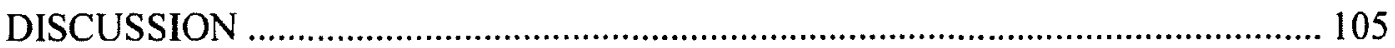

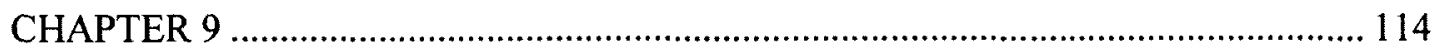

Concurrent effects of familiarity and kinship on social affiliations in convict cichlid

(Amatitlania siquia) young

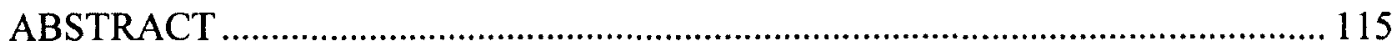

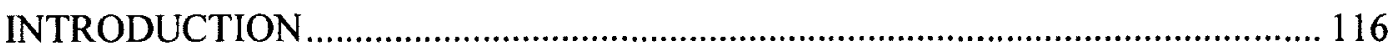

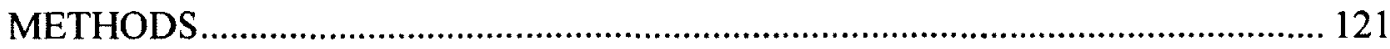

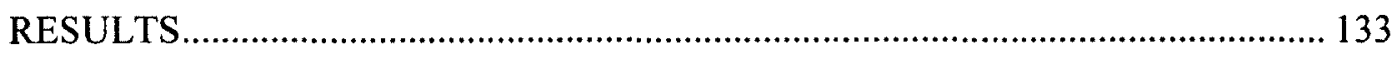

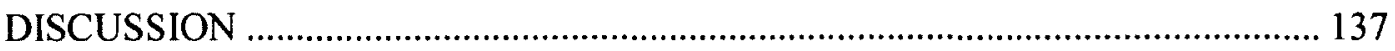

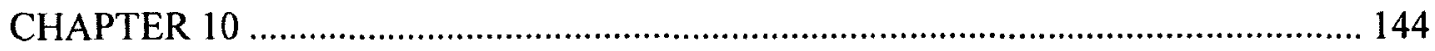

Separation anxiety?: Consequences of spatial separation from the family unit in the young of a biparental fish, the convict cichlid (Amatitlania siquia)

ABSTRACT 


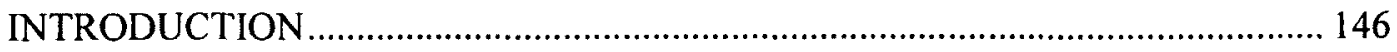

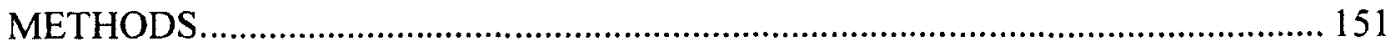

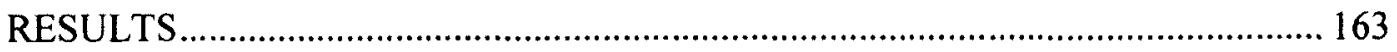

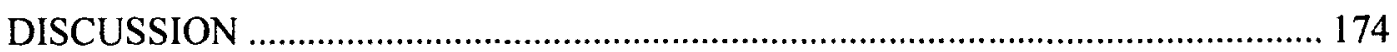

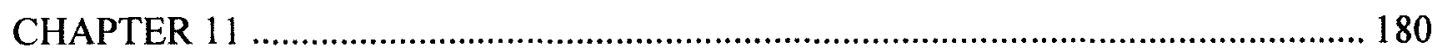

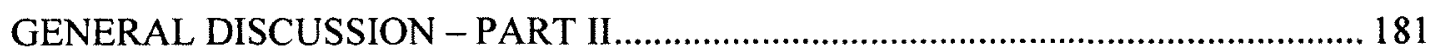

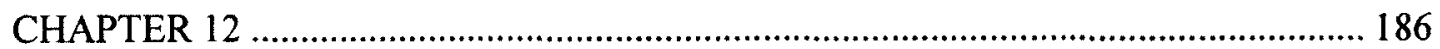

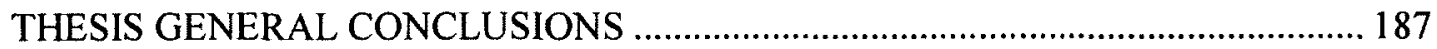

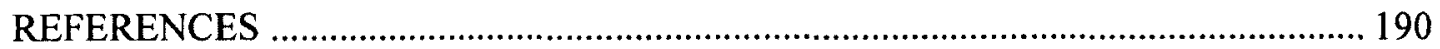

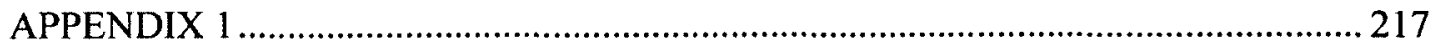

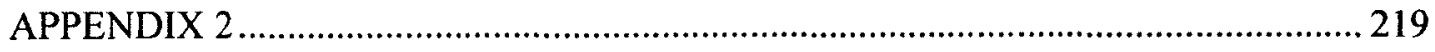




\section{LIST OF TABLES}

Table 4.1. Shoal collections and observations over a consecutive 13-day sampling period.

Table 4.2. Network measures for four different banded killifish edge-filtered social networks (= SRI net) originally containing 120 individuals (filtered at SRI values $\geq 0.1, \geq$ $0.3, \geq 0.5, \geq 0.7$ and $\geq 0.9$, respectively). Labels in the top row represent standard network measures: $\mathrm{N}_{\mathrm{gcc}}=$ the number of individuals in the giant connected component, $\mathrm{E}$ $=$ the number of observed edges in the network, $E_{\max }=$ the maximum number of potential connections in the network, $\mathrm{k}=$ mean number of degrees, $\mathrm{C}=$ the mean clustering coefficient (where $C_{\text {rand }}$ is that of a random network*), $\mathrm{L}=$ the average path length (where $\mathrm{L}_{\mathrm{rand}}$ is that of a random network*) and $\mathrm{B}=$ the average betweenness of the network. The network dissolved at a SRI value of $\geq 0.9$ into 23 components with no giant component cluster apparent. Consequently, average network values could not be computed at SRI $\geq$ 0.9 . 53

Table 7.1. Characteristics of four microsatellites optimised for the convict cichlid, Amatitlania siquia. The size range and minimum number of alleles are based on data for 356 individually genotyped fry from 15 broods, still under parental care, collected from 10 pools in the Rio Cabuyo, Costa Rica. 
Table 7.2. Allele determinations at four microsatellite loci (AcitI, Acit2, Acit3, Acit4) for wild-caught convict cichlid fry from one example brood (Brood I) illustrate how 'host' fry can be distinguished from 'foreign' fry. .82

Table 7.3. Allele designations of three genetically distinct groups of fry identified in Brood I, and the inferred parental genotypes. .83

Table 8.1. The brood composition of 50 convict cichlid broods collected from 12 pool areas in the Rio Cabuyo, Costa Rica. Of the 50 broods, 39 contained foreign fry. Sibling groups of foreign fry (FF) were found in many broods (=FF Sibsets; e.g. Set1) and fry that could not be accurately placed into a sibling group are represented by [FF Mix]. The body size (BL) range of these foreign fry groupings was compared to the body size range of the inferred host fry and categorized as smaller than (=sm), same size as (=same) or larger than (=lg) the host fry (HF) sib-set. $98-99$

Table 8.2. The body size distribution of unmixed broods (containing no foreign fry), which represent $22 \%$ of total number of wild convict cichlid broods sampled. Body lengths $(B L)$ ranged across the entire developmental spectrum from newly freeswimming fry $(\sim 5 \mathrm{~mm})$ to fry approaching independence $(\sim 10$ to $13 \mathrm{~mm})$. Even pools with a relatively high number of broods contained unmixed broods. .100 
Table 8.3. The mean ( \pm s.e.) body length of host fry (HF) and associated potential extrapair copulation (EPC) sibsets, representing a total of 13 out of 50 broods sampled.

Table 10.1. Results from a multinomial logit regression model ( $\log$-likelihood $=-64.48$, $\chi^{2}=41.99, p<0.0001$, for three possible trial outcomes: returned successfully to the brood (Returned), hid/refuged in leaf litter (Refuged), or eaten by a predator (Eaten). The predictor variables were treatment (distance released from brood) and focal fish body length (FFSize) were included in the model. The comparisons in the model were an outcome compared to (vs.) the reference outcome within all possible outcome combinations and predictors. Significant differences are boldfaced. None of the focal fish returned to the brood when released from $80 \mathrm{~cm}$, therefore accurate p-values and coefficients could not be computed (italicised and indicated by $N A$ ). 167

Table 10.2. Comparisons of Cox proportional hazards models and associated AIC values for the combinations of the predictor variables (displacement distance, focal fish body length, and the time-dependent covariate of focal fish body length) for field (a) and lab (b) data. Focal fish family was a cluster variable for both the field and lab models, and river was a second cluster variable for the field data. Model 3 was the best-fit model (lowest AIC value*) in both cases. All $\triangle \mathrm{AIC}$ values here are the differences in AIC value compared to the best fit model 3. 
Table 10.3. Results from the best-fit Cox proportional hazards model for the field (a) and lab (b) data (Field data: overall Wald $z=9.88, \mathrm{df}=4, p=0.043$; Lab Data: overall Wald $z=43.03, \mathrm{df}=5, p<0.0001)$. Distance treatment was a significant variable contributing to the return rate of focal fry to the brood in both the field and lab experiments, and FFSize was a significant variable in the lab experiment. The hazards ratio is represented by $\exp (\operatorname{coef})$ and $\exp (-\operatorname{coef})$. Note that none of the focal fish returned to the brood when released at $80 \mathrm{~cm}$ in the field; consequently, the model parameters for this treatment could not be calculated 172 


\section{LIST OF FIGURES}

Figure 3.1. Schematic (top view) of the experimental tank arena. The area between the perforated stimulus shoal bottle (dashed-lined circle) and the boundary of the shoalpreference zone (solid-lined circle) was the shoal preference zone ( $s$ and $l$, respectively). Zones $f$ and $j$ represented collectively the central zone, whereas $d$ and $k$ denote the end zones. Letters in italics denote keystrokes used in JWatcher for recording location of the focal fish

Figure 3.2. Mean (+ S.E.) proportion of total shoaling time spent near $(\leq 100 \mathrm{~mm})$ the familiar stimulus shoal for juvenile banded killifish $(n=43)$ and juvenile bluegill sunfish $(n=50) . \mathrm{A}^{\text {**' }}$ denotes a $p$-value $<0.05$, proportion of shoaling time spent with familiar stimulus shoal compared to proportion expected by chance for each species separately (above a bar) and compared between the two species. Proportions were compared using one-sample $t$-tests (when comparing to 0.50 ) and a two-tailed $t$-test when comparing between species. The horizontal stippled line denotes the behaviour expected by chance $(=0.50)$

Figure 4.1. Banded killifish social networks of 120 individuals (red circles), wherein the edges were filtered at a simple ratio index $(\mathrm{SRI})$ of a) $\geq 0.1$ and $b) \geq 0.3$. Both networks represent one giant connected component (GCC), where node sizes are scaled to the body size of the individual and the numbers to the right of nodes indicate individual ID........50 
Figure 4.2. Banded killifish social networks of 120 individuals (\# IDs) where edges were filtered at a simple ratio index (SRI) of a) $\geq 0.5$ and $b) \geq 0.7$. The GCC is in red and additional components (separated from the GCC) are indicated by the different colours. In b),blue nodes represent individuals who were no longer connected to the network... 51

Figure 4.3. The network edge-filtered at $S R I \geq 0.9$, wherein there was no longer a GCC and the network dissolved into 23 components. These components represent individuals that were always (or almost always) captured in the same shoal together and may represent strong cliques within the network $(C=1)$. The nodes are sized according to relative body length and the colours represent the relative black spot load of the fish $($ white $=0 ;$ light grey $=1-5 ;$ dark grey $=6-10 ;$ olive green $=11-15 ;$ black $=\geq 16)$. The location of each component illustrated above is random and are spread out for visual purposes only.

Figure 4.4. Body length of each individual fish compared to the mean body length of all neighbouring individuals in their component in the SRI $\geq 0.9$ edged-filtered network. This network contained 23 components (no GCC), varying from 2 to 7 individuals. Body length was correlated amongst component members when ranked amongst all individuals in this filtered network (Kendall's rank correlation: tao $=0.190, \mathrm{n}=82, z=2.54, p=$ $0.011)$. 
Figure 4.5. Black spot number of each individual fish compared to the mean body length of all individuals in their component (= neighbours) in the SRI $\geq 0.9$ edge-filtered network. This resulted in 23 components (no GCC), varying from 2 to 7 individuals. Black spot number was not correlated amongst component neighbours when ranked against other individuals in this filtered network (Kendall's rank correlation: tao $=0.030$, $\mathrm{n}=82, z=0.388, p=0.70)$.

Figure 4.6. Body length of each individual fish in the SRI $\geq 0.7$ edge-filtered network compared to their individual betweenness score. Body length was significantly rank correlated to betweenness (Kendall's rank correlation: tao $=0.13, \mathrm{n}=120, z=2.05, p=$ $0.04)$.

Figure 4.7. Black spot count of each individual fish in the SRI $\geq 0.7$ edge-network compared to their individual betweenness score. Black spot count and betweeness were not significantly correlated (Kendall's rank correlation: tao $=-0.06, \mathrm{n}=120, z=-0.95, p$ $=0.34)$.

Figure 8.1. Relationship between the mean brood body length of foreign fry and that of host fry within 31 mixed broods. The diagonal dashed line is the line of equivalence $(x=$ y), where the mean body lengths of foreign fry and host fry within individual broods are identical. The variation around this line increases with increasing body length [not including the outlier Brood V at $(\dagger)$, which had only one foreign fry]. Points above the 
line indicate that mean foreign fry body length was greater than host foreign fry body length, whereas points below the line indicate that mean foreign fry body length was less than that of host fry 104

Figure 9.1. An example of the set-up of paired rearing aquaria, contained in a water bath, in which newly-hatched young from hypothetical breeding Pair 'A' and Pair 'B' (a set) were placed and reared until tested for their social association preferences. The numbers in brackets indicate the number of young in a particular compartment of the aquarium; each aquarium contained an equal number of fish from each kin group. These numbers were chosen such that the compartment with the largest number of stimulus fish would not be crowded. The particular end compartment in which the stimulus fish (SS) were introduced was randomized. When focal fish from the central compartment of TANK 1 were tested individually in the choice apparatus, they were given a choice to associate with each of four shoals constituted (indicated by the arrows) using stimulus fish (SS) reared in the other two compartments of the aquarium, as denoted by the numbered arrows $(1=$ FK, 2 = UFK, $3=$ FNK, 4 = UFNK).

Figure 9.2. Top view of the experimental four-way choice apparatus. For each trial, the order of the stimulus shoal types (FK, UFK, FNK and UFNK) was randomized with respect to their placement into the end compartment of each arm of the apparatus (SS\#1, SS\#2, SS\#3, SS\#4). The dashed lines in the arms indicate the locations of clear perforated screens, which allowed the transmission of visual and chemical cues between the 
stimulus shoals and the focal fish. The central cylinder was used to temporarily hold the focal test fish (FF) during a viewing period, allowing for its receipt of visual and chemical cues originating from each of the four stimulus shoals.

Figure 9.3. Mean ( $\pm \mathrm{SE}$ ) proportion of shoaling time that small $(6.0-7.5 \mathrm{~mm}, \mathrm{SL})$ and large $(8.0-9.0 \mathrm{~mm})$ focal fry spent with each of the four stimulus shoal types (denoted in the inset box). Each mean value shown was compared against a proportion of 0.25 (indicated by dashed horizontal time) expected by chance using the one-sample $t$-test. Although all proportion data were arc-sine transformed prior to statistical analysis, the results shown here are for untransformed data. Any significant difference (with Bonferroni correction, $\alpha=0.0125$ ) from that expected by chance are shown on the figure.

Figure 9.4. Percentage (and actual number inside histogram bars) of small (6.0-7.5 $\mathrm{mm})$ and large $(8.0-9.0 \mathrm{~mm})$ focal fry that exhibited a preference to affiliate with a particular stimulus shoal out of the four stimulus shoal types presented (denoted in the inset box). The preferred shoal is the one that the focal fry spent the most time shoaling with in a given trial. The distribution patterns of preferred stimulus shoal types exhibited by small and large focal fry were compared using the $G$-test of independence $(\alpha=0.05)$. For each fish body-size category separately, the observed frequency distribution of preferred shoal types was compared against a null distribution expected by chance (denoted by the horizontal dashed-line) using the goodness-of-fit $G$-test $(\alpha=0.05) \ldots .136$ 
Figure 10.1. Top-down view of the laboratory experimental apparatus where each end compartment contained an artificial plant, clay pot and water heater. One of the two end compartments (randomized for each trial) housed the parents and brood mates of the focal fry. The central compartment was the testing/displacement area and was separated from the end compartments by clear, perforated dividers. During a trial, focal fish were displaced to one of four distances $(20,40,60$ or $80 \mathrm{~cm})$ from the edge of the end compartment containing its parents and home brood. Thin bamboo skewers (vertical lines in the central compartment) were partially buried in the gravel substratum of the central test compartment at $10-\mathrm{cm}$ intervals. 160

Figure 10.2. Proportion of focal fish displaced from their home brood that either returned safely to brood, hid/refuged in to leaf litter or were eaten by fish predators upon release into the river at different displacement distances from their home brood and guarding parents. Four focal fish from each of 25 focal broods were displaced and released at each distance treatment. Replicate sample sizes were $23,23,25$ and 23 focal fish for the distance treatment, $20,40,60$ and $80 \mathrm{~cm}$, respectively; two focal fish in each of treatments 20,40 and $80 \mathrm{~cm}$ were either lost from sight or the brood disappeared during a trial. 166 
Figure 10.3. 'Survival' plot of the proportion of displaced focal fish (in the field experiment) that did not return to their home brood (=DNR) as a function of time since being released into the river at different distances from the brood (where the longest time to return was $310 \mathrm{~s}$ ). The four curves represent the four different displacement distances $(20,40,60$ or $80 \mathrm{~cm} ; n=23,23,25$, and 23 , respectively) from which focal fry were released relative to the location of the home brood

Figure 10.4. 'Survival' plot of the proportion of displaced focal fish (in the laboratory experiment) that did not return to their home brood and parents (= DNR) as a function of time since being released into the experimental tank at different distances from the brood (where the longest time to return was $1800 \mathrm{~s}=30$-min trial). The four curves represent the four different displacement distances $(20,40,60$ or $80 \mathrm{~cm} ; \mathrm{n}=22$ for each treatment $)$ from which focal fry were released relative to the location of the home tank compartment. 


\section{LIST OF APPENDICES}

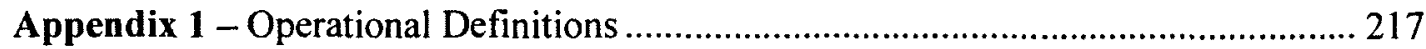

Appendix 2 - Co-author Permission Letters....................................................... 219 


\section{CHAPTER 1}

General Thesis Introduction 
Chapter 1 - General Thesis Introduction

\section{THESIS INTRODUCTION}

\section{Group Living: composition, dynamics and costs and benefits}

Group living is widespread throughout the animal kingdom (see Krause \& Ruxton 2002 and references therein). However, wild animal groups vary widely in membership size, composition, structure and stability (Alexander 1974), and include large aggregations (bold-faced terms are defined in Appendix 1) (Norris \& Schilt 1988), smaller stable cooperative groups (Le Vin et al. 2010) and frequently changing fissionfusion groups (Lehmann \& Boesch 2004; Smith et al. 2008; Kelley et al. 2011), to name a few examples. Thus, understanding the proximate and ultimate factors that have led to sociality has long been of interest to evolutionary and behavioural ecologists (Alexander 1974; Krause \& Ruxton 2002; Ruckstuhl 2007).

The structure and social organisation of animal groups often relates to the ecology of the organism (Jarman 1974), and thus the diversity of social groups observed in the animal kingdom likely reflects the extraordinary range of ecological settings (Sueur et al. 2011). Particularly important ecological factors that can influence sociality in both evolutionary and ecological time scales are the threat of predation and the abundance, distribution and type of food on which species depend to survive and reproduce (Jarman 1974; Sueur et al. 2011; Krause \& Ruxton 2002).

Group dynamics vary both within and between species. Some social groups are highly structured and relatively stable, with a hierarchy amongst individuals (Hinde 1976), while others are unstable with group membership constantly changing (Krause \& Ruxton 2002). Furthermore, the tendency to form social associations can vary throughout 
an individual's life time. Some animals live in groups during their entire life, some only during early ontogenic stages, and others only group together during the breeding season (Krause \& Ruxton 2002). Animal groups also vary remarkably in their group membership sizes (Alexander 1974; Parrish \& Edelstein-Keshet 1999; Krause \& Ruxton 2002).

Fission-fusion social groups are dynamic and are constantly changing as individuals join or leave based on their continuous assessment of costs and benefits associated with group membership (Krause \& Ruxton 2002). Benefits include reduced individual risk of predation risk (Norris \& Schilt 1988; Krause \& Ruxton 2002), increased foraging efficiency (Foster 1985; Krause \& Ruxton 2002), and heat conservation for individuals within the group (Krause \& Ruxton 2002). However, group living can also be costly, with individual risk of parasitism (by contagious parasites; Côté \& Poulin 1995), competition for food resources (Johnsson 2003) and risk of brood parasitism in some parental care species (Krause \& Ruxton 2002) potentially increasing with increasing group size. Therefore, group living is context dependent and members join or leave based on their individual state and the current associated costs and benefits (e.g. Krause 1994).

The dynamics of grouping behaviour have been well studied (reviewed by Krause \& Ruxton 2002). Generally, contemporary research on group living emphasizes the associated costs and benefits from the perspective of the individual (Alexander 1974; Krause \& Ruxton 2002). How an individual assesses these costs and benefits of joining and leaving a group is important as it would influence both the survival and fitness of that individual. Moreover, groups are often non-random in composition (reviewed in Krause 
Chapter 1-General Thesis Introduction

\& Ruxton 2002). Individuals may preferentially associate with one another based on similar phenotypic traits (Hoare et al. 2000b), sex (reviewed in Ruckstuhl \& Neuhaus 2005; Ruckstuhl 2007), kinship (Möller et al. 2006; Piyapong et al. 2011) and/or social familiarity (Griffiths \& Ward 2006). Preferences for familiar individuals develop over time through repeated interactions between individuals, thus requiring the cognitive ability to recognize individuals (Griffiths \& Magurran 1997a). Such preferred associations have implications for the evolution of cooperative interactions, such as in predator inspection behaviour (Dugatkin 1991; Dugatkin \& Alfieri 1991a; Dugatkin \& Alfieri $1991 b$ ), and can affect the stability and composition of social groups.

An advantage to being in a social group (versus being solitary) is that social information is now available to an individual (Valone \& Templeton 2002). In changing environments, information from either conspecifics or sometimes heterospecifics can be crucial for survival (Coolen et al. 2003; Dall et al. 2005). Advantages of having access to and using social information within groups include learned predator recognition from conspecifics (Mathis et al. 1996) and better information on foraging patch quality (Valone \& Templeton 2002; Coolen et al. 2003). If preferred associations based on social familiarity are important when choosing group mates, then perhaps information gained from familiars is beneficial. Indeed, non-familiar individuals do exploit foraging route information from groups of familiar individuals (Ward \& Hart 2005). This could be advantageous as the acquisition and use of social information can be costly under certain circumstances (Giraldeau et al. 2002), and thus familiars may potentially be viewed as a 'more reliable source' of information about the environment. Furthermore, familiarity is 
important in different contexts (outside of group living), such as mate-choice (Boyd \& Blaustein 1985; Hughes et al. 1999; Kelley et al. 1999), resource competition (Ward \& Hart 2003), and territoriality (Griffiths \& Ward 2006; Liebgold \& Cabe 2008).

Examining the role of familiarity in the formation and maintenance of social associations among individuals would contribute to a more comprehensive understanding of the dynamics of group composition, which is still not fully understood (Krause \& Ruxton 2002; Russell et al. 2004). Associations based on familiarity could have important implications for the transmission of social information and diseases/parasites within and between groups (Krause \& Ruxton 2002; Croft et al. 2003; Russell et al. 2004; Wey et al. 2008). Furthermore, repetitive interactions amongst individuals within groups may favour reciprocal altruism and the evolution of cooperation (Dugatkin 1997). If advantages are conferred to individuals that affiliate preferentially with others based on familiarity, then such preferences could have important evolutionary consequences.

\section{General Objective and Organization of the Thesis}

The general objective of my thesis is to further contribute to our understanding of the potential mechanisms underlying preferred social associations in fishes, which commonly form fission-fusion social groups in nature (Godin 1986; Pitcher \& Parrish 1993; Krause \& Ruxton 2002). The thesis focuses on the potential roles of social familiarity and kinship in the formation and maintenance of non-random social associations in two different model fish systems, the banded killifish (Fundulus diaphanus) and the convict cichlid (Amatitlania siquia). 
My thesis is organized into two main sections, each with its own general introduction and general discussion that 'book-end' individual data-based chapters. The first section focuses on the role of social familiarity on shoaling behaviour in the banded killifish in both the laboratory (Chapter 2) and field (Chapter 3; see General Introduction - Part I). In the second section, Chapters 7, 8 and 9 describe the early ontogenic social environment experienced by young convict cichlid fish and characterize the genetic (kinship) structure of broods of young in their natural environment. In Chapter 9, I investigate experimentally how social familiarity and kinship shape social association preferences in young cichlids during early ontogeny, when they are most vulnerable to predation. Lastly, as an extension of this work and in relation to brood mixing, I experimentally test (in Chapter 10) for the ability of convict cichlid young to return to their family (parents and brood mates) when spatially separated from their family unit in both the laboratory and the field (see General Introduction - Part II). 


\section{CHAPTER 2}

\section{Part I - Introduction}

Banded Killifish Shoals \& Social Familiarity 


\section{GENERAL INTRODUCTION - PART I}

Group living in fishes occurs in the form of shoals and schools. A shoal can be defined as an aggregation of fish(es), together for social reasons with no implication for structure or form of the aggregation (Godin 1986; Pitcher \& Parrish 1993). This differs from a fish school, a subset of a shoal, which implies polarity (synchronized swimming) and thus structure for the group (Pitcher \& Parrish 1993). Shoaling behaviour has been well studied, particularly in the Trinidadian guppy, Poecilia reticulata, banded killifish, European minnow, Phoxinus phoxinus, and three-spined stickleback, Gasterosteus aculeatus (e.g., Seghers 1974; Dugatkin \& Godin 1992; Krause et al. 1996a; Krause et al. 1998; Lachlan et al. 1998; Hoare et al. 2000a; Croft et al. 2003; Godin et al. 2003; Hoare et al. 2004). The evolution of shoaling behaviour has been largely influenced by two main benefits it confers upon shoal members, namely, anti-predation benefits and foraging benefits (Godin 1986; Pitcher \& Parrish 1993; Viscido et al. 2004). Different mechanisms underlie anti-predation benefits of shoaling, and anti-predation tactics may vary across species (reviewed by Godin 1986; Krause \& Ruxton 2002). Anti-predation mechanisms of group living include increased probability of detecting predators ('manyeyes' hypothesis), predator confusion and risk dilution with increasing group size (Godin 1986; Parrish 1989; Pitcher \& Parrish 1993; Krause \& Ruxton 2002). Foraging benefits may occur in environments where food is patchily distributed, as there is an increased chance of any given individual finding a food source when foraging in an increasingly large group (Dugatkin \& Mesterton-Gibbons 1996; Krause \& Ruxton 2002). Shoals may also allow individuals to gain access to defended resources. For example, in the blue 
tang, Acanthurus coeruleus, shoaling is the only means by which individuals can gain access to algal mats, as they are defended by damselfish and a lone blue tang will be chased away (Foster 1985). Shoaling behaviour, in addition to providing foraging and anti-predation benefits, also facilitates social learning (Laland \& Williams 1997; Swaney et al. 2001; Croft et al. 2003). Social learning is particularly important as an individual can learn vital information regarding their environment, such as foraging routes and predator recognition, at a greater rate as a member of a shoal than when alone (Laland \& Williams 1997; Croft et al. 2003).

Free-ranging shoals are not composed of random individuals (Griffiths \& Magurran 1999; Croft et al. 2003). Previous studies have demonstrated phenotypic assortment of individuals within wild shoals, and many fish species actively group into shoals according to body length, parasite load, sometimes by sex, and preferentially with conspecifics (Hoare et al. 2000a; Hoare et al. 2000b; Ward \& Krause 2001; Hoare \& Krause 2003). Similar to many other animals, fishes are capable of individual recognition of conspecifics (e.g. Dugatkin \& Wilson 1993; Magurran et al. 1994). This could be particularly important for the formation of fish shoals, which frequently break apart and reform (Croft et al. 2003). The cognitive ability to recognise specific conspecifics implies that fish could preferentially associate with certain individuals over others. With repeated social associations, these individuals would then potentially become 'familiars'.

Familiarity in fishes can be defined as a 'preferred association with certain individuals which have previously interacted' (Ward \& Hart 2005, page 329), and this 
requires time and frequent interactions. Preferred associations in fishes have been previously studied, initially in the context of pair-wise associations and the tit-for-tat strategy in predator inspection behaviour (Dugatkin 1991; Dugatkin \& Alfieri 1991a; Dugatkin \& Alfieri 1991b). Shoaling with familiar individuals may benefit shoal members through enhanced social learning (Swaney et al. 2001), decreased competition for resources (Barber \& Wright 2001), reduced aggression (Barber \& Wright 2001; Seppä et al. 2001), increased foraging rates (Swaney et al. 2001; Ward \& Hart 2005) and enhanced shoal cohesiveness which may reduce individual risk of predation (Chivers et al. 1995; Barber \& Wright 2001).

Moreover, social preferences based on familiarity must be important, as they can override preferences for conspecifics that are based on similar phenotypes (Ward et al. 2003) or preferred group (shoal) sizes (Barber \& Wright 2001). Because association preferences may result in the formation of non-random groups, familiarity also has important implications for group structure.

The following two chapters (Chapters 3 and 4) thus focus on the potential role of social familiarity on shoaling behaviour in the banded killifish. This species is a particularly suitable model species in this context because much is already known about their shoaling behaviour both in nature and in the laboratory (e.g. Krause et al. 1996a, 1996b; Krause et al. 1999; Hoare et al. 2000a; Krause et al. 2000). Because banded killifish shoal during their entire life history, shoaling with familiar individuals would presumably be adaptive, but has yet to be characterized in this species. 
In Chapter 3, I tested in the laboratory for shoaling preferences in juvenile banded killifish and juvenile bluegill sunfish (Lepomis macrochirus) for familiar and unfamiliar shoal mates using a binary-choice paradigm. These two species were compared because they are sympatric in my study lake population (see Methods section) and have different shoaling life histories, with the banded killifish shoaling during their entire life history and the bluegill sunfish shoaling only during the juvenile phase. Thus, social familiarity may potentially play different roles in shoaling partner choice in these two species. In Chapter 4, I expanded on my laboratory work from Chapter 3 to characterize the social structure of free-ranging banded killifish shoals, and the potential influence of social familiarity (as evident by the presence of 'cliques') in a wild population using social network analyses. Lastly, in Chapter 5, I summarize my main findings from the previous two data-based chapters, their limitations, and provide some suggestions for future directions. 


\section{CHAPTER 3}

Social familiarity and shoal formation in juvenile fishes

This chapter is published as: Lee-Jenkins, S.S.Y. and J.-G.J. Godin. 2010. Social familiarity and shoal formation in juvenile fishes. Journal of Fish Biology 76, 580-590. It is reproduced here with permission from Wiley-Blackwell Publishing $\mathbb{C}$ 


\begin{abstract}
The potential influence of social familiarity in shoal-choice decisions was investigated in two sympatric species of north temperate fish, juvenile banded killifish (Fundulus diaphanus) and juvenile bluegill sunfish (Lepomis macrochirus). Groups of socially familiar and unfamiliar conspecifics were formed in the laboratory using wildcaught fish. Juvenile banded killifish demonstrated a strong preference for familiar conspecific shoal mates, whereas juvenile bluegill sunfish exhibited no preference for either unfamiliar or familiar conspecific shoal mates. The differential influence of familiarity on shoal-mate choice in juveniles of these two species could be due to their different ecologies, local population densities and life histories.
\end{abstract}




\section{INTRODUCTION}

In group-living organisms, the decision with whom to associate can affect an individual's fitness (Krause \& Ruxton 2002). In fishes, shoals (social groups) are typically non-randomly assorted (Hoare et al. 2000a; Krause et al. 2000) by species (Krause \& Godin 1994a) and body length (Ranta et al. 1992; Krause \& Godin 1994a; Ward \& Krause 2001), and sometimes by colour (McRobert \& Bradner 1998) and parasite load (Krause \& Godin 1996). Functionally, such assortative shoaling results in the group appearing uniform, which may increase antipredator benefits via the confusion effect (Landeau \& Terborgh 1986; Theodorakis 1989). However, factors other than obvious phenotypic characteristics can also influence shoal-mate choice (Krause \& Ruxton 2002).

In recent years, the effect of social familiarity on shoal choice has been examined (reviewed in Griffiths \& Ward 2006). Social familiarity is a socialization process that may result in an individual preferentially affiliating with others with whom it has previously associated socially (Griffiths 2003 ; Griffiths \& Ward 2006). This social preference develops over time; for example, it has been shown to take 12 days in the Trinidadian guppy, Poecilia reticulata Peters (Griffiths \& Magurran 1997a). Shoaling with familiar individuals may confer advantages such as reduced predation risk (Chivers et al. 1995; Griffiths et al. 2004), increased foraging success (Ward \& Hart 2005), reduced competition for resources (Höjesjö et al. 1998) and increased rates of social learning (Swaney et al. 2001; Ward \& Hart 2005). Moreover, such preferred associations may be retained for several weeks following separation of familiar individuals from one 
another (Brown \& Smith 1994; Bhat \& Magurran 2006). Although several species of fishes are known to prefer to shoal with familiar individuals, some of the evidence for this phenomenon is ambiguous or conflicting (e.g. the guppy: see Griffiths \& Magurran 1998; Godin et al. 2003). Moreover, some fish species have no preference for familiar shoal mates or there are even situations where familiar shoal mates are actively avoided (Frommen et al. 2007a; Gómez-Laplaza \& Fuente 2007). Whether familiarity occurs through individual or general group recognition, or even via a chemical cue preference for fish occupying the same habitat or sharing a similar diet, are important questions, which have been addressed in fishes only recently (Ward et al. 2004, 2005; Webster et al. 2007).

While several studies have tested in the laboratory for a preference for familiar shoal mates in fishes (reviewed in Griffiths \& Ward 2006), none have examined concurrently the influence of social familiarity in shoal formation among sympatric species with different social life histories. The current study therefore investigated the potential influence of social familiarity on shoal-mate preference in juveniles of two sympatric fish species; the banded killifish (Fundulus diaphanus) and the bluegill sunfish (Lepomis macrochirus). Both species are known to shoal (Brown 1985; Godin \& Morgan 1985 ) and commonly co-occur in lakes of eastern North America (Scott \& Crossman 1973). In the current study, these two species co-occur in the small, shallow littoral zone of the study lake, and are of similar body size during the juvenile stage. Mixed-species shoals are occasionally observed (but species segregation within shoals typically occurs). However, these two species differ in aspects of their life-history; banded killifish retain 
their shoaling behaviour throughout their life, whereas bluegill sunfish become territorial during the adult phase (Scott $\&$ Crossman 1973). Therefore, given the differences in their life histories and if familiarity is important for shoaling species, juvenile killifish would be expected to prefer to shoal with social familiars more strongly than juvenile bluegill sunfish. However, previous studies have revealed preferences for familiar shoal mates in bluegill sunfish (Brown \& Colgan 1986; Dugatkin \& Wilson 1992). While no such study has been done with banded killifish, free-ranging killifish shoals in the wild exhibit low shoal fidelity, with frequent shoal membership changes (Hoare et al. 2000a). Based on the latter findings, a preference for familiar shoal mates might alternatively be expected in juvenile bluegill sunfish but not in juvenile banded killifish. These two alternative hypotheses are tested in the current study.

\section{METHODS}

\section{Field Site and Fish Collection}

I collected a total of 100-120 juveniles each of the banded killifish and bluegill sunfish by beach seining (seine length $=3.7 \mathrm{~m}$ ) in the littoral zone of a shallow, sandy

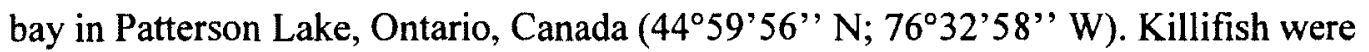
collected on 10 July 2007 and bluegill sunfish on 13 August 2007. Separate collections were made for the two species based on local fish availability and to ensure that fish were not collected during each species' respective reproductive season (April and May, sometimes as late as June, for killifish, Houston 1990; from May to July for bluegill sunfish, Scott \& Crossman 1973). Following collection, the fish were placed into coolers 
containing lake water and transported to the laboratory at Carleton University (transit time about $1.5 \mathrm{~h}$ ). Juvenile fishes were used as subjects to avoid the confounding effect of reproductive behaviour on social associations and because shoaling is an important behaviour during early life-history stages of fishes in general (Shaw 1978; Pitcher \& Parrish 1993). Both species were often observed to shoal (i.e. individuals within three body lengths of their nearest neighbour; sensu Pitcher \& Parrish 1993), occasionally in mixed-species shoals, at the field site.

\section{Fish Holding Conditions}

Laboratory housing conditions were identical for both species. For each species separately, I created 10 different groups of familiar fish by placing 10 fish into each of 10 glass holding tanks ( $38 \mathrm{~L} ; 610 \times 310 \times 290 \mathrm{~mm}$; L x W x H) in the laboratory immediately following their collection in the field. Fish were chosen haphazardly from the coolers in forming these groups. Extra fish were placed into a common stock tank. All holding tanks were visually and chemically isolated from one another. Each tank contained aged tap water, a 2-cm layer of natural aquarium gravel, an artificial plant for cover and a carbon filter, and was exposed to overhead fluorescent lighting on a $13 \mathrm{~h}$ $\mathrm{L}: 11 \mathrm{~h} \mathrm{D}$ cycle. Water temperature varied between $19-22^{\circ} \mathrm{C}$, which is within the natural range of temperatures the fishes experience in Patterson Lake over the summer and early fall.

If any fish died within the first three days of holding, they were removed and replaced with a fish from the stock tank; mortality during this period was low ( $1 \%$ of 
killifish and $2 \%$ of bluegill) and varied little between holding tanks throughout the study (ranging from 0 to 2 dead fish). Fish remained in their holding tanks for 18 days to allow individuals to 'familiarize' with their tank mates. During this period, fish were fed frozen brine shrimp (Hikari ${ }^{\odot}$ Bio-Pure Brine Shrimp, Hikari ${ }^{\odot}$ Sales USA, Inc.) ad libitum two to three times daily. Griffiths and Magurran (1997a) demonstrated that 12 days was required for familiarity to develop in the Trinidadian guppy; therefore, to ensure the development of familiarity in fishes from this study and to compensate for the replacement of any mortality during the first three days, a longer familiarity period of 18 days was chosen.

\section{Experimental Apparatus}

Two identical experimental apparatuses (experimental tanks) were used. One focal fish from each holding tank was tested each day to control for any potential tank and day effects. Each experimental tank was constructed of Plexiglas $(1060 \times 400 \times 380 \mathrm{~mm})$ and covered externally (on all four sides) with tan paper to minimize any external visual disturbances. The tanks contained aged tap water (150 mm height) and approximately 20 $\mathrm{mm}$ of natural aquarium gravel on the bottom. Uniform overhead illumination was provided by a centred fluorescent tube (Sun-Glo ${ }^{\circ}$ Hagen Inc., Montréal, Canada), which simulated the spectrum of sunlight. A full length mirror hung at $45^{\circ}$ at the back and above the tank, which allowed videotaping of the focal fish and stimulus shoals from the side of the tank (into the mirror) without disturbance. Each trial was recorded using a video camera (SONY video Hi8, model CCD-TR3400). Each experimental tank (Figure 


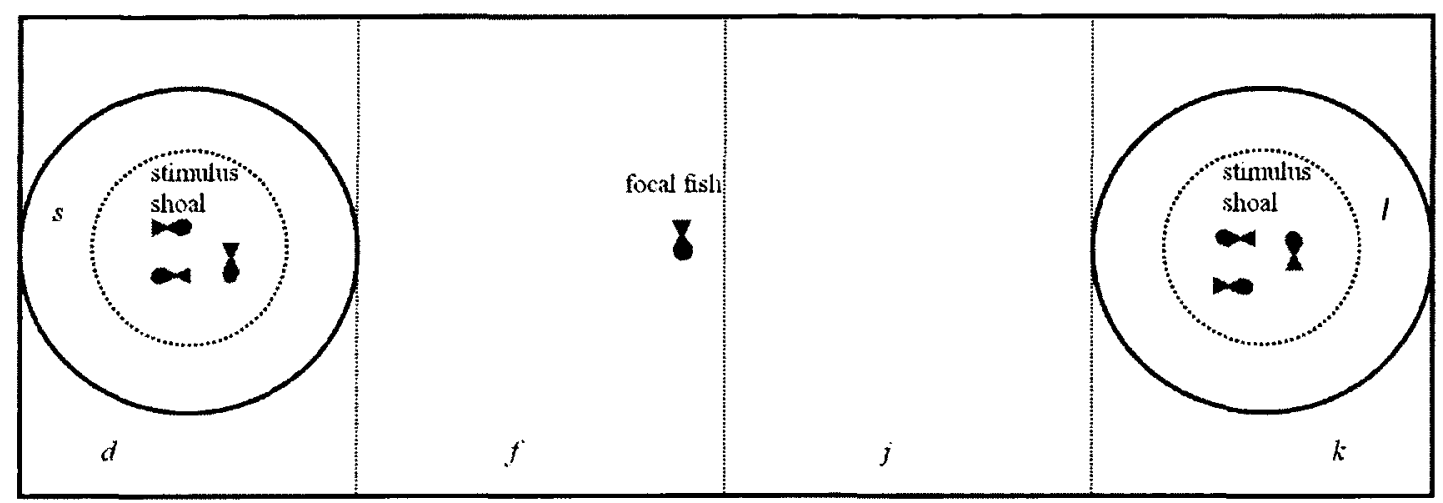

Figure 3.1. Schematic (top view) of the experimental tank arena. The area between the perforated stimulus shoal bottle (dashed-lined circle) and the boundary of the shoalpreference zone (solid-lined circle) was the shoal preference zone ( $s$ and $l$, respectively). Zones $f$ and $j$ represented collectively the central zone, whereas $d$ and $k$ denote the end zones. Letters in italics denote keystrokes used in JWatcher for recording location of the focal fish. 
3.1) was 'divided' into three unequal zones using pieces of clear, lined Plexiglas placed on the substrate across the width of the tank. The zones included the two end zones (each $290 \mathrm{~mm} \times 400 \mathrm{~mm}$ ) and a larger central zone (always the middle section; $480 \mathrm{~mm} \times 400$ $\mathrm{mm})$. In the centre of each end zone, a circular shoal preference zone was delineated ( 300 mm diameter, boundary marked with airline tubing on the substrate) and contained a stimulus shoal bottle in its centre (a clear, perforated 2-L bottle of $100 \mathrm{~mm}$ diameter). Focal fish were thus exposed to both visual and chemical cues from the stimulus shoals. During a trial, one bottle contained a stimulus 'shoal' of familiar conspecifics and the other bottle contained a stimulus shoal of unfamiliar conspecifics. A focal fish that entered either preference zone was thus within $100 \mathrm{~mm}$ of the stimulus shoal and deemed 'shoaling' with it. The shoaling criterion (i.e. $\leq 100 \mathrm{~mm}$ from a stimulus shoal) represented approximately 2-3 fish body lengths, which is within the range of observed inter-individual distances for shoaling fishes in nature (Pitcher \& Parrish 1993), including juvenile killifish and sunfish in Patterson Lake (personal observations).

\section{Experimental Design}

I gave focal fish the choice to 'shoal' with either a stimulus shoal of 3 familiar conspecifics ( $=$ from the same holding tank) in one end zone or a stimulus shoal of 3 unfamiliar conspecifics (= from a different holding tank) in the opposite end zone. Each of the 10 holding tanks for each species separately was 'paired' with another holding tank for the entire experiment (e.g. tank A and B), such that five pairings were formed (A\&B, $C \& D, E \& F, G \& H, I \& J)$. On a given trial day, a focal fish from each holding tank was 
tested for its shoal choice. Trials were paired such that, for a given pair of holding tanks (e.g. A \& B), stimulus shoals were selected from both tanks and a focal fish from each tank was tested using the same pair of stimulus shoals. The order of use of the focal fish (e.g. from A or B first) was randomized using a random numbers table to control for any time-of-day effect. The tank end zone for the location of the two stimulus shoals was randomized for the 'first trial' and remained in the same side for the 'second trial' of each paired trial. As such, the familiar shoal (and similarly the unfamiliar shoal) was located on the right side of the tank in half the trials and on the left side for the other half to control for any potential side bias of the focal fish. A total of 50 focal fish were tested ( 5 focal fish from each holding tank) for each species separately.

\section{Experimental Protocol}

Fish were fed 30 min prior to testing to standardize their hunger level, as hunger has been shown to affect fish shoaling behaviour (Hensor et al. 2003). To minimize potentially confounding phenotypic traits, individuals comprising the stimulus shoals within trials were matched for body length and for number of external parasitic cysts, visible as tiny black spots (likely from a trematode worm; see Krause \& Godin 1996), on the left side of the body, as both these factors have been shown to affect choice of shoal mates in fishes (Ranta et al. 1992; Krause \& Godin 1996). The average ( \pm SE) standard body lengths of all killifish and bluegill sunfish were $44.56 \pm 0.51 \mathrm{~mm}$ (range $=35-57$ $\mathrm{mm}$ ) and $41.15 \pm 0.30 \mathrm{~mm}$ (range $=36-49 \mathrm{~mm}$ ), respectively. The standard body lengths of fish in the matched pairs of stimulus shoals ( $1=$ left side; $2=$ right side) were similar 
(mean \pm S.E.; killifish shoal $1=43.25 \pm 0.48 \mathrm{~mm}$, shoal $2=44.00 \pm 0.48 \mathrm{~mm}$, two-way ANOVA: $F=1.29, \mathrm{df}=1,24, p=0.26$; bluegill shoal $1=41.49 \pm 0.41 \mathrm{~mm}$, shoal $2=$ $41.32 \pm 0.32 \mathrm{~mm}, F=0.26, \mathrm{df}=1,24, p=0.61$ ), as were the estimated number of ectoparasitic cysts on their flanks (killifish shoal $1=3.17 \pm 0.33$, shoal $2=2.57 \pm 0.36$; two-way ANOVA: $F=1.52, \mathrm{df}=1,24, p=0.22$; bluegill shoal $1=2.51 \pm 0.27$, shoal $2=$ $2.21 \pm 0.24 ; F=0.72, \mathrm{df}=1,24, p=0.40$ ). The average $( \pm \mathrm{SE})$ standard body lengths of focal killifish and focal bluegill sunfish were $44.18 \pm 0.49 \mathrm{~mm}($ range $=37-57 \mathrm{~mm})$ and $42.00 \pm 0.39 \mathrm{~mm}($ range $=36-49 \mathrm{~mm})$, respectively. For each experimental trial, the focal fish and the conspecifics forming the stimulus shoals were matched as closely as possible for body length (within $3 \mathrm{~mm}$ ). The above body length ranges for subject fish are smaller than the body length ranges reported for adults of each species; namely, 58 - 70 mm standard length for adult killifish and $69-295 \mathrm{~mm}$ standard length for adult bluegill sunfish (Scott \& Crossman 1973). Therefore, the fish used in the current study are most likely juveniles.

Each focal fish sequentially experienced an initial exploratory period, followed by a shoal-viewing period, and finally a shoal-preference trial (wherein data were collected). Paired stimulus shoals were dip-netted from their holding tanks and temporarily held in separate, covered, opaque buckets containing aged tap water until the viewing period. A focal fish was then dip-netted from its holding tank and placed into an opaque container, which was slowly poured into the centre of the experimental tank. It was allowed to swim freely in this tank for $10 \mathrm{~min}$ (= exploratory period). During this period, the stimulus shoal bottles in each of the two end zones were empty. After the 10-min exploratory 
period, the focal fish was gently dip-netted and placed in a clear, perforated cylinder (diameter $=152 \mathrm{~mm}$ ) in the centre of the experimental tank and stimulus shoals were placed in their respective bottles in the end zones. The focal fish was then allowed to view and receive chemical cues from both stimulus shoals for $20 \mathrm{~min}$. Following this viewing period, the central cylinder was slowly lifted and the focal fish allowed to swim freely and to shoal with either stimulus shoal. The trial started when the focal fish was either hovering in the water column or started swimming. Each trial lasted $30 \mathrm{~min}$, during which the behaviour of the focal fish was videotaped. After the trial was completed, the stimulus shoals were returned to their respective buckets and the water in the experimental tank was stirred vigorously to disrupt any residual chemical cue gradients from the previous trial. For a second (paired) trial, that followed the same protocol as described above, the same paired stimulus shoals were used, but a different focal fish from the other (paired) holding tank was used. At the end of this second trial, the experimental tank was drained and rinsed and refilled with new aged tap water. There was no effect of focal fish order (first or second) in paired trials on the proportion of shoaling time spent with the familiar stimulus shoal for either study species (killifish: ANOVA, $F=0.87, \mathrm{df}=1,41, p=0.36 ;$ bluegill ANOVA, $F=0.31, \mathrm{df}=1,48, p=0.58$ ). Individual focal fish were used only once (always naïve), and paired stimulus shoals were used for only two consecutive (paired) trials. They were returned to their respective holding tanks after use in the behavioural trials. Once trials commenced, a clear, perforated divider was inserted in each holding tank so that used focal fish were separated from the remainder of the fish to ensure that focal fish were tested only once. Stimulus 
fish were sometimes used for more than one trial pairing, and previous focal fish were sometimes used to form stimulus shoals. Stimulus shoal fish were observed to ensure that behaviour was consistent across trials. During the viewing period, the stimulus fish would hover inside their respective bottle and nip the bottle wall in the direction of the nearby focal fish. When the focal fish approached a stimulus shoal, the stimulus fish would increase activity and attempt to approach the focal fish. Both species demonstrated this behaviour and exhibited similar activity levels in the stimulus shoal bottles.

\section{Data Analysis}

I analyzed trials in random order (pre-determined by a random numbers sequence from 'Random.org') and 'blindly' with respect to the identity of the paired stimulus shoals (familiar vs. unfamiliar). Videotaped trials were analysed using JWatcher v1.0 (Blumstein et al. 2006); time spent by the focal fish in both of the shoal preference zones (Figure 3.1) was recorded.

I decided a priori that a focal fish had to have 'sampled' both stimulus shoals at least once (entered the shoal preference zone of both stimulus shoals) to be included in the data analyses. A one-sample $t$-test was used to compare the proportion of total shoaling time the focal fish spent near $(\leq 100 \mathrm{~mm})$ the familiar stimulus shoal to the proportion of total shoaling time expected to be spent near the familiar shoal by chance $(=0.50)$, for each species separately. Two-tailed $t$-tests were also used to compare the proportion of total shoaling time spent shoaling with the familiar stimulus shoal between killifish and sunfish and also, more generally, to compare proportion of trial time spent 
shoaling between the two species. Finally, the frequency of switching behaviour of focal fish (= the number of times the focal fish switched from one preference zone to the other) was compared between the two species using the $t$-test (two-tailed).

All proportional data were arcsine transformed to 'normalize' their distribution prior to analysis. For two-tailed $t$-tests, the degrees of freedom were adjusted for unequal variances between treatment groups. Statistical analyses were performed using JMP 4.0 (SAS Institute Inc., Cary, NC, U.S.A.) and SPSS v13 (SPSS Inc., Chicago, IL, U.S.A.).

\section{RESULTS}

Of the 50 focal fish tested for each species, 43 focal killifish and 50 focal sunfish met our shoaling criterion; that is, they sampled both stimulus shoals at least once. Thus, all the results presented here were based on these 43 focal killifish and 50 focal sunfish.

Killifish spent significantly more time shoaling than bluegill sunfish (mean \pm S.E $=39.4 \pm 3.1 \%$ versus $31.8 \pm 1.4 \%$ of the trial period, respectively; two-tailed $t$-test: $t=$ $2.00, \mathrm{df}=60, p=0.05$ ). However, the frequency of sampling stimulus shoals (switching from one stimulus shoal preference zone to the other) did not differ between killifish and bluegill sunfish $(14.9 \pm 1.7$ and $17.9 \pm 1.0$, respectively; two-tailed $t$-test: $t=1.99, \mathrm{df}=$ $70, p=0.14)$

Familiarity with conspecifics influenced shoal-choice decisions differently in the two species. Killifish preferred to shoal with familiar conspecifics over unfamiliar ones, where $59.1 \%$ of shoaling time was spent with the familiar stimulus shoal (one-sample 


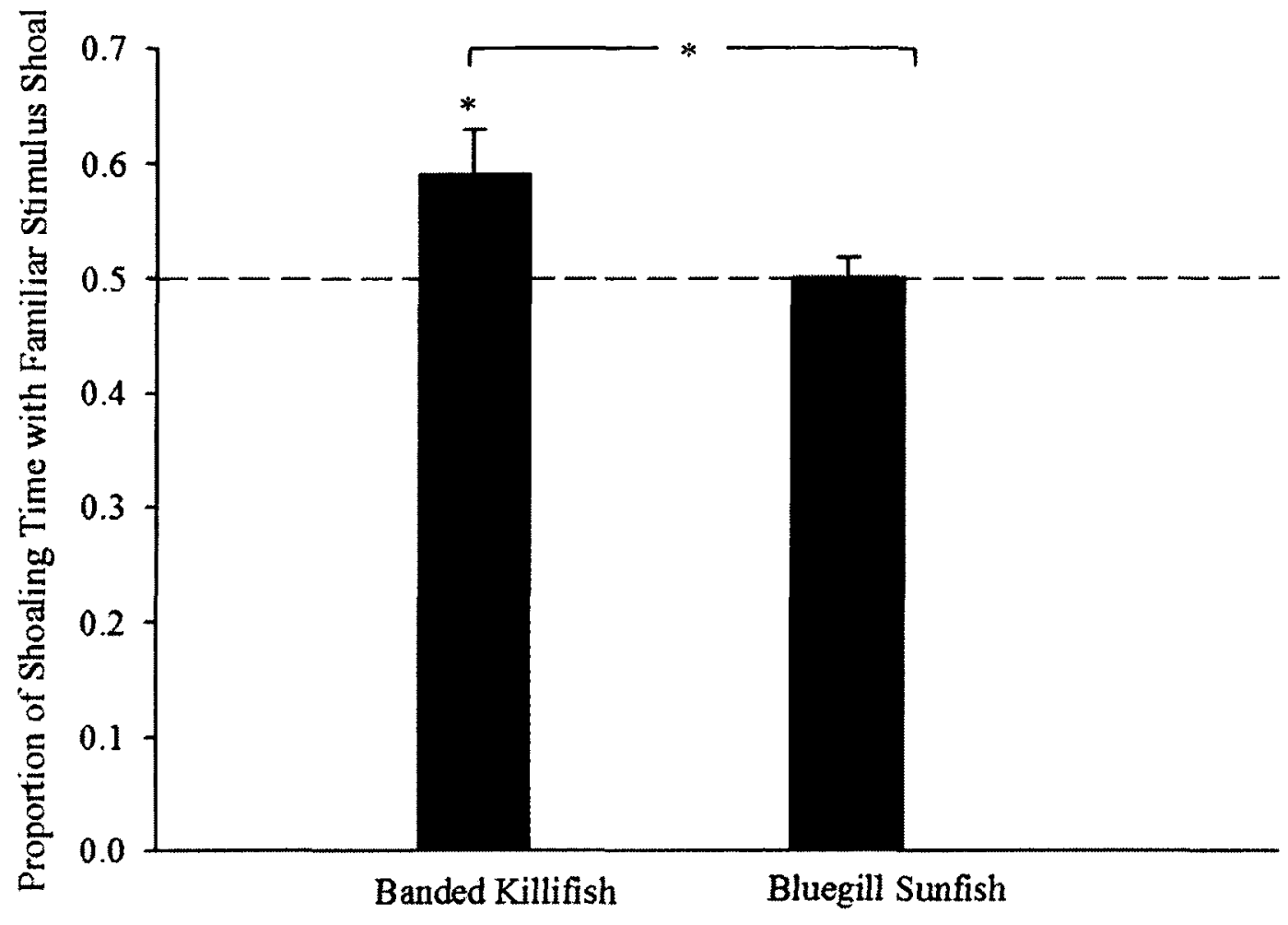

Fish Species

Figure 3.2. Mean ( + S.E.) proportion of total shoaling time spent near $(\leq 100 \mathrm{~mm})$ the familiar stimulus shoal for juvenile banded killifish $(n=43)$ and juvenile bluegill sunfish $(n=50) . \mathrm{A}^{* *}$, denotes a $p$-value $<0.05$, proportion of shoaling time spent with familiar stimulus shoal compared to proportion expected by chance for each species separately (above a bar) and compared between the two species. Proportions were compared using one-sample $t$-tests (when comparing to 0.50 ) and a two-tailed $t$-test when comparing between species. The horizontal stippled line denotes the behaviour expected by chance $(=0.50)$. 
$t$ - test: $t=2.02$, df $=42, p=0.02$; Figure 3.2). In comparison, bluegill sunfish showed no preference to shoal with either familiar or unfamiliar conspecifics; only $50.2 \%$ of their shoaling time was spent with the familiar stimulus shoal (one sample $t$-test: $t=2.01, \mathrm{df}=$ $49, p=0.96$; Figure 3.2 ). Consequently, killifish more strongly preferred to shoal with familiar shoal mates than bluegill sunfish (two-tailed $t$-test: $t=2.00, \mathrm{df}=55, p=0.03$ ).

\section{DISCUSSION}

The current study revealed that sympatric juvenile banded killifish and juvenile bluegill sunfish differed in their shoal-mate preferences; killifish strongly preferred to shoal with familiar conspecifics, whereas bluegill sunfish exhibited no shoaling preference for either familiar or unfamiliar conspecifics.

The absence of shoal-mate preference based on social familiarity in bluegill sunfish is somewhat unexpected, given the known cognitive recognition ability of this species. Dugatkin and Wilson (1992) demonstrated that adult bluegill sunfish preferred to affiliate with a familiar conspecific over an unfamiliar one based on visual cues alone. Brown and Colgan (1986) reported that, of three sunfish species (rock bass, pumpkinseed, and bluegill) tested for a familiarity preference, only juvenile bluegill sunfish showed a preference for familiar shoal mates. They suggested that bluegills should prefer familiar shoal mates because they are frequently found in open water and, as such, shoals are more likely to remain together due to increased vulnerability to piscivorous predators in the pelagic zone of lakes. In contrast, at the Patterson Lake field 
site, juvenile bluegills were commonly found in or near weedy areas of the littoral zone where they are presumably less vulnerable to predators. Moreover, in Brown and Colgan's study (1986), bluegills deemed as 'familiars' were originally captured in a trap together, whereas those used as unfamiliars were taken from a different area of the lake. As such, a preference based on cues associated with a shared habitat (e.g. Webster et al. 2007; Ward et al. 2004, 2005), rather than social familiarity per se, may explain Brown and Colgan's (1986) results, especially given that their fish were tested after only being together for 3 to 7 days. Differences in bluegill sunfish life history phase (adult versus juvenile), habitat where fish originated and experimental protocol could partially explain the differences observed between results of our study and those of Dugatkin and Wilson (1992) and Brown and Colgan (1986).

In the current study, killifish spent on average $59 \%$ of their shoaling time with familiar shoal mates, which is similar to percent shoaling times spent with familiars reported for juvenile guppies (59\%; Griffiths \& Magurran 1999), rainbowfish, Melanotaenia spp. (69\%; Brown 2002), Texas shiners, Notropis amabilis Girard (67\%; Farmer et al. 2004), and blacktail shiners, Cyprinella venusta Girard (66\%; Farmer et al. 2004), for example. The measure of shoal preference used here (time spent within 100$\mathrm{mm}$ radius of a stimulus shoal) was more conservative than that used in many previous studies. In comparison, in other binary-choice experiments, the particular half of the tank where the focal fish is located is often the (more liberal) measure of stimulus shoal preference that is used (e.g. Brown \& Smith 1994; Farmer et al. 2004; Frommen \& Bakker 2004). 
Whether killifish exhibit a preference to associate with familiar conspecifics in nature remains uncertain. Hoare et al. (2000a) conducted a mark-and-recapture study on the composition of free-ranging shoals in the banded killifish in a different lake than the current study. They found at their field site that killifish appeared to exhibit no shoal fidelity, as individuals often switched between shoals of different membership sizes and apparently did not remain with particular shoal mates for any extended period. Observed killifish shoals in the littoral zone of Patterson Lake were comprised of less than 40 individuals (personal observations, 2007), whereas they ranged from between 38 and 160 individuals per shoal in Hoare et al.'s (2000a) study. Large group membership sizes and weak group fidelity would constrain the development of social familiarity among group members and preference to affiliate with familiar individuals (Griffiths \& Magurran 1997b). Perhaps the smaller killifish shoals observed in Patterson Lake facilitate the development and use of social familiarity in shoal-choice decisions in killifish from this study population, at least under laboratory conditions.

Moreover, at the current field site, juvenile bluegill sunfish were far more abundant in the littoral zone than juvenile banded killifish in the summer and early fall of 2006 and 2007 (personal observations). The high density of juvenile bluegills at this field site may have constrained the development and expression of individual or group recognition (leading to familiarity) in this population, as increasing group size is known to adversely affect the development and use of familiarity in shoal-choice decisions (Griffiths \& Magurran 1997b). Dugatkin and Wilson (1993) suggested that developing individual recognition abilities when living in large groups may be too costly. Ward et al. 
(2005) similarly noted that, when local population size is large, individuals may rely more on a general form of odour recognition than on actual individual recognition in deciding with whom to shoal. If juvenile bluegill sunfish use general odour recognition, then this form of recognition may not have been evident in our study as each tank had similar habitat conditions (temperature, water chemistry, fish density) and all fish were fed the same diet. Moreover, a role for social familiarity in shoaling in the wild may be more evident for those species that live in relatively small groups (Griffiths \& Magurran 1997b). Therefore, in the littoral zone of Patterson Lake, shoaling based on social familiarity by juvenile bluegill sunfish may not be favoured because of their relatively high population density and larger shoal sizes compared with banded killifish. In comparison, as killifish were found at much lower densities and in smaller group sizes in this lake, the development and use of social familiarity in individual shoaling decisions may have been favoured in this population, as exhibited in the current laboratory study. Similarly, other studies have found differences in the role of social familiarity in individual shoal-choice decisions within a species. For example, results from experiments with guppies from high- and low-predation populations in Trinidad differed (Griffiths \& Magurran 1998; Godin et al. 2003), suggesting that the development of familiarity or preference for familiars and its role in shoal formation may differ between and within populations of the same species (Godin et al. 2003).

Killifish are a strong shoaling species (Godin \& Morgan 1985; Morgan \& Godin 1985; Krause \& Godin 1994a) and therefore may benefit from shoaling with familiar individuals, potentially through increased antipredator benefits as shoaling in killifish 
reduces predation risk (Godin \& Morgan 1985; Morgan \& Godin 1985; Krause \& Godin 1994a). In contrast, bluegill sunfish shoal during the juvenile life-history stage (Brown 1985), but become more aggressive and territorial during the adult stage (Scott \& Crossman 1973). This difference in life-history might explain in part the different influence of social familiarity on individual shoal-choice decisions between these two study species.

Although the role of familiarity in shoal choice has been previously studied extensively in the laboratory, few studies to date have related laboratory results to field observations (Krause et al. 2000; but see Ward et al. 2002a). Preferential shoaling with familiar individuals may result in the formation and maintenance of social networks within natural populations of fishes (Croft et al. 2005a). Perhaps preferred social associations in juvenile bluegill sunfish occur in nature, but were simply not expressed or confounded under laboratory conditions in the current study. A field mark-recapture study in Patterson Lake (cf. Ward et al. 2002a; Croft et al. 2005a) might therefore reveal preferential social associations among individuals and thus provide insights into the social dynamics of these two species. Moreover, future laboratory studies examining shoal-mate preferences based on general habitat cues (e.g. sandy versus weedy habitat) or diet cues in bluegill sunfish from Patterson Lake could ascertain whether general habitat or diet recognition play a role in shoal-mate choice in this species. Such future laboratory and field work would further contribute towards understanding the role of different recognition mechanisms (general versus individual recognition) in the formation of social associations among free-ranging fishes in nature. 
Chapter 3-Familiarity and Shoaling

\section{ACKNOWLEDGEMENTS}

I would like to thank Alex Wilson for his field assistance and Rodena Bell for access to Patterson Lake. 


\section{CHAPTER 4}

Using social network analysis to examine preferred social associations in wild banded killifish (Fundulus diaphanus) 


\begin{abstract}
Preferential associations or affiliations among individuals based on similar phenotype and(or) social familiarity can potentially lead to the formation and maintenance of non-random social groups in natural populations. Here, I used social network analysis to quantitatively characterize social associations among individuals and the fine-scaled structure of social groups or shoals in free-ranging banded killifish (Fundulus diaphanus), and to determine if social cliques exist, in a natural population. Using a simple ratio index (SRI), I weighted network edges (social association among individuals) and compared edge-filtered networks based on observed association strengths. Banded killifish networks were highly connected at low SRI values, likely due to gambit-of-the-group sampling with large shoal sizes. However, as the strength of association increased with increasing edge-filtering SRI levels, the presence of cliques within the population became evident and calculated values for network clustering coefficient and path length became increasingly different from values expected from random associations among individuals. At a SRI $\geq 0.9$, the network dissolved and 23 components or social cliques, and no giant connected component, was evident. These cliques were assorted by fish body length. At an edge-filter of SRI $\geq 0.7$, where 110 of 120 individuals were connected to another individual (with 1 general network and 3 separate components), the network measure 'betweenness' was positively rank correlated to fish body length but not to ectoparasite load, suggesting that at this network level, larger fish have more central roles or positions within the network. These novel results contribute to our understanding of social organization of animals in nature.
\end{abstract}


Chapter 4 - Wild Killifish Social Networks

\section{INTRODUCTION}

In animal groups, social associations between individuals are often non-random in nature (Krause \& Ruxton 2002; Krause et al. 2007; Croft et al. 2009). Individuals will sometimes preferentially associate with certain social partners and this preference may be based on phenotypic traits, such as species, body size, parasite load or sex (Krause \& Ruxton 2002; Ruckstuhl \& Neuhaus 2005). Moreover, preferred affiliations can also be based on kinship (Wey \& Blumstein 2010; Piyapong et al. 2011) or repeated social interactions, known as social familiarity (Griffiths and Magurran 1997a; Griffiths \& Ward 2006). In fission-fusion societies, group composition is dynamic as individuals frequently leave their current social group and join other groups (Krause \& Ruxton 2002). Such fission-fusion group dynamics raise interesting questions on fine-scale population structure and the influence of association preferences on information and disease transmission through a population. Given such group dynamics and frequent shuffling of group membership in larger groups in particular, the presence of more stable 'cliques of familiars' within a population may be difficult to detect.

Social network analysis is one method for examining group associations at the population level, and is increasingly being used in the fields of animal behaviour and ecology (Krause et al. 2007; Croft et al. 2008; Wey et al. 2008). In social network analysis, individuals (= nodes) are connected with each other based on observed social interactions or associations based on spatial proximity (= edges) over multiple sampling periods (e.g. Croft et al. 2004). Data from these sampling periods are combined and collectively mapped to illustrate direct and indirect connections between all observed 
individuals. Calculated network parameters, association indices, filtering levels and statistics used often depend on the specific question, hypothesis or affiliation pattern(s) being addressed (Croft et al. 2008; Wey et al. 2008; Croft et al. 2011). Social networks are increasingly being used in behavioural ecology (Krause et al. 2007; Wey et al. 2008) and have been applied to examine social structure in dolphin societies (Lusseau \& Newman 2004; Lusseau et al. 2006), group structure in the guppy (Croft et al. 2004; Croft et al. 2006; Croft et al. 2009), and kinship patterns in dominance, grooming and foraging interactions in meerkats (Madden et al. 2012), among other examples.

Fish shoals (social groups) are an excellent example of fission-fusion societies (Krause \& Ruxton 2002). Shoal membership is constantly changing, as individuals join and leave groups (Croft et al. 2009) and from the daily reshuffling events that occur when shoals break apart at dusk and reform the following morning. However, fishes often assort according to phenotype, associating preferentially with conspecifics, by body length, and sometimes by visible parasite load and sex (Krause \& Godin 1996; Hoare et al. 2000a; Hoare et al. 2000b; Ward \& Krause 2001; Hoare \& Krause 2003; Croft et al. $2005 b$ ). Less is known about how familiarity preferences may translate into the presence of 'social cliques' within free-ranging shoals (but see Ward et al. 2002a). When individuals can be identified and their social associations recorded over time, cliques can be identified using social network analysis (Croft et al. 2008).

In the previous chapter, I demonstrated that juvenile banded killifish (Fundulus diaphanus) preferred to associate with familiar over unfamiliar conspecifics in the laboratory (Lee-Jenkins \& Godin 2010). In the latter study, killifish were kept in the same 
tank for 18 days prior to testing so as to allow familiarity preferences to develop. In wild killifish populations, it is unclear whether such preferred associations occur (Hoare et al. $2000 a$ ). Moreover, if killifish occur frequently in large shoal sizes, familiarity between individuals may be less likely to occur (Griffiths \& Magurran 1997b). Many studies on the shoaling behaviour of the banded killifish have been done, primarily from the Lake Morice population in New Brunswick, Canada (e.g. Krause et al. 1996a, 1996b; Krause et al. 1999; Hoare et al. 2000a; Krause et al. 2000; Ward et al. 2002b). Killifish actively choose shoal mates, assort preferentially with conspecifics and similarly-sized individuals in nature (Krause et al. 2000). However, in a study by Hoare et al. (2000a), shoal-specific tags were assigned to 10 killifish shoals that were resampled in the field over a number of days; no shoal fidelity was evident, suggesting a lack of cliques in this population or a need for higher individual-based resolution (using individual tags) to identify cliques if present.

Visible, external parasitism is common in my study killifish population, often appearing as epidermal 'black spots' and occasionally as a few white cysts on the body (personal observations). The black spots are the result of the metacercariae of a digenean trematode parasite encysting in the skin of the fish (second intermediate host) and are not 'contagious' to nearby fish (Krause \& Godin 1994b). In a laboratory study by Krause \& Godin (1996), 'unparasitized' killifish significantly preferred to associate with other unparasitized fish over stimulus fish who appeared to be parasitized with black spot (= black ink spots injected subcutaneously on the flanks to simulate natural cysts), and this preference increased with increasing 'parasite' load in the non-preferred conspecifics. 
However, when given the choice between unparasitized and mixed (parasitized and unparasitized fish) shoals, focal killifish shoaled randomly. Moreover, in a natural population, killifish were not found to assort according black spot load (Krause et al. $1996 a, 1996 b$; Krause et al. 1999), but rather fish with black spot occupied peripheral locations in shoals (Ward et al. 2002b). Based on these findings, the role of ectoparasites (i.e. black spot) on in the formation of particular social associations and shoal composition in the killifish remains unclear.

The objective of this current study was to characterize the social network structure of free-ranging banded killifish in a natural population. Moreover, given that individual killifish from my study population (Patterson Lake) preferred socially familiar over unfamiliar conspecifics as shoal mates in the laboratory (Chapter 3; Lee-Jenkins \& Godin 2010), but did not demonstrate shoal fidelity in a study by Hoare et al. (2000a), I was particularly interested in determining whether wild banded killifish form social 'cliques' and whether individuals assort by body size and(or) ectoparasite load (= black spot or metacercariae cysts) within social networks.

\section{METHODS}

\section{Study Species}

Banded killifish $(\mathrm{n}=171$ fish, mean \pm s.e. $=4.74 \pm 0.06 \mathrm{~cm}$ standard length, range $=3.2-7.2 \mathrm{~cm}$ ) were collected by beach seine over a 3-day period in early May 2010 (water temperature $=13-16^{\circ} \mathrm{C}$; seine length $=3.7 \mathrm{~m}$ ) in the shallow littoral zone of the western bay of Patterson Lake, Ontario, Canada ( $44^{\circ} 60^{\prime} \mathrm{N} ; 76^{\circ} 33^{\prime} \mathrm{W}$ ). At the end of 
each collection day, killifish were transported back to Carleton University in coolers filled with lake water (see Lee-Jenkins \& Godin 2010, or Chapter 3 for details) and all fish were housed together in a large fibreglass tank $(213 \times 66 \times 58 \mathrm{~cm} \mathrm{~L} \mathrm{x} \mathrm{W} \mathrm{x} \mathrm{H,} \mathrm{46-cm}$ water depth) containing a natural gravel substratum, artificial plants and filtered aged water (maintained at about $20^{\circ} \mathrm{C}$ ). Killifish were fed daily with frozen brine shrimp (Hikari ${ }^{\circ}$ Bio-Pure Brine Shrimp).

\section{Tagging: Identifying Individuals}

Six days after the first collection (and three days after the last collection), 149 killifish were individually tagged using visible implant elastomer or VIE tags (Northwest Marine Technology Inc.). Each fish was anaesthetised using MS-222 (0.08g MS-222, buffered with $0.16 \mathrm{~g}$ sodium hydrogen carbonate, per litre of aged tap water) and given unique two-colour tags for identification. A small amount of elastomer $(=\operatorname{tag})$ was injected subcutaneously on the dorsum of the fish using a syringe ( 29 gauge, $1 \mathrm{cc})$, with six potentially different tag locations used; Left Side (=L) Front, Right Side (=R) Front, L Middle, R Middle, L Back, and R Back. 'Front' tags were anterior to the dorsal fin, 'middle' tags were beside the dorsal fin and 'back' tags were posterior to the dorsal fin. A total of five different tag colours were used (red, orange, white, blue and pink). Tag combinations were created in such a way that tag colour identification would not be ambiguous (e.g. pink and orange were never used together). Tagged killifish were kept in a laboratory tank for four days to recuperate from the tagging procedure and to monitor 
tag retention and any mortalities. Only four fish died during this period, and no tags were lost.

A total of 145 tagged killifish were released into Patterson Lake at their initial capture site five days after tagging. Therefore, for a given fish, a maximum of nine days and a minimum of seven days in the laboratory prior to release in the field were possible. It is known that 12 days and 18 days are required for a shoaling preference for familiar conspecifics to develop in the guppy, Poecilia reticulata (Griffiths \& Magurran 1997a) and the banded killifish (see Chapter 3; Lee-Jenkins \& Godin 2010), respectively. Therefore, laboratory-induced familiarity preferences among tagged killifish fish whilst held in the laboratory in the current study were unlikely to have developed prior to their return to their lake of origin for subsequent tracking.

An additional 22 killifish were kept in the same tank in the laboratory (i.e. not released into their lake of origin after capture); half of these fish were tagged and the other half were not tagged. After one week, each fish was given a binary choice to shoal with either a size-matched tagged or a size-matched sham-tagged conspecific to test for any effect of the visible tags or the tagging procedure on social-association preferences. Neither tagged or sham-tagged fish exhibited a preference for either sham or tagged stimulus fish when the (arcsine-transformed) proportion of shoaling time spent with the tagged stimulus fish was compared to random choice (i.e. the null expectation of 0.50 ; one-sample $t$-test: tagged focal fish, $t=-0.16, \mathrm{df}=10, p=0.88$; sham-tagged focal fish, $t$ $=-1.18, \mathrm{df}=10, p=0.26)$. These tagged individuals were kept in the laboratory for two months to monitor tag retention; no tags were lost during this time. VIE tags are known 
to cause few mortalities and to be retained by individual fish for several months (e.g. Dewey \& Zigler 1996; Wilson \& Godin 2009). Therefore, I have considerable confidence that the tagged killifish that were released in Patterson Lake retained their individual tags for the duration of the current study and that individual fish could thus be reliably identified when subsequently observed as members of sampled shoals in the field.

\section{Phenotypic Attribute Measures}

When individual fish had been anaesthetized, and prior to the tagging procedure, their right and left sides were digitally photographed. Each photograph was viewed on a computer monitor and the number of ectoparasitic black spots and white cysts on both flanks of the fish were enumerated and the fish's standard body length was measured using ImageJ software. Body length and prevalence of black spots were used as individual-specific phenotypic attribute measures in my social network analyses (white cysts were not common and excluded from the analysis, see Results section).

\section{Collecting Social Network Data}

Five days after releasing tagged individuals into Patterson Lake, I observed and collected distinct shoals daily from the littoral zone of the lake between 11:00-14:00 hrs for 13 consecutive days (15-26 May). This 5-day 'break period' between release and resampling allowed ample time for the re-integration and mixing of tagged fish into the population and for frequent fission-fusion events to occur between free-ranging shoals. 
For a given day of sampling, tagged fish were deemed to be associating with one another if they were caught or observed (and confirmed) to be within the same shoal (= gambit of the group), or within 3 body lengths of each other (Pitcher \& Parrish 1993). Lone tagged fish were also captured, but were shoaling with non-tagged individuals. Distinct shoals were observed and confirmed independently by two observers, digitally photographed with a polarized telephoto lens when possible, and then collected in their entirety using a beach seine without causing artificial fission-fusion events. Collected fish were kept in coolers filled with lake water until all sampling had been completed for the day. All tagged individuals within each collected shoal were identified, after which a group photograph of all the fish in the shoal was taken from above whilst they were still in their cooler as a further record of recaptured individuals. After all individuals from the sampled shoals had been identified and photographed on a given day, they were released together into the lake near the site of their capture and allowed to freely mix. Thus, fish were only resampled once daily (i.e. belonged to one shoal only on a giving sampling day). These association data for individually-tagged fish were accumulated over the 13day period and form the basis for the construction of the social network.

\section{Social Network Analysis}

Using the social association data gathered on individually-tagged fish (see above), a simple ratio index (SRI) was calculated between each individual and all other individuals in the dataset. The SRI is a measure of the weighted associations (= edges) between individuals (= nodes) in a network and thus the relative strength of an association 
between any two individuals (Croft et al. 2008; Whitehead 2008; Croft et al. 2009). It is calculated as $\mathrm{SRI}=\mathrm{X} /\left[\mathrm{X}+\mathrm{Y}_{\mathrm{ab}}+\mathrm{Y}_{\mathrm{a}}+\mathrm{Y}_{\mathrm{b}}\right]$, where $\mathrm{X}$ is the number of times two individuals were observed in the same group, $\mathrm{Y}_{\mathrm{a}}$ is the number of times individual ' $\mathrm{a}$ ' was viewed in a group without ' $b$ ', $Y_{b}$ is the number of times individual ' $b$ ' was viewed in a group without ' $a$ ', and $Y_{a b}$ the number of times both $a$ and $b$ were viewed but were not in the same group. Calculated SRI values potentially range between 0 and 1 , with a $\mathrm{SRI}=0$ indicating that two individuals never associated and a $\mathrm{SRI}=1$ indicating that the pair was always associated together when observed. An association matrix of all pairwise SRI values was created using the social network software program SOCPROG (Whitehead 2008, 2009).

Only fish that were recaptured on more than one sampling day were used to construct the association matrix, because weak association edges created from infrequently observed associations are known to bias social network data (Croft et al. 2008). I used SRI values instead of observed association frequencies because SRI values weight association data rather than rely on absolute counts of the number of times individuals were observed together. For example, if two individuals ('a' and 'b') were shoal mates 4 times, this may be counted as a high absolute association value. However, if individual ' $a$ ' was re-sampled 8 times and the other 4 times ' $b$ ' was absent or in a different shoal, then only half of the time was individual ' $a$ ' with ' $b$ '. Because I am interested in the role of familiarity on social associations and particularly on the presence of persistent cliques in the population, the SRI method of weighting network edges provides a more robust indication of true preferred associations at a population-level 
scale. When social networks are being constructed based on the 'gambit of the group', as in the current study, weighted measures of associations have been demonstrated to be more robust than unweighted ones (Franks et al. 2010). Moreover, because fish shoals are fission-fusion groups and individuals within a group may be frequently or infrequently found together at any given sampling time (Krause \& Ruxton 2002), a weighted association index is most appropriate for determining which individuals have strong or true associations (Croft et al. 2009)

\section{Network Filtering and Network Measures}

Constructed social networks were initially visualized using NETDRAW (Borgatti 2002) at different SRI values (or SRI edge-filters) to first qualitatively examine network connections and structure. Standard network measures were calculated to characterize banded killifish network structure at varying SRI values using UCINET 6.0 (Borgatti et al. 2002). These measures were mean network degree (k), mean clustering coefficient (C), mean path length (L), and mean betweenness (B) (Croft et al. 2004, 2008). For example, for individual ' $a$ ', a particular network degree value indicates how many neighbours (edges) 'a' has, the clustering coefficient describes how connected the neighbours of ' $a$ ' are to each other (cliquishness), the path length describes the smallest number of edges required to connect ' $a$ ' to any another node or individual (e.g. 'b'), and betweenness describes the number of times the minimum path length between two nodes must 'go through' individual 'a' (see Croft et al. 2008 for more detailed descriptions). For the average $C$ and $L$, a corresponding random $C$ and random $L$ value was calculated. This 
is done by keeping the number of degrees, nodes and edges of the observed network constant, whilst randomizing all possible connections (E) between individuals (see Croft et al. 2008).

\section{Social Associations and Individual Phenotypic Attributes}

The potential influence of the phenotypic attributes (body length and number of ectoparasitic black spots) of individual fish on their social associations was ascertained using non-parametric Kendall's rank correlation analysis in R v2.15.11 (R Development Core Team 2008). First, in the SRI $\geq 0.7$ network, I examined how these attributes might correlate to an individual's betweenness values in the network, where a higher betweenness value indicates that a particular individual has a more central role in the network than others. I also compared individual body length to the mean body length of all other (neighbouring) individuals in a component (clique) across all cliques, in the (SRI $\geq 0.9$ ) network (Croft et al. 2006). This was similarly done for black spot count and these comparisons ascertained whether cliques in this network assorted by body size and black spot count. Justification for using these edged-filtered networks (SRI $\geq 0.7$ and $S R I \geq 0.9$ levels) in the above correlational analysis is provided in the Results section below.

\section{RESULTS}

Over the 13-day resampling period, I recaptured 131 of the 145 tagged killifish (a $90 \%$ recapture rate), corresponding to a total collection of 38 shoals and 525 fish records 
(Table 4.1; no shoals were observed on day 13 of sampling). Of the 131 recaptured fish, 11 individuals were only observed once and were removed from the social network data set, thus leaving 120 repeatedly-observed individuals for social network analysis.

The mean ( \pm s.e.) body length (at the time of tagging) of these 120 fish was $4.97 \pm$ $0.06 \mathrm{~cm}$ (range $=3.16-7.25)$ and they had $5.89 \pm 0.59$ black spots (range $=0$ to 27$)$ and between 0 to 3 white cysts (mode $=0$ ) on their sides; only 23 fish had white cysts. As mentioned above, the phenotypic assortment of white cysts was not examined because of its low prevalence in the population.

Visual inspection and network measures of the SRI edge-filtered networks indicated that individuals were highly connected at low SRI values (see Table 4.2; Figure 4.1), resulting in a high clustering coefficient and small average path length. This result is likely an artefact that commonly occurs in 'gambit-of-the-group' sampling and low association weights/indices (Croft et al. 2008; Franks et al. 2010). At low SRI values of $\geq$ $0.1-0.3$, all 120 individuals were directly or indirectly connected, forming a giant component cluster (GCC: Figure 4.1). As the SRI value increased, separate components that were no longer connected to the GCC emerged. The SRI $\geq 0.5$ edge-filtered network had two components: the GCC (118 individuals) and one separate component of two individuals (Figure 4.2a). The SRI $\geq 0.7$ edge-filtered network had 4 components (Figure $4.2 b)$, namely, the GCC (100 individuals), a component of 6 individuals and two components with 2 individuals each. In addition, 10 individuals were no longer connected to any individuals in the network at this higher association index (Figure 4.2b). At a SRI $\geq 0.9$, the GCC completely dissolved and 23 separate components were left (Figure 4.3). 
These components varied in membership size (from 2 to 7 individuals) and represented individuals who were almost always or always observed in the same shoal (Figure 4.3).

Not surprisingly, as edges were filtered for higher SRI values, the mean degree of the network decreased, indicating that individuals had fewer neighbours. The clustering coefficient also decreased until the network was filtered at $\mathrm{SRI} \geq 0.9$, where its value $=1$. This indicated that, for a given node in this network, all its neighbours were connected, indicating a high level of cliquishness within these components (Table 4.2; Figure 4.3). When the observed clustering coefficient (C) was compared to the random clustering coefficient $\left(C_{\text {rand }}\right)$ for a given network, they were the same at a low $S R I \geq 0.1$, but $C$ was greater than $\mathrm{C}_{\text {rand }}$ for the other the edge-filtered networks with a GCC. At the highest filtering level with a GCC (SRI $\geq 0.7$ ), individual nodes were considerably more clustered $(C=0.58)$ than expected from random $(C=0.15$; Table 4.2). Likewise, the observed path length $(L)$ was always greater than the random path length $\left(L_{\text {rand }}\right)$, and this difference increased with increasing edge-filtering. Thus, on average, the minimum path length connecting any two individuals in the network increased with increasing edgefiltering level. The betweenness value (B) also increased with increasing filtering, indicating that the average number of shortest paths between a pair of nodes that passed through a given individual increased. In other words, particular individuals had greater roles (i.e. key social connectors to other individuals) in the network.

When the GCC dissolved into 23 components or cliques at $\mathrm{SRI} \geq 0.9$, the body length of individuals within a component was correlated to the mean body length of (neighbouring) individuals in that component (Kendall's rank correlation: tao $=0.190, \mathrm{n}$ 
$=82, z=2.54, p=0.011$; Figure 4.4). This was not true for black spot count (Kendall's rank correlation: tao $=0.030, \mathrm{n}=82, z=0.388, p=0.70$; Figure 4.5 ). These results suggest that individual fish within cliques were assorted by body length but not by ectoparasite load (black spot).

For the highest edged filtered network (SRI $\geq 0.7$ ) that contained a GCC thus generating network measures (Table 4.2), the body length of an individual was marginally correlated to its betweenness value in the network (Kendall's rank correlation: tao $=0.13, \mathrm{n}=120, z=2.05, p=0.04 ;$ Figure 4.6$)$, but black spot count was not (Kendall's rank correlation: tao $=-0.06, \mathrm{n}=120, z=-0.95, p=0.34$; Figure 4.7). Of course, I could not carry out such a correlational analyses on betweenness at the SRI $\geq$ 0.90 edge-filtering level because the general network dissolved into a number of components or cliques at this level, and thus no network measures could be generated for comparison (Table 4.2), as previously mentioned above. 
Table 4.1. Shoal collections and observations over a consecutive 13-day sampling period.

\begin{tabular}{|c|c|c|c|}
\hline Day & \# Shoals & ID\# (\# members) & Total \# Fish \\
\hline 1 & 1 & $1(1)$ & 4 \\
\hline 2 & 3 & $\begin{array}{l}2(107) \\
3(5) \\
4(1)\end{array}$ & 113 \\
\hline 3 & 5 & $\begin{array}{l}5(9) \\
6(20) \\
7(52) \\
8(2) \\
9(2) \\
\end{array}$ & 85 \\
\hline 4 & 5 & $\begin{array}{l}10(20) \\
11(13) \\
12(4) \\
13(13) \\
14(10) \\
\end{array}$ & 60 \\
\hline 5 & 7 & $\begin{array}{l}15(32) \\
16(8) \\
17(1) \\
18(12) \\
19(2) \\
20(5) \\
21(4) \\
\end{array}$ & 64 \\
\hline 6 & 4 & $\begin{array}{l}22(10) \\
23(6) \\
24(5) \\
25(46) \\
\end{array}$ & 67 \\
\hline 7 & 4 & $\begin{array}{l}26(10) \\
27(51) \\
28(22) \\
29(6)\end{array}$ & 89 \\
\hline 8 & 2 & $\begin{array}{l}30(8) \\
31(2)\end{array}$ & 10 \\
\hline 9 & 1 & $32(1)$ & 1 \\
\hline 10 & 2 & $\begin{array}{l}33(11) \\
34(2)\end{array}$ & 13 \\
\hline 11 & 1 & $35(1)$ & 1 \\
\hline 12 & 3 & $\begin{array}{l}36(3) \\
37(13) \\
38(2)\end{array}$ & 18 \\
\hline 13 & 0 & 0 & 0 \\
\hline
\end{tabular}



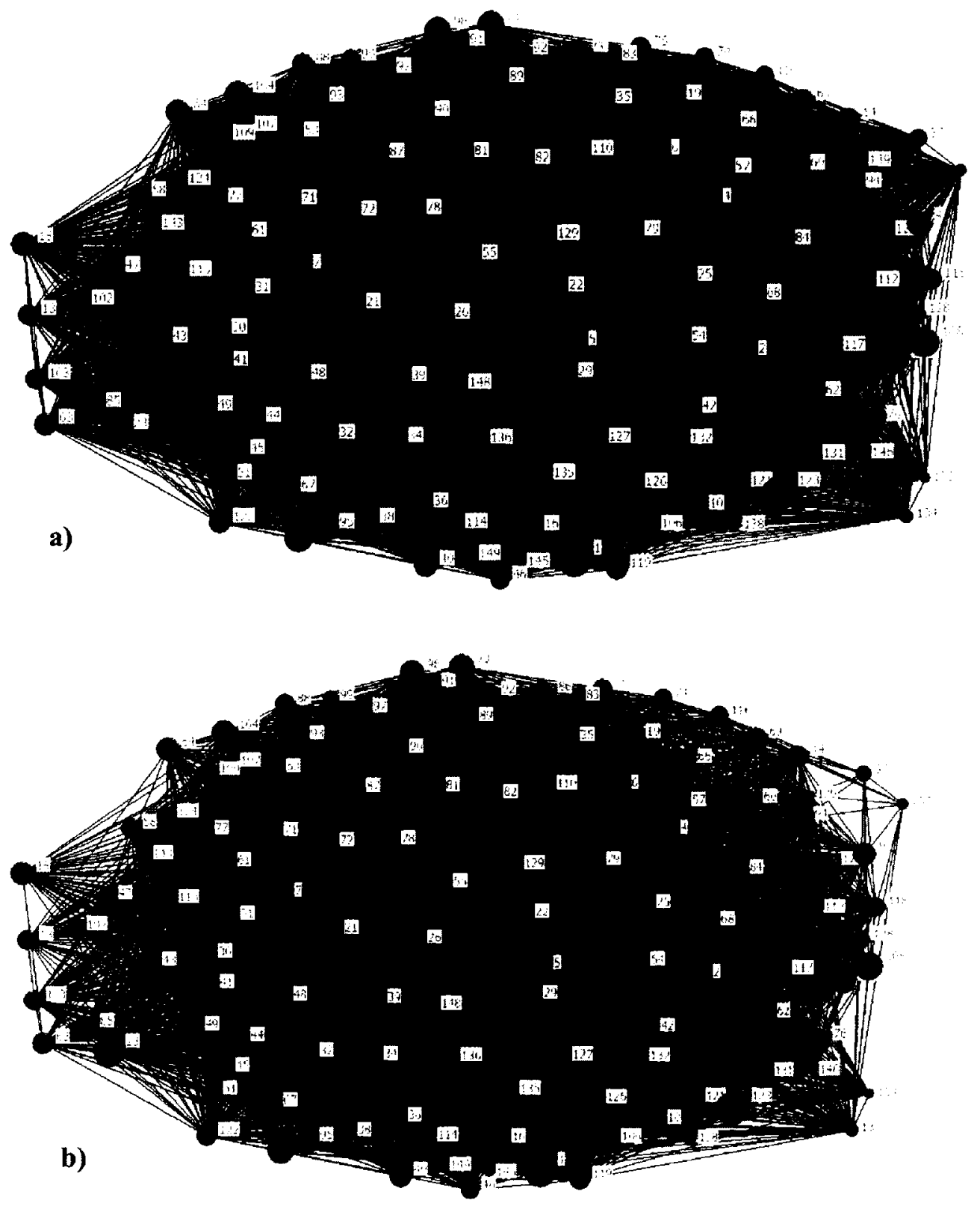

Figure 4.1. Banded killifish social networks of 120 individuals (red circles), wherein the edges were filtered at a simple ratio index (SRI) of $\mathbf{a}) \geq 0.1$ and $\mathbf{b}) \geq 0.3$. Both networks represent one giant connected component (GCC), where node sizes are scaled to the body size of the individual and the numbers to the right of nodes indicate individual ID. 


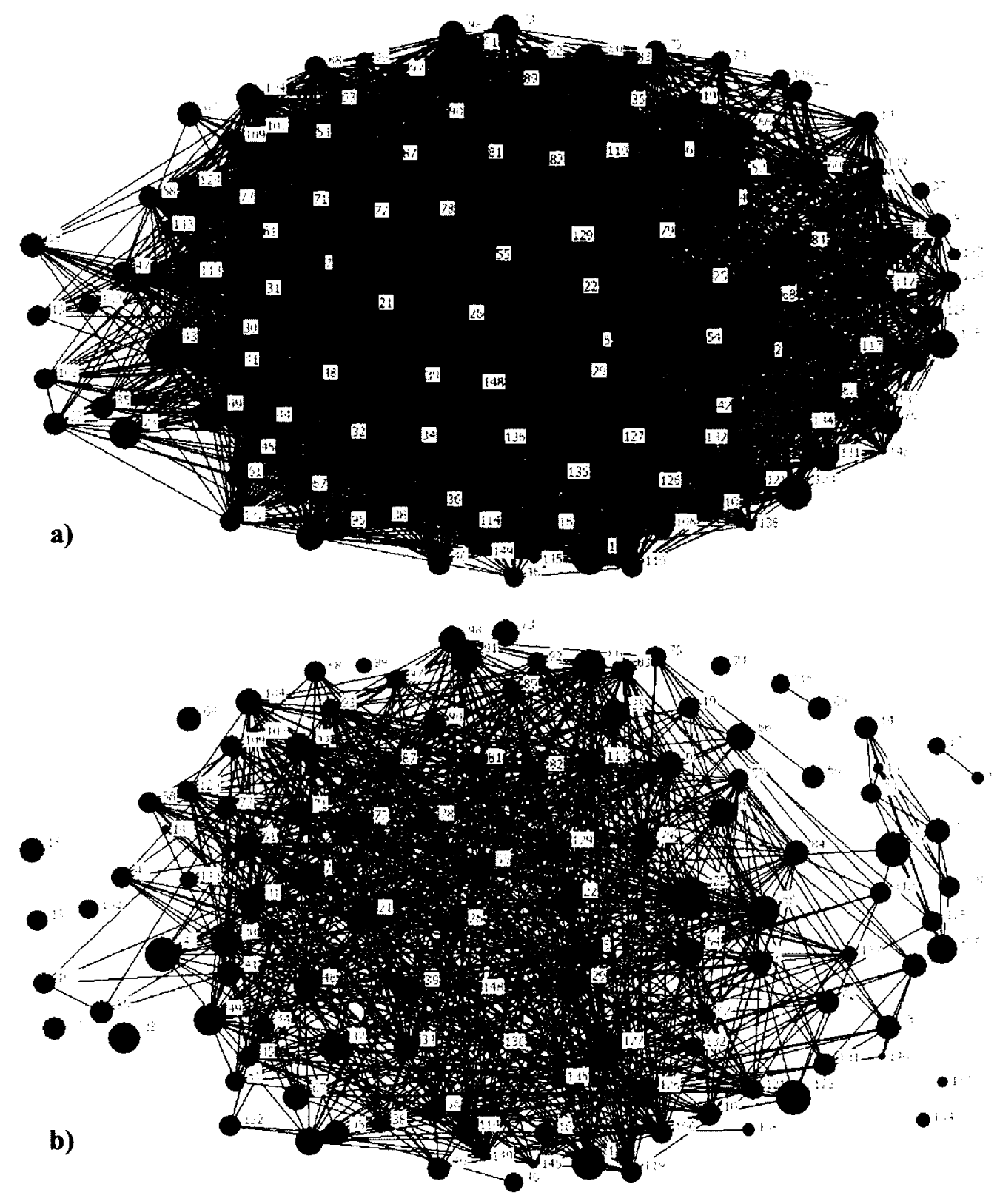

Figure 4.2. Banded killifish social networks of 120 individuals (\# IDs) where edges were filtered at a simple ratio index (SRI) of a) $\geq 0.5$ and b) $\geq 0.7$. The GCC is in red and additional components (separated from the GCC) are indicated by the different colours. In b), blue nodes represent individuals who were no longer connected to the network. 


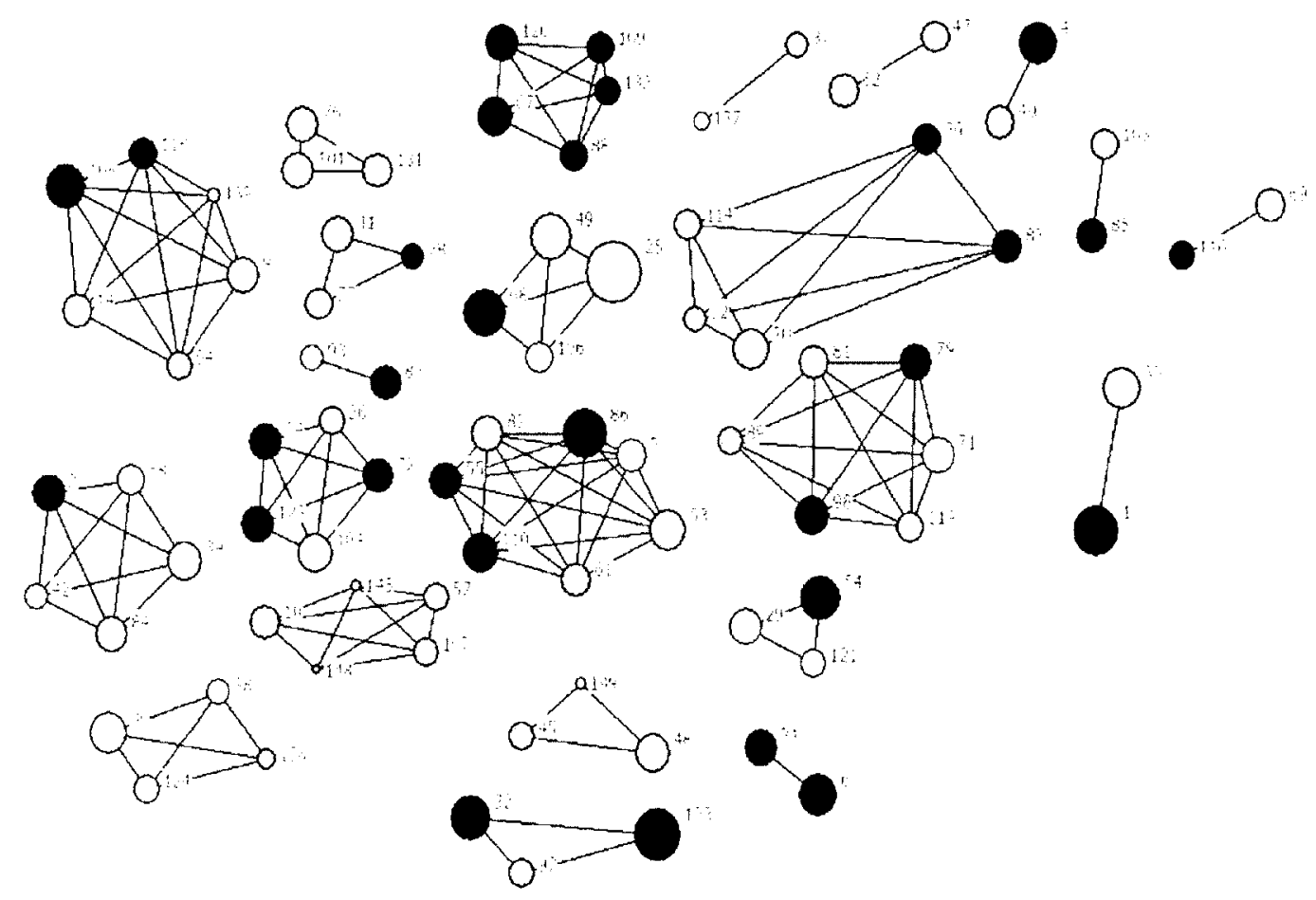

Figure 4.3. The network edge-filtered at $\mathrm{SRI} \geq 0.9$, wherein there was no longer a GCC and the network dissolved into 23 components. These components represent individuals that were always (or almost always) captured in the same shoal together and may represent strong cliques within the network $(\mathrm{C}=1)$. The nodes are sized according to relative body length and the colours represent the relative black spot load of the fish (white $=0$; light grey $=1-5$; dark grey $=6-10$; olive green $=11-15$; black $=\geq 16$ ). The location of each component illustrated above is random and are spread out for visual purposes only. 
Table 4.2. Network measures for four different banded killifish edge-filtered social networks ( $=$ SRI net) originally containing 120 individuals (filtered at SRI values $\geq 0.1, \geq$ $0.3, \geq 0.5, \geq 0.7$ and $\geq 0.9$, respectively). Labels in the top row represent standard network measures: $\mathrm{N}_{\mathrm{gcc}}=$ the number of individuals in the giant connected component, $\mathrm{E}$ $=$ the number of observed edges in the network, $E_{\max }=$ the maximum number of potential connections in the network, $\mathrm{k}=$ mean number of degrees, $\mathrm{C}=$ the mean clustering coefficient (where $C_{\text {rand }}$ is that of a random network*), $L=$ the average path length (where $\mathrm{L}_{\text {rand }}$ is that of a random network ${ }^{*}$ ) and $\mathrm{B}=$ the average betweenness of the network. The network dissolved at a SRI value of $\geq 0.9$ into 23 components with no giant component cluster apparent. Consequently, average network values could not be computed at SRI $\geq$ 0.9 .

\begin{tabular}{llllllllll}
\hline SRI net & $\mathbf{N}_{\text {gcc }}$ & $\mathbf{E}$ & $\mathbf{E}_{\max }$ & $\mathbf{k}$ & $\mathbf{C}$ & $\mathbf{C}_{\text {rand }}{ }^{*}$ & $\mathbf{L}$ & $\mathbf{L}_{\text {rand }}{ }^{*}$ & $\mathbf{B}$ \\
\hline $\mathbf{0 . 1}$ & 120 & 7038 & 7140 & 117.3 & 0.99 & 0.99 & 1.10 & 1.00 & 0.85 \\
\hline $\mathbf{0 . 3}$ & 120 & 5535 & 7140 & 92.2 & 0.87 & 0.77 & 1.23 & 1.06 & 13.71 \\
\hline $\mathbf{0 . 5}$ & 118 & 3531 & 6903 & 58.8 & 0.75 & 0.50 & 1.52 & 1.17 & 29.66 \\
\hline $\mathbf{0 . 7}$ & 100 & 918 & 4950 & 15.2 & 0.58 & 0.15 & 2.61 & 1.69 & 66.71 \\
\hline $\mathbf{0 . 9}$ & 0 & - & - & - & - & - & - & - & - \\
\hline
\end{tabular}

${ }^{*}$ Note: the random network keeps the number degrees, nodes and edges constant, but randomizes all possible connections $(\mathrm{E})$ between individuals. 


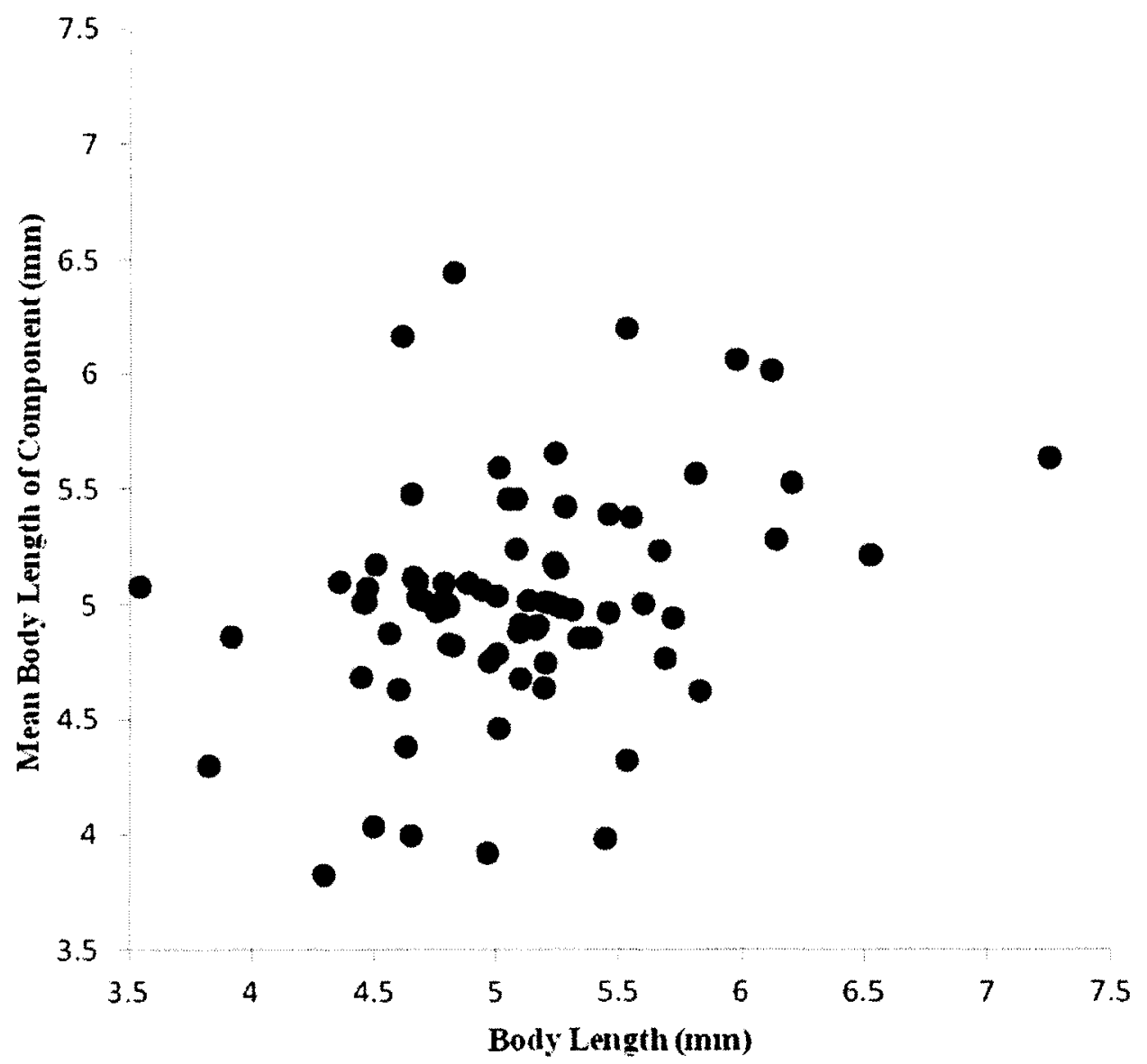

Figure 4.4. Body length of each individual fish compared to the mean body length of all neighbouring individuals in their component in the SRI $\geq 0.9$ edged-filtered network. This network contained 23 components (no GCC), varying from 2 to 7 individuals. Body length was correlated amongst component members when ranked amongst all individuals in this filtered network (Kendall's rank correlation: tao $=0.190, \mathrm{n}=82, z=2.54, p=$ $0.011)$. 


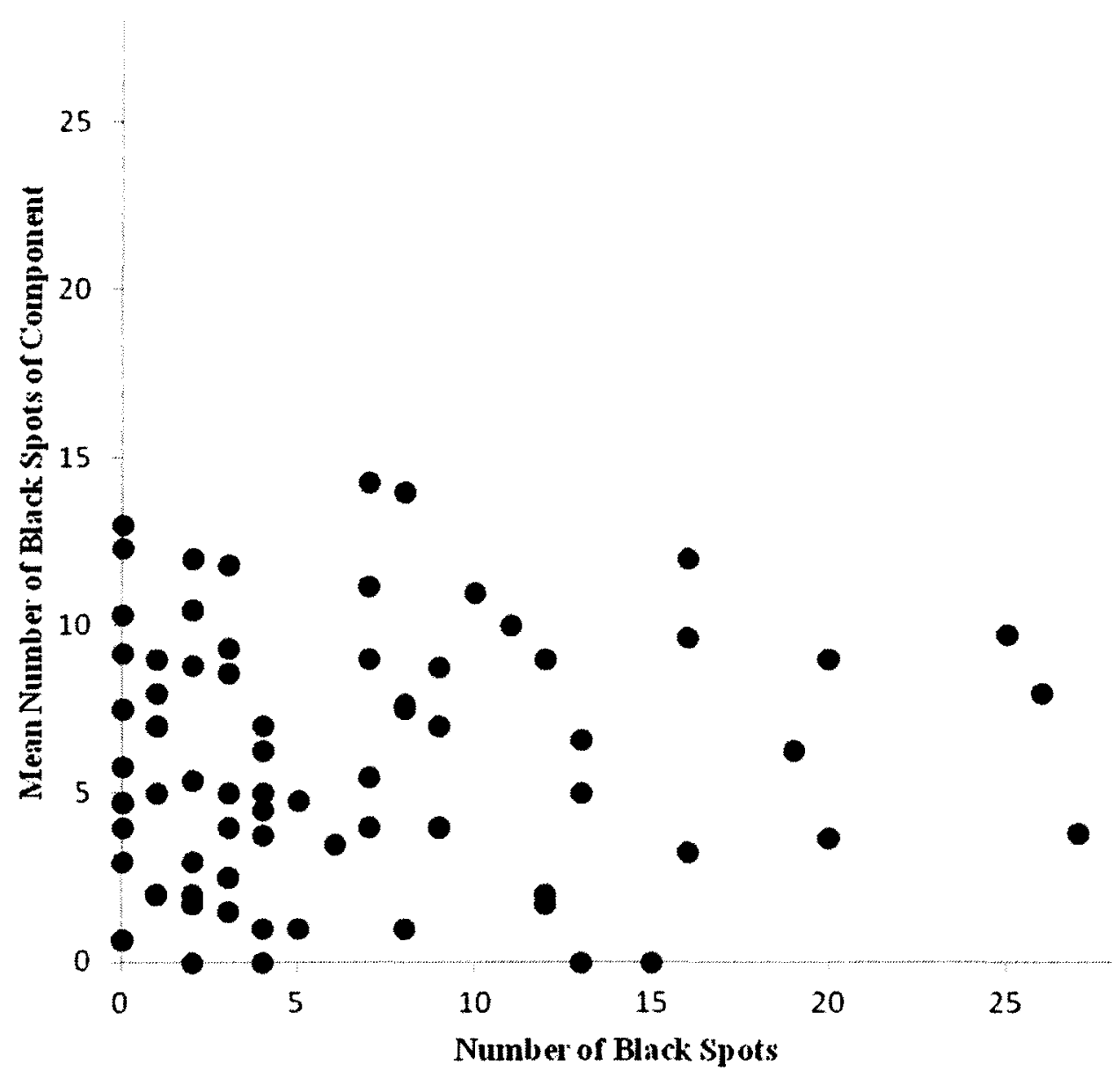

Figure 4.5. Black spot number of each individual fish compared to the mean body length of all individuals in their component (= neighbours) in the SRI $\geq 0.9$ edge-filtered network. This resulted in 23 components (no GCC), varying from 2 to 7 individuals. Black spot number was not correlated amongst component neighbours when ranked against other individuals in this filtered network (Kendall's rank correlation: tao $=0.030$, $\mathrm{n}=82, z=0.388, p=0.70$ ). 


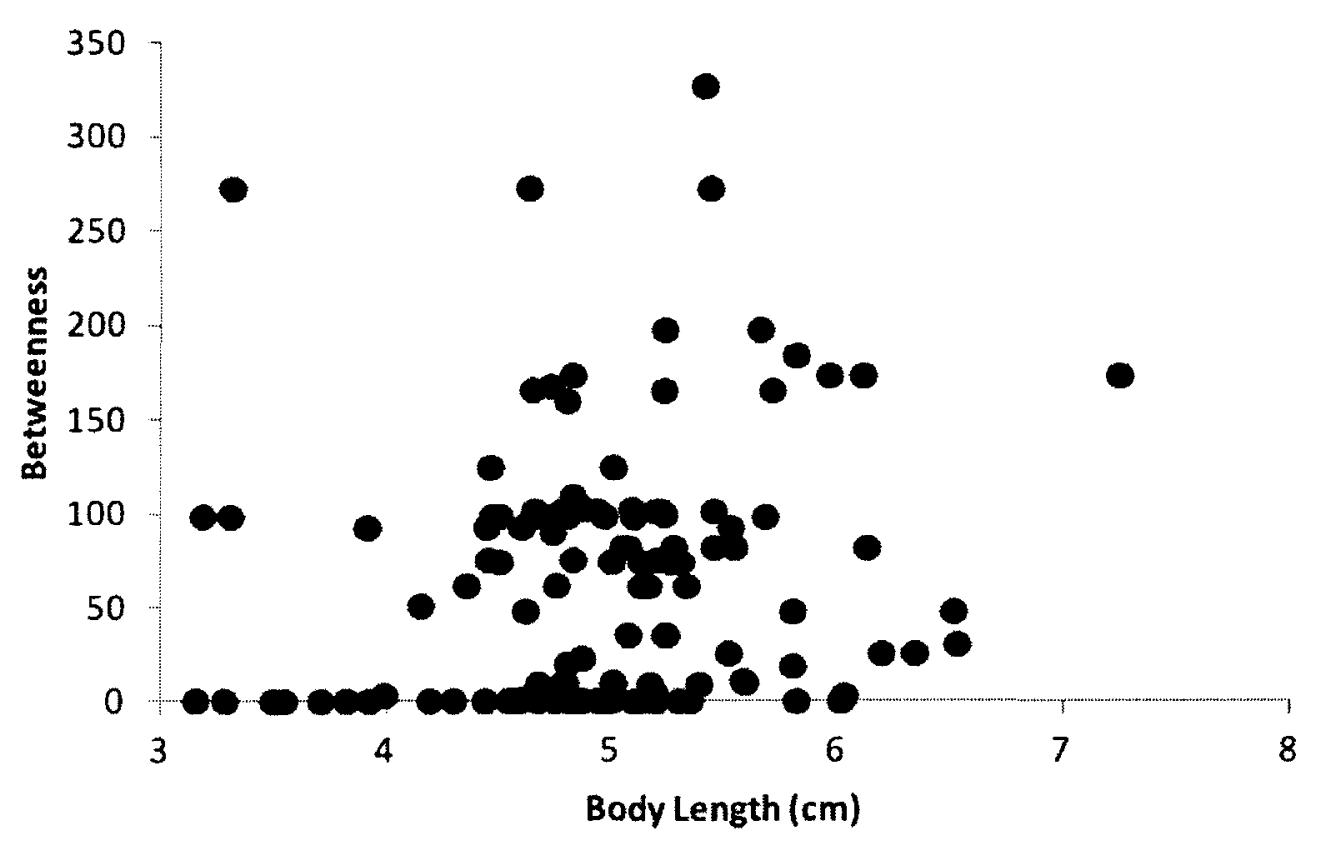

Figure 4.6. Body length of each individual fish in the SRI $\geq 0.7$ edge-filtered network compared to their individual betweenness score. Body length was significantly rank correlated to betweenness (Kendall's rank correlation: tao $=0.13, \mathrm{n}=120, z=2.05, p=$ 0.04). 


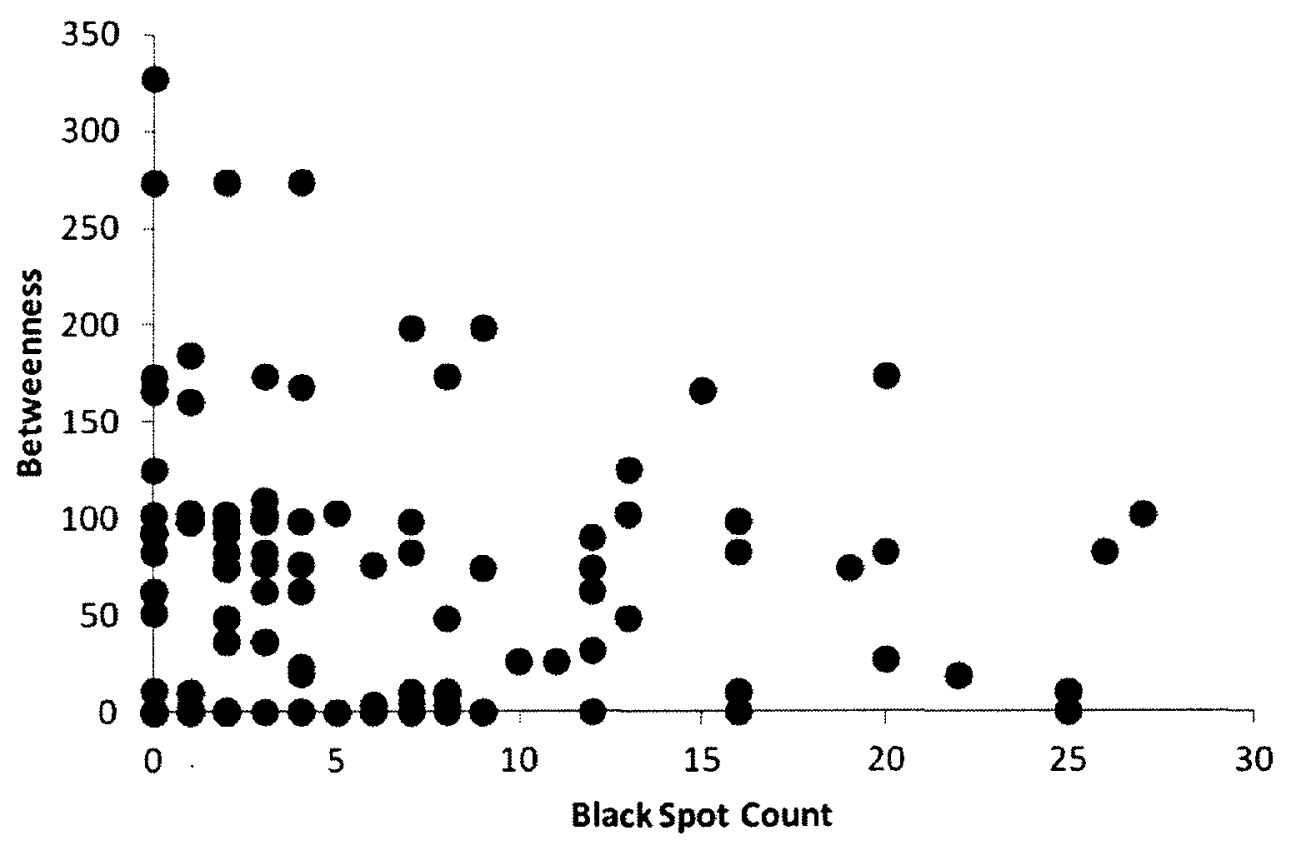

Figure 4.7. Black spot count of each individual fish in the SRI $\geq 0.7$ edge-network compared to their individual betweenness score. Black spot count and betweeness were not significantly correlated (Kendall's rank correlation: tao $=-0.06, \mathrm{n}=120, z=-0.95, p$ $=0.34$ ). 


\section{DISCUSSION}

The preference to socially associate with familiar individuals occurs in many species of fishes (reviewed in Griffiths \& Ward 2006), including the banded killifish (Chapter 3; Lee-Jenkins \& Godin 2010). However, whether and how this preference is manifested in the wild, particularly at a fine-scale, population level, is not well understood. Preferentially associating with familiar individuals has many benefits, including increased rate of learning (Ward \& Hart 2005), decreased individual predation risk through greater group cohesion and increased responsiveness to predator attacks (Chivers et al. 1995; Griffiths et al. 2004), decreased aggression (Griffiths et al. 2004) and increased cooperation between individuals (Croft et al. 2006). However, if individuals frequently encounter unfamiliar individuals, a preference for familiar shoal mates can decrease (Griffiths et al. 1997b; Griffiths et al. 2007). In the current study, free-ranging killifish shoals varied in membership size, and some were quite large $(\geq 100$ individuals) during my sampling period. Therefore, it may be difficult for familiarity preferences to initially develop and be maintained in the wild.

The results of my current study indicate that social cliques of free-ranging killifish were present (at least among the tagged fish at a network filtering level of SRI $\geq 0.9$ ) in Patterson Lake population, as would be expected if individual killifish prefer to shoal with familiar conspecifics (Chapter 3; Lee-Jenkins \& Godin 2010). Using this association strength index (SRI), I examined associations between individual fish accounting for the number of times that any given individual (say ' $a$ ') was present without another particular individual (say 'b'). At an SRI $\geq 0.7$, all except three of 23 observed killifish cliques were 
connected to the general network (GCC). Familiarity plays an important role in information transfer within social groups (Hoare \& Krause 2003; Krause et al. 2007), wherein familiar individuals more readily learn a new task from each other than unfamiliar individuals (Swaney et al. 2001). If individuals within a clique learn a novel behaviour and are connected to the GCC, then they could potentially influence the transmission of acquired information through the network (Krause et al. 2007).

The position of an individual within a social network is important because it may influence its access to information and resources (Wey et al. 2008). When comparing body size and black spot count to betweenness scores across all individual killifish in the $\geq 0.7$ SRI edged-filtered network, I found that larger fish had higher betweenness scores. Betweenness scores indicate the relative role that individuals play within a network and represent the number of minimum path connections between all pair-wise individual combinations in the network that must go through that node (individual). Thus, larger fish could indirectly have more access to the information flow pathway through a network. If these individuals are adults, then this could be advantageous for younger juvenile killifish because they could potentially learn antipredator behaviours (e.g. areas to avoid in the lake) or the better foraging areas from their larger network mates. Conversely, larger individuals could have wider access to information transmitted through the network, but at the potential cost of increased risk of disease and contagious parasite transmission (Hoare \& Krause 2003). Future work should investigate the spatial location of individuals in cliques within the social network, to ascertain whether cliques are spread out or clustered together within the network. Such research would shed light on the relative 
interactive strategies of social cliques within the population (Krause et al. 2010) and how cliques influence information flow through networks. The membership size of cliques (e.g. 2 vs. 7 individuals) may also affect the magnitude of a clique's influence within the network. It would thus be informative to note the location of cliques within wild shoals of fishes; for example, are cliquish individuals more frequently found in the front leadership positions of shoals or within the safety of the centre of shoals and does any such spatial positioning depend on clique size? Within social groups, the spatial position of individuals is often non-random (Krause \& Ruxton 2002). In fishes, individuals with higher hunger levels and parasite load tend to occupy positions at the periphery than the centre of the shoal and to shoal less than satiated and non-parasitized individuals (e.g. Krause \& Godin 1994b; Ward et al. 2002b; Hensor et al. 2003).

Previous studies on shoal associations based on phenotypic characteristics, such as body length and black spot count, have typically been at the shoal-level (e.g. Hoare et al. 2000a; but see Ward et al. 2002a). Typically, a number of shoals are captured in their entirety in the wild, and the composition of entire groups are compared based on a phenotypic trait of the group as a whole or individuals between these groups are randomized to look at shoal structure. At the shoal level, small persistent cliques would not be evident because individuals are not uniquely tagged and data are not collected over multiple days as they are for social network studies. Individual tags allowed me to examine the social fine structure of the population (Krause et al. 2010). In some of these aforementioned killifish field studies, shoals were found to not be assorted by black spot count; similarly killifish cliques were not assorted by black spot count. 
The 23 cliques present in my current dataset were assorted by body length but not by black spot load (when compared to other cliques). Because body length in fishes can reflect chronological age, individuals within these cliques were possibly of similar age or potentially kin. If so, then preferences for familiar individuals may initially occur or develop during early-life stages. Whether cliques form based on an initial preference for particular phenotypic traits (leading to repeated interactions and familiarity between individuals) or if preferences develop from frequent associations based on a nonphenotypic trait is unclear. Croft et al. (2009) demonstrated that behavioural phenotype (shyness vs. boldness) strongly affected social network structure in the guppy, where shy individuals had more social connections with other conspecifics than bold fish and that these connections were stronger in association strength. Moreover, this behaviouralphenotype assortment was not predicted by individual morphological traits. It appears that network-scale repetitive interactions in the wild (leading to cliques) can be complex, and it is unknown whether social cliques and other network characteristics are stable or dynamic over longer time scales (e.g. across the seasons). Higher-resolution sampling of social groups within a population would be needed to address this question.

Another potentially fruitful area for future research would be to quantify the spatial positions of individuals within fish shoals when collecting social network data to ascertain the identity of the closest neighbours of an individual within the shoal. This would be particularly useful in species with large shoal sizes. Assuming associations between individuals based on the gambit of the group is currently a caveat in social network studies, which potentially creates associations between individuals that may not 
exist, especially in large groups. While weighted-association indices, such as the SRI used in the current study, help to ameliorate this problem (Franks et al. 2010), one still has to arbitrarily choose an edge-filter value when analyzing any network (Croft et al. 2008). Consequently, higher-resolution group-level data would likely reveal more reliable structured networks with fewer edges, potentially confirm the presence of stable cliques within networks and moreover, that any detected cliques represent individuals that are closely associating with each other within a group. During my current field study, I was able to obtain (bird's-eye view) photographs of some of the sampled free-ranging shoals prior to collection; these data will later be used as a preliminary step to explore how associations in network data change with the inclusion of nearest-neighbour data. In this context, the use of small portable proximity loggers, which record the identity of individuals who approach within a certain distance of another individual, represent a particularly promising new method for investigating social networks in the future (Krause et al. 2011). 


\section{ACKNOWLEDGEMENTS}

I would like to thank Alex Wilson for his tagging expertise which made this project possible. The collection of these data would not have been possible without the field assistance of Adam Densmore, Rebecca Warmington and Alex Wilson. Thank you to Rodena Bell who gave me access to her property on Patterson Lake and to Darren Croft who offered helpful suggestions at the beginning of this project. 


\section{CHAPTER 5}

\section{Part I - Discussion}

Banded Killifish Shoals and Social Familiarity 


\section{GENERAL DISCUSSION - PART I}

\section{Summary of Main Findings}

In Chapter 3, juvenile killifish preferred familiar over unfamiliar shoal mates, but juvenile bluegill sunfish demonstrated no preference for either stimulus shoal type. I attributed this difference to their different shoaling life histories, namely, killifish shoal throughout their entire life history and bluegill sunfish do not. This difference in preference could also potentially be due to their differing population densities (during the specific period of my field study). I later expanded on this work by performing a markand-recapture field study, in which I characterized the social network structure of freeranging juvenile and adult banded killifish in the study lake population. I found that, at weak social association levels, individuals were highly connected owing primarily to the large shoals in which tagged fish were occasionally found in. At higher social association strengths, larger fish had higher betweenness network values, indicating that they play more central roles within the network. Moreover, at high association strengths, cliques of individuals were present, suggesting that social familiarity might influence the formation and maintenance of social associations and thus the structure of natural social groups in this species. Interestingly, these social cliques were assorted by body length, suggesting active social association preferences among individuals.

\section{Limitations and Future Directions}

Social network theory importantly assumes that all individuals are associating or interacting with each other if they are captured or observed within the same social group 
(= gambit of the group: Croft et al. 2008; Franks et al. 2010). My field data revealed that some wild banded killifish shoals can be quite large in membership size, and consequently it is unlikely that all individuals within larger killifish shoals were repeatedly 'interacting' per se with others. By using a weighted association index, I attempted to minimize this constraint in the analysis of the killifish social network here. In the future, the acquisition and use of data on nearest-neighbour associations within free-ranging animal groups, using advanced electronic tagging methodology, should prove promising in improving the resolution of social networks.

Another challenge relates to the number of tagged individuals released into the population. Although I collected all of the killifish possible during my 3-day collection period, a number of untagged individuals were still present during my resampling period. It is near impossible to precisely know the size of an animal population and thus judging the accuracy of the social structure characterized by a social network study. Therefore, whether my social network represents the social population at large is unknown.

Characterizing social structure within animal populations from year to year would provide further context for the role of familiarity in the formation and maintenance of social groups and whether social structure is dynamic or stable over time. For example, in 2007, when I collected wild killifish from Patterson Lake for my laboratory experiment, the population size appeared lower based on number of fish seined per effort compared with the numbers of killifish I observed in the same lake in 2010. Population size could be a constraint on the development of familiarity between individuals, because there is likely a cognitive limit to the number of conspecifics an individual animal can recognize 
and remember when choosing who to associate with socially (Griffiths \& Magurran 1997b). Moreover, ecological conditions, such as food availability, habitat type and parasite and predator population sizes within a lake, typically change from year to year. Since such ecological factors can determine group size and composition (Krause \& Ruxton 2002), future studies on how they may influence the structure of social networks and cliques within networks should prove fruitful. While my two studies here suggest that social familiarity plays a role in social associations in the banded killifish, how an association preference for familiars develops in this species remains unclear. One possible mechanism is an initial phenotypic assortment of individuals into social groups, leading secondarily to frequent interactions among individuals and the development of familiarity, which in turn reinforces social affiliations based on familiarity and the emergence of social cliques. Several studies have shown that shoaling with familiars in fishes confers individual fitness-related benefits (e.g. Swaney et al. 2001; Chivers et al. 1995; Ward \& Hart 2005) and thus could be favoured evolutionarily under certain ecological conditions. 


\section{CHAPTER 6}

\section{Part II -Introduction}

Social Associations in the Convict Cichlid in Early Ontogeny 


\section{GENERAL INTRODUCTION - PART II}

The social organisation of animal groups is most commonly described in terms of the adult stage. However, to truly understand a social system, it is important to understand the behavioural ontogeny of the juvenile stage (Michener 1981). In those species wherein young are reliably surrounded by siblings during early life history stages, the use social familiarity as a proxy for kinship could be a reliable means of kin recognition (Mateo 2004). However, in many species, particularly those exhibiting alloparental care, the young encounter and interact with nonkin and consequently social familiarity alone would not accurately identify kin. These two types of 'social cues' are sometimes used synonymously in the kin discrimination literature (Tang-Martinez 2001), but associating with familiar individuals can confer different benefits and have different social implications than those resulting from associating with kin (Griffiths \& Magurran 1999; Liebgold \& Cabe 2008). Associating with kin can have important fitness benefits in terms of kin selection (Hamilton 1964). However, competition may intensify within kin groups and at some point it may be advantageous to alternatively associate with nonkin (Griffiths \& Armstrong 2001). Thus, the roles of social familiarity and kinship in social associations during early ontogeny not only have implications for group structure, and the ability of young to recognize kin, but association preferences for familiars and/or kin could change during early ontogeny owing in part to the physical changes that an individual experiences during their development.

This second portion of my thesis centered around free-swimming convict cichlid young or 'fry' and on their social associations based on social familiarity and kinship. 
Previous work on this species had alluded to the occurrence of brood mixing in the wild during the extended biparental care of free-swimming young (Wisenden \& Keenleyside 1992). If brood mixing does occur, then it could potentially influence the social encounters and associations (within a given brood) experienced by young during early ontogeny.

Therefore, the second part of my thesis consists of four data chapters focusing on confirming the presence of brood mixing in the wild and investigating experimentally how this phenomenon may shape the development of association behaviours in convict cichlid young. Specifically, in Chapter 7 , I describe the optimisation of microsatellite loci used for genotyping young convict cichlids within field-collected broods and the methodology by which sibsets (groups of siblings) can be identified in convict cichlid broods. This methodology is used in Chapter 8 to characterize the genetic structure of each of 50 wild broods to ascertain whether brood mixing actually occurs in a wild population. Given that brood mixing was prevalent and that young were potentially surrounded by kin and nonkin, in my study population, I then experimentally disentangle (in Chapter 9) the effects of social familiarity and kinship on shoaling or association preferences in young convict cichlids. Lastly, as a potential brood mixing mechanism, I examine experimentally in both the field and laboratory (in Chapter 10) the consequences of spatial separation from parents (and the brood) to determine whether young that are separated from their parents and brood mates can find their way back to their family. In closing this second section, in Chapter 11 , I summarize the main results of this research and discuss limitations and future directions. Finally, in Chapter 12, I provide some brief 
concluding thoughts on my thesis as a whole and where my research fits into the broader context of the field of Behavioural Ecology. 


\section{CHAPTER 7}

Polymorphic microsatellite loci optimised for studies on the convict cichlid fish (Amatitlania siquia)

This chapter is published as: Lee-Jenkins, S.S.Y., Densmore, A.M., Godin, J.-G.J. \&

Smith, M.L. 2011. Polymorphic microsatellite loci optimised for studies on the convict cichlid fish (Amatitlania siquia). Environmental Biology of Fishes, 92, 261-266.

doi: 10.1007/s10641-011-9829-8

It was reproduced here with permission from the publisher Springer $\mathbb{C}$ 


\begin{abstract}
The neotropical convict cichlid fish (Amatitlania siquia) is an important model species for the study of animal behaviour. It is therefore surprising that no genetic markers are available for this species. Here, I have optimised four polymorphic microsatellite loci for use with this fish, where each locus comprises between 9 and 28 alleles. I demonstrate how these markers can be used to genotype fry and for the analyses of genetic structure and prevalence of interfamilial mixing within biparental broods of wild convict cichlids. These microsatellites will facilitate future research, hitherto not possible, on the molecular, behavioural and evolutionary ecology of the convict cichlid and possibly other closely related species.
\end{abstract}




\section{INTRODUCTION}

Cichlids (Family Cichlidae) are a diverse group of tropical fishes widely used in behavioural and evolutionary biology studies (Keenleyside 1991 $a$; Barlow 2000). In particular, the neotropical convict cichlid (Amatitlania siquia; synonymous to $A$. nigrofasciata) breeds readily in aquaria and is easily observed in its natural habitats (e.g. Wisenden \& Keenleyside 1992; Wisenden 1995; Lehtonen 2008) and has thus been used as a study organism in a range of disciplines, including but not limited to fish biology (Keenleyside 1991a) and neuroscience (Reddon \& Hurd 2009). The convict cichlid has been a particularly important model study species in behavioural and evolutionary ecology to address questions on reproductive behaviour, foraging behaviour, habitat selection, territoriality, aggression, chemical ecology and physiology, among others (e.g. Grant \& Guha 1993; Wisenden 1995; Brown et al. 2006).

Although widely studied, there are surprisingly no genetic markers available for the convict cichlid. This has hampered certain types of research with this species in the fields of molecular, behavioural and evolutionary ecology. For example, the interesting phenomenon of brood mixing has previously been inferred for wild convict cichlids based on behavioural field observations (Wisenden \& Keenleyside 1992), but has yet to be confirmed using genetic techniques. Brood mixing is the presence of young in a brood that are not the progeny of the focal parents who care for them, the latter phenomenon being referred to as alloparental care (Wisenden 1999). Alloparental care of nondescendant young is potentially maladaptive and thus presents a challenge to evolutionary theory (Wisenden 1999). 
Here, I report on my characterisation and optimisation of four polymorphic microsatellite loci for the convict cichlid that will be of considerable interest to those studying this and other neotropical cichlid species. I demonstrate how these microsatellite loci can be used to investigate behavioural and evolutionary questions, such as the occurrence and prevalence of brood mixing in wild convict cichlids.

\section{METHODS}

I carried out initial optimisation of DNA extraction and PCR protocols using laboratory-reared convict cichlids. For assessing allelic diversity at microsatellite loci, I used convict cichlid fry (free-swimming young) obtained from multiple broods collected (with a dip-net whilst snorkeling) along the Rio Cabuyo in Costa Rica. Broods were immediately preserved in isopropyl alcohol and individual fry were subsequently transferred to separate tubes containing $95 \%$ ethanol for laboratory storage. The Rio Cabuyo consists of a series of open pool areas, where each pool is interconnected to adjacent pools by a riffle/stream section. As such, fish can potentially swim between pool areas (either upstream or downstream). However, the degree of dispersal between pools by convict cichlid fry is unknown.

For DNA extractions, tissue $\left(5-20 \mathrm{~mm}^{3}\right)$ was taken from the anterior end (the head) of the fish and added to $250 \mu \mathrm{l}$ of $0.5-\mathrm{mm}$ glass beads (BioSpec Products Inc., Bartlesville, OK, U.S.A.), $400 \mu$ l of extraction buffer ( $10 \mathrm{mM}$ TRIS $\mathrm{pH}=8 ; 10 \mathrm{mM}$ EDTA $\mathrm{pH}=8 ; 3.4 \mathrm{mM} \mathrm{SDS} ; 20 \mathrm{mM} \mathrm{NaCl}_{2}$ ), and $400 \mu \mathrm{l}$ of $24: 1$ chloroform:isoamyl alcohol in a 1.5-ml microcentrifuge tube. The sample was homogenized using a MM301 
mixer mill (Retsch, Hann, Germany) for $17 \mathrm{~min}$ at 30 beats $\cdot \mathrm{s}^{-1}$. Tubes were centrifuged at $21,000 \mathrm{rcf}$ for $5 \mathrm{~min}$ and the supernatant transferred to $600 \mu \mathrm{l}$ of cold $95 \%$ ethanol and 60 $\mu \mathrm{l}$ of $7.5 \mathrm{M}$ ammonium acetate for overnight storage at $4^{\circ} \mathrm{C}$. Samples were again centrifuged as above, the liquid decanted and the pellet rinsed with $400 \mu \mathrm{l}$ of cold $70 \%$ ethanol and dried briefly under vacuum. The pellet was resuspended in $20-80 \mu \mathrm{l}$ of distilled, deionized water $\left(\mathrm{ddH}_{2} 0\right)$ and DNA concentrations were measured (ND-1000 NanoDrop Spectrophotometer, Wilmington, Delaware, U.S.A.). A working stock (100$200 \mathrm{ng} \cdot \mu \mathrm{l}^{-1}$ ) was prepared and stored at $-20{ }^{\circ} \mathrm{C}$ and the remaining DNA extraction was stored at $-80^{\circ} \mathrm{C}$.

I attempted PCR amplification with each of seven microsatellite loci that were previously characterised from other cichlid fish species; TMO-M27, TMO-4C4, UNH002, Acit1, Acit2, Acit3, and Acit4 (see Kellogg et al. 1995; Zardoya et al. 1996; Streelman \& Karl 1997; Noack et al. 2000). PCR products were obtained for all loci except for TMO$4 C 4$ and amplicon sizes were examined in each of five unrelated individuals using $10 \%$ polyacrylamide gels (PAGE; Bio-Rad Laboratories, Hercules, CA, U.S.A.). Only loci that yielded different sized amplicons based on PAGE were selected for further optimisation and sequence characterisation; there were four such loci, Acitl, Acit2, Acit3 and Acit4. Primer sequences for each locus are based on Noack et al. (2000) and are described in Table 7.1.

PCR reactions included 100-200 ng template DNA, $1 \mu$ l of each primer (concentrations varied between 65 and $82 \mu \mathrm{g} \cdot \mathrm{ml}^{-1}$; Table 7.1 ), $0.4 \mu \mathrm{l}$ of $10 \mathrm{mM} \mathrm{dNTP}$ mix, $2 \mu \mathrm{l}$ 10X Taq Buffer, $0.2 \mu \mathrm{l}$ of Taq Polymerase (Bioshop Inc., Burlington, ON, 
Canada), $1.2 \mu \mathrm{l}$ (Acitl) or $0.8 \mu \mathrm{l}$ (Acit2,Acit 3, Acit 4$)$ of $\mathrm{MgCl}_{2}$ and were brought to $20 \mu \mathrm{l}$ with $\mathrm{ddH}_{2} \mathrm{O}$. PCR conditions were optimised at: initial $95^{\circ} \mathrm{C}$ denaturing step for $10 \mathrm{~min}$, followed by 30 (Acitl) or 35 (Acit 2 , Acit 3 , Acit 4 ) cycles of $95^{\circ} \mathrm{C}$ for $30 \mathrm{~s}$ (denaturation), $49^{\circ} \mathrm{C}($ Acit 1$)$ or $52.5^{\circ} \mathrm{C}$ (Acit 2, Acit 3, Acit 4$)$ for $30 \mathrm{~s}$ (primer annealing) and $72{ }^{\circ} \mathrm{C}$ for 30 $\mathrm{s}$ (polymerization). Following the last cycle, an additional $10 \mathrm{~min}$ at $72{ }^{\circ} \mathrm{C}$ was used prior to sample storage at $4{ }^{\circ} \mathrm{C}$.

I used fluorescently labelled forward primers (Table 7.1; Acit1, Acit2 and Acit3 from Bioshop Inc. and Acit4 from Applied Biosystems Inc., Foster City, CA, USA) for fragment analysis with an ABI 310 Genetic Analyser (Applied Biosystems Inc.). AcitI PCR products were diluted 1:20 with autoclaved $\mathrm{ddH}_{2} \mathrm{O}$ and combined with $12 \mu \mathrm{l}$ of formamide and $0.15 \mu \mathrm{l}$ of ROX size standard (100-400 bp with a peak at every $25 \mathrm{bp}$; BioVentures Inc., Murfreesboro, TN, U.S.A.). Acit2, Acit3, and Acit4 PCR products were analysed together by mixing $2 \mu$ of each PCR product with $54 \mu$ of autoclaved $\mathrm{ddH}_{2} \mathrm{O}$ water, and $1.5 \mu \mathrm{l}$ of this dilution was added to $12 \mu \mathrm{l}$ of formamide and $0.15 \mu \mathrm{l}$ of ROX size standard. These amounts of PCR product were used in capillary electrophoresis to obtain electropherogram peak heights of between 500 and 2000 relative fluorescence units. All samples were heated at $95^{\circ} \mathrm{C}$ for $5 \mathrm{~min}$ and then placed on ice for $5 \mathrm{~min}$. Optimised ABI 310 capillary electrophoresis settings were as follows: Module = GS STR POP4 $(1 \mathrm{~mL}) \mathrm{D}$; Injection Time $=12 \mathrm{~s}$; Injection $\mathrm{kV}=15.0 ;$ Run $\mathrm{kV}=13.0$; Run Temperature $=60^{\circ} \mathrm{C} ;$ Run Time $=26 \mathrm{~min}($ Acit $)$ or $45 \mathrm{~min}($ Acit 2, Acit 3, Acit 4$)$. Allele sizes were determined using GeneMarker (SoftGenetics, State College, PA, U.S.A.) and TANDEM (Matschiner \& Salzburger 2009). 


\section{RESULTS \& DISCUSSION}

The allele characteristics presented in Table 7.1 are based on 356 individually genotyped fry from 15 wild convict cichlid broods (still under parental care) collected

from 10 pools (pool areas ranged between 200 and $800 \mathrm{~m}^{2}$ ) along a circa $3-\mathrm{km}$ stretch of the Rio Cabuyo. The observed numbers of alleles in the convict cichlid (Table 1) are equivalent (Acit 1 and Acit2) or greater than (Acit3 and Acit4) those reported for the neotropical Midas cichlid, Amphilophus citrinellum (Noack et al. 2000). I did not find any evidence of null alleles at any of these four convict cichlid loci in the 356 individually genotyped fry; all fry produced amplicons at all four loci (i.e. no homozygous nulls were detected). In addition, no excess homozygosity was detected for any of the loci examined in Brood I (explained further below and in Tables 7.2 and 7.3). Independent assortment among Acit2, Acit 3 and Acit 4 could not be rejected $\left(\chi^{2}\right.$ test, $\mathrm{P} \geq$ 0.76 in all pairwise comparisons) using the largest Group A set of fry from Brood I (Table 7.2). It is therefore unlikely that any of these loci are closely linked. Linkage disequilibrium associated with Acit 1 could not be tested in Group A of Brood I because both parents are inferred to be homozygous at this locus. More comprehensive tests for linkage disequilibrium and null alleles with these four loci awaits our ongoing analysis of a much larger set of wild broods and fry.

To illustrate the utility of these microsatellites to characterise the genetic structure of fish broods, I present preliminary results on one example wild-caught brood (Brood I) of convict cichlid under biparental care. The entire brood was collected, but I did not obtain genetic samples from the two adult fish (parents) guarding the brood for the 
following reason. The main objective was to collect broods in their entirety to characterise their complete genetic composition and thereby obtain an accurate assessment of the degree of brood mixing in wild convict cichlids. If the parents had been collected before the brood, then the unguarded fry would most likely have been eaten by predators (the Rio Cabuyo contains an abundance of fish predators). Moreover, parental convict cichlids can be difficult to capture by dip-net after brood collection because females will search a large area for their fry and males are likely to disperse or spend time away from the collection area after brood loss (Wisenden et al. 2008). By opting not to chase after and attempt to capture parental fish, I minimised local disturbance and the likelihood of fry scattering, and thus maximised our chances of collecting broods in their entirety.

Allele sizes at all four microsatellite loci were determined for each of the 23 fry comprising Brood I (Table 7.2). Based on Mendelian inheritance, it is expected that full siblings will share a set of four or fewer alleles at each locus. In Brood I, 18 of the 23 fry shared a set of three or fewer alleles at each locus ( 2 alleles for Acit1, 3 for Acit2, 2 for Acit 3 and 3 for Acit4), consistent with an origin from a single parent pair (Table 7.3). I assume that this majority group of fry (Group A) within Brood I were offspring of the 'resident' parent pair, and we infer the parental genotypes as shown in Table 7.3. Analyses of the genotypes of the five remaining fry revealed that four fry (Group B) likely originated from one non-resident parent pair, while one fry (Group C) originated from a second non-resident parent pair. Therefore, Brood I was clearly made up of at least three genetically distinct groups of offspring, distinguished by having different 
biological parents. Whether or not it is correct that the two resident adults (not sampled) were the parents of the majority of fry (Group A) in the brood, as I assume, my analysis nonetheless shows that brood mixing, or 'adoption' (Wisenden 1999), occurs in wild convict cichlids as was previously hypothesised based on field behavioural observations (Wisenden \& Keenleyside 1992).

I demonstrated that the allelic diversity in the four loci optimised here provides sufficient resolution to identify cases of brood mixing in wild convict cichlids. Although I do not have genetic samples from the parents, I am currently using a software program KINALYZER (which assigns full-sib groups without parental information using a consensus algorithm; see Ashley et al. 2009) to analyse a large sample of 50 broods (collectively consisting of $>1,800$ fry; see Chapter 8 ) to obtain estimates of the prevalence of brood mixing and adoption in a wild population of convict cichlid, and to test hypotheses regarding whether parents choose which fry they prefer to 'adopt' (Wisenden \& Keenleyside 1992), amongst other questions. These microsatellite markers can also be used to examine other behavioural and ecological questions about convict cichlid biology, such as the degree of fry dispersal from natal pools within the Rio Cabuyo population. Moreover, the socially monogamous mating system (Wisenden 1995) of the convict cichlid can be genetically examined using the microsatellite markers described here by identifying any potential instances of extra-pair copulations in the wild. As such, the optimisation of these microsatellites is a first step towards facilitating future research, hitherto not possible, on the molecular, behavioural and evolutionary ecology of the convict cichlid and possibly other related neotropical species. 
Table 7.1. Characteristics of four microsatellites optimised for the convict cichlid, Amatitlania siquia. The size range and minimum number of alleles are based on data for 356 individually genotyped fry from 15 broods, still under parental care, collected from 10 pools in the Rio Cabuyo, Costa Rica.

\begin{tabular}{|c|c|c|c|c|c|c|}
\hline Locus & Primer sequence $\left(5^{\prime}-3^{\prime}\right)$ & Repeat type & $\begin{array}{l}\text { Allele size range } \\
\text { (in base pairs) }\end{array}$ & $\begin{array}{l}\text { Fluorescent } \\
\text { dye used on } \\
\text { F Primer }\end{array}$ & $\begin{array}{l}\text { Observed } \\
\text { number } \\
\text { of alleles }\end{array}$ & $\begin{array}{l}\text { GenBank } \\
\text { accession } \\
\text { number }\end{array}$ \\
\hline Acit] & $\begin{array}{l}\text { F: AAATGAGTTCAGCGATGGCTGAG } \\
\text { R: TGCACATCATGTCCGCCGAACA }\end{array}$ & $\begin{array}{l}(\mathrm{AG})_{9-14}(\mathrm{~A})_{11-15} \\
\text { complex }\end{array}$ & $157-173$ & HEX & 9 & HQ292647 \\
\hline Acit 2 & $\begin{array}{l}\text { F: GGCACTGAGGATTTATATTACAGG } \\
\text { R: GAGGTCCAGCTGAGAACAGGG }\end{array}$ & $\begin{array}{l}(\mathrm{TG})_{12-42} \\
\text { sinple }\end{array}$ & $161-231$ & HEX & 28 & HQ292648 \\
\hline Acit 3 & $\begin{array}{l}\text { F: CTTAAGGTGTACCTGCTTAGC } \\
\text { R: GAGTGGGAAGACAGATGTTGAGG }\end{array}$ & $\begin{array}{l}(\mathrm{GT})_{22+0} \\
\text { simple }\end{array}$ & $153-213$ & 6-FAM & 26 & $\mathrm{HQ} 292649$ \\
\hline Acit4 & $\begin{array}{l}\text { F: CCTTCCTACTAGTTAGTCTTTCAC } \\
\text { R: CACATAGCACAGTGCATTCACCC }\end{array}$ & $\begin{array}{l}(\mathrm{GT})_{17-37} \\
\text { complex }\end{array}$ & $326-402$ & NED & 22 & $\mathrm{HQ} 317442$ \\
\hline
\end{tabular}

'Repeat characteristics are based on sequencing of $\geq 3$ alleles for each locus and do not directly correspond to the allele size range or observed number of alleles; "simple" microsatellites contain one repeat type, "complex" microsatellites contain internuptions and/or more than one type of repeat - see accessions for details.

'Microsatellites submitted under Amatitlania nigrofasciata (syn= A. siquia) to GenBank and the accession sequences inchude primer sequences. 
Table 7.2. Allele determinations at four microsatellite loci (AcitI, Acit2, Acit3, Acit4) for wild-caught convict cichid fry from one example brood (Brood I) illustrate how 'host' fry can be distinguished from 'foreign' fry.

\begin{tabular}{|c|c|c|c|c|c|c|c|c|}
\hline Err group and $\mathrm{ID}^{2}$ & Aciil allelel & Acitl allele? & Int 2 allelel & Acit allele? & Acit3 allelel & Acit3 allele? & Acitt allelel & Acity allek? \\
\hline \multicolumn{9}{|l|}{ Group A ('host' fiv) } \\
\hline 101 & 163 & 167 & 183 & 209 & 157 & 177 & 376 & 396 \\
\hline I03 & 163 & 167 & $18 \hat{j}$ & 183 & 177 & 177 & 376 & 396 \\
\hline 104 & 163 & 167 & 183 & 209 & 177 & 177 & 376 & 396 \\
\hline 106 & 163 & 167 & 183 & 183 & 157 & 177 & 378 & 396 \\
\hline I07 & 163 & 167 & 169 & 183 & 177 & 177 & 378 & 396 \\
\hline 108 & 163 & 167 & 169 & 209 & 177 & 177 & 376 & 396 \\
\hline 109 & 163 & 167 & 183 & 183 & 157 & 177 & 378 & 396 \\
\hline II0 & 163 & 167 & 169 & 209 & 177 & 177 & 376 & 396 \\
\hline III & 163 & 167 & 169 & 209 & 157 & 17 & 378 & 396 \\
\hline III & 163 & 167 & 183 & 209 & 177 & 17 & 378 & 396 \\
\hline II5 & 163 & 167 & 183 & 183 & 177 & 177 & 378 & 396 \\
\hline I16 & 163 & 167 & 169 & 209 & 177 & 177 & 376 & 396 \\
\hline $\mathbf{n 7}$ & 163 & 167 & 183 & 183 & 157 & 177 & 378 & 396 \\
\hline 118 & 163 & 167 & 169 & 209 & 177 & 1.7 & 378 & 396 \\
\hline 119 & 163 & 167 & 169 & 183 & 157 & 177 & 376 & 396 \\
\hline $\mathbf{L 0}$ & 163 & 167 & 169 & 209 & 177 & 177 & 378 & 396 \\
\hline I2I & 163 & 167 & 169 & 209 & 157 & 17 & 378 & 396 \\
\hline 22 & 163 & 167 & 169 & 183 & 177 & 177 & 376 & 396 \\
\hline \multicolumn{9}{|c|}{ Group B ('forcign' (n) } \\
\hline 105 & 163 & 163 & 163 & 183 & 171 & 191 & 366 & 376 \\
\hline III & 163 & 173 & 161 & 183 & 153 & 191 & 366 & 396 \\
\hline IIS & 167 & 173 & 161 & 183 & 171 & 191 & 366 & 366 \\
\hline It & 163 & 173 & 161 & 201 & 153 & 199 & 366 & 396 \\
\hline \multicolumn{9}{|c|}{ Growp C ('foreign' fry) } \\
\hline I3) & 159 & 167 & 181 & 191 & 175 & Iह1 & 376 & 376 \\
\hline
\end{tabular}

'A majority (78\%, Group $A)$ of "Brood $T^{\prime}$ fry have genotypes tat are corsistent with the view that they originated from a single parental pair, whereas the genotypes of fry in Groups B (4 fry) and C (1 fy) are inferred to originate from different parents (see Tajle 3 ). 
Table 7.3. Allele designations of three genetically distinct groups of fry identified in Brood I and the inferred parental genotypes.

\begin{tabular}{|c|c|c|c|}
\hline Locus & $\begin{array}{l}\text { Group A } \\
\text { (18 host fry') }\end{array}$ & $\begin{array}{l}\text { Group B } \\
\text { (4 foreign fry. } 105,112,113,24 \text { ) }\end{array}$ & $\begin{array}{l}\text { Group C } \\
\text { (1 foreign fry: 123) }\end{array}$ \\
\hline $\begin{array}{l}\text { Acitl } \\
\text { inferred parental genotypes }\end{array}$ & $163 / 163 \times 167 / 167$ & $163 / 167 \times 163 / 173$ & $159 /-\times 1671^{8}$ \\
\hline fry genotypes (Hobserved) ${ }^{c}$ & $163 / 167(18)$ & $\begin{array}{l}163 / 163(1) \\
163 / 173(2) \\
167 / 173(1)\end{array}$ & $159 / 167(1)$ \\
\hline $\begin{array}{l}\text { Acit? } \\
\text { inferred parental genotypes }\end{array}$ & $169 / 183 \times 183 / 209$ & $161 /-\times 183 / 201$ & $181 /-\times 191 /$ \\
\hline fry genotypes (Hobserved) & $\begin{array}{l}169 / 183(3) \\
169 / 209(7) \\
183 / 183(5) \\
183 / 209(3) \\
\end{array}$ & $\begin{array}{l}161 / 183(3) \\
161 / 201(1)\end{array}$ & $181 / 191(1)$ \\
\hline $\begin{array}{l}\text { Acit3 } \\
\text { inferred parental genotypes }\end{array}$ & $157 / 177 \times 177 / 177$ & $153 / 171 \times 191 / 199$ & $175 / \times 181 /-$ \\
\hline fry genotypes ( tobserved) & $\begin{array}{l}157 / 177(7) \\
177 / 177(11)\end{array}$ & $\begin{array}{l}153 / 191(1) \\
153 / 199(1) \\
171 / 191(2) \\
\end{array}$ & $175 / 181(1)$ \\
\hline $\begin{array}{l}\text { Acitf } \\
\text { inferred parental genotypes }\end{array}$ & $376 / 378 \times 396 / 396$ & $366 / 396 \times 366 / 376$ & $376 \% \times 376 i-$ \\
\hline fry genotypes (\#observed) & $\begin{array}{l}376 / 396(8) \\
378 / 396(10)\end{array}$ & $\begin{array}{l}366 / 366(1) \\
366 / 376(1) \\
396 / 366(2)\end{array}$ & $376,376(1)$ \\
\hline
\end{tabular}




\section{CHAPTER 8}

Genetic evidence for brood mixing and alloparental care in the convict cichlid fish (Amatitlania siquia) in nature 


\section{ABSTRACT}

Alloparental care, or care of non-descendent offspring, represents a potential challenge to evolutionary theory. The convict cichlid fish (Amatitlania siquia) exhibits an extended period of biparental care of its brood, where parents accept foreign fry (freeswimming young from another mated pair) into their own brood and thus provide alloparental care. To date, all evidence for putative brood mixing and adoption events in this species is indirect and inferred from behavioural observations and brood manipulations. The genetic composition of convict cichlid broods in nature remains unknown. To better understand the structure of wild convict cichlid broods, I characterised, using polymorphic microsatellite markers, the genetic composition of 50 broods collected along 12 pools in the Rio Cabuyo, Costa Rica. My results unequivocally show that brood mixing is common in the Rio Cabuyo, as $78 \%$ of sampled broods contained foreign fry. Moreover, $26 \%$ of broods contained 'foreign fry sibsets' that may have resulted from extra-pair copulations, which are not expected in the apparently socially monogamous convict cichlid. The degree of brood mixing varied, ranging from no foreign fry present to a possibility of over seven 'families' contributing foreign fry to focal host broods. In some cases, body-size assortment of host and foreign fry based on genotype within mixed broods was evident, but overall host fry body size did not differ from foreign fry body size on average. The current study thus provides the first genetic evidence for brood mixing and alloparental care in the convict cichlid in nature and raises new questions about the mechanisms underlying brood mixing and the mating ecology of this fish species. 


\section{INTRODUCTION}

In many animal species, the provisioning of parental care is essential for the survival of young (Clutton-Brock 1991). Consequently, parents may expend vast amounts of energy feeding and/or protecting young from predators to maximize offspring survivorship. Contrarily, alloparental care, or care of non-descendent young (Wisenden 1999), may represent a conundrum to evolutionary theory because alloparental adults incur costs (e.g. energy, risk of predation) while providing care for offspring that are not their own (Riedman 1982). The evolution of this apparently maladaptive behaviour, which occurs in numerous species, has intrigued evolutionary and behavioural biologists (reviewed in Riedman 1982; Wisenden 1999). For example, brood adoption and consequent alloparental care has been documented in more than 120 species of mammals and 150 species of birds (Riedman 1982).

To a large extent, our knowledge on the behavioural ecology of alloparental care of unrelated young has been provided by studies on birds (Eadie et al. 1988; Natase \& Sherry 1997; Codenotti \& Alvarez 1998; Kalmbach 2006). The developmental stage and degree and type of alloparental care varies significantly, with perhaps the most extreme example exhibited by host species that care for interspecific brood parasites, from egg incubation to fledging, at a survival cost to their own young (Payne 1977). Alloparental care in birds includes brood parasitism, crêching, gang brooding and brood adoptions (Payne 1977; Riedman 1982; Kalmbach 2006). Instances of alloparental care of freemoving or mobile young are most commonly demonstrated by precocial bird species, 
wherein true 'adoption' behaviour is evident as parents and their offspring actively accept foreign young into their brood or family (Nastase \& Sherry 1997; Kalmbach 2006).

Fish species that provide parental care will also, in many instances, exhibit alloparental care (Wisenden 1999). Examples of alloparental care, particularly of freeswimming young, have been demonstrated predominantly in cichlid fishes (Family Cichlidae), where both inter- and intra- specific adoption have been documented (McKaye \& McKaye 1977). The neotropical convict cichlid (Amatitlania siquia) is putatively one such species. Convict cichlids are substrate brooders that provide biparental care of young, from the egg stage, throughout the free embryo (wriggler) stage, and for four to six weeks during the exogenous feeding/free-swimming stage (= 'fry') until the fry have reached independence, between 10 to $12 \mathrm{~mm}$ in body length (Fraser and Keenleyside 1995). As fry increase in body size, the brood and the parents become a mobile group unit, swimming and foraging along the river substrate during the day (Keenleyside et al. 1990; Wisenden 1995). Biparental care in this species primarily involves vigorous defence of young against fish predators, which is crucial to brood survival and for fry to successfully reach independence (Keenleyside et al. 1990; Wisenden 1995). Previous field behavioural studies on wild convict cichlids have alluded to the occurrence of intraspecific brood mixing events. In particular, Wisenden and Keenleyside (1992) repeatedly visited wild broods during the parental care period and found that some broods increased in membership size during the breeding season and/or two different size classes of free-swimming young were visible within a brood in some of these instances. These observations suggested that parents were potentially accepting 
'foreign fry' (fry that are not their offspring) into the brood. Their follow-up experimental manipulations indicated that guarding parents would generally accept fry that were of similar size or smaller than their own offspring or 'host fry' (Wisenden \& Keenleyside 1992, 1994). This acceptance of foreign fry into the brood based on body size discrimination could be due to either parental misidentification of foreign fry as their own offspring or selective adoption and/or acceptance of foreign fry into the brood that do not pose a threat to their own offspring (McKaye \& McKaye 1977; Wisenden \& Keenleyside 1992, 1994). Moreover, benefits through group dilution effect or differential predation (of smaller foreign fry) would provide benefits to host fry within a brood. Although the acceptance of smaller or similar-sized foreign fry present little threat to host fry, larger foreign fry are occasionally accepted by convict cichlid parents in nature (Fraser \& Keenleyside 1995). This would appear to be risky, as larger foreign fry may outcompete smaller host fry for food or be aggressive towards them. In experiments, acceptance of larger foreign fry was found in instances where host fry were at a more robust developmental stage at around 7 to $8 \mathrm{~mm}$ in standard length (Fraser et al. 1993; Fraser 1996). These aforementioned combinations of field and laboratory experiments indicate that the body size of host and foreign fry influence the readiness of parental convict cichlid to accept foreign fry into their brood. Moreover, the size range of foreign fry accepted in experimental manipulations appears to depend upon the developmental stage or size of host fry. Therefore, if brood mixing and active adoption occurs in the wild, the body size of fry would likely play a role in the success of brood mixing events and in the size structure of mixed broods. 
While the natural occurrence of brood adoption and mixing events in the convict cichlid has been alluded to, and has been examined using field manipulation and laboratory experiments (Wisenden \& Keenleyside 1992; Fraser et al. 1993; Wisenden \& Keenleyside 1994; Fraser 1996; Fraser \& Keenleyside 1995), the actual prevalence and degree of brood mixing in nature remains unknown. Consequently, the main objective of my study was to confirm whether brood mixing occurs in wild convict cichlids using microsatellite genetic markers and to characterize the prevalence and degree of brood mixing. If brood mixing occurs, then I predicted that genotype data of young should reveal that brood mixing occurs more frequently than previously inferred from previous, more conservative field observations on broods (Wisenden \& Keenleyside 1992). Moreover, genetic data will allow me to compare intra-brood body size distributions to determine if mixed broods can be distinguished based on body size 'classes' of fry. I predicted that if size classes are distinguishable within a mixed brood, then the majority of the foreign fry would be smaller or similar in body length to the host fry, as previously demonstrated in field experimental manipulations (Wisenden \& Keenleyside 1992). I also predicted that, as host fry become larger, the size difference between foreign fry and host fry may increase, due to parents being less discriminatory. The current study provides for the first time genetic evidence for brood mixing, and associated alloparental care, in the convict cichlid in nature. My novel results form the basis for future experimental investigations into the potential mechanism(s) underlying brood mixing in the wild in this and other species. 


\section{METHODS}

\section{Field Site and Study Population}

My field site was along a circa 3-km long stretch of the Rio Cabuyo, Costa Rica. This stretch of Rio Cabuyo was located in the Lomas Barbudal Biological Reserve $\left(10^{\circ} 27^{\prime} \mathrm{N}, 85^{\circ} 20^{\prime} \mathrm{W}\right)$ in the Guanacaste region of Costa Rica. During the dry season, this river consists of a series of long open pool areas connected to adjacent pools by riffle/stream sections, where fish immigration and emigration between pools is possible. The substrate of the river can vary between pools, but mainly consists of rocks, sand and gravel with some instances of large boulder rock-face shelves. Typically, pool water depth is shallow along the shoreline and deeper towards the centre of the pool (personal observations). In some pools the substratum is covered with considerable leaf litter, from the surrounding tree canopy. Fish density and diversity may also vary between pools, but generally fish diversity in this river included (juvenile and adult): convict cichlids, other cichlids (Neetroplus nematopus, Amphilophus longimanus, Parachromis dovii), characins (Astyanax aeneus), catfish (Rhamdia nicaraguensis), and large poecilids (Poeciliopsis turrubarensis). All of these fishes are potential predators on convict cichlid fry (personal observations; Keenleyside et al. 1990).

\section{Brood Collections}

Using dip-nets, I collected 50 broods (totalling 1816 fry) under biparental care from 12 pools (surface areas ranging between 200 and $800 \mathrm{~m}^{2}$ ) while snorkelling in the Rio Cabuyo, and 1 outgroup brood (105 fry) from the nearby Rio Potrero (to compare 
alleles and genetic brood composition) during the dry season in February 2008. Guarding parents were visually spotted, and the entire brood was collected by carefully 'herding' fry into a dip net. Of the 50 broods collected, 2 broods (Broods CC \& DD) represent incomplete samples. Each of the collected broods was preserved in isopropyl alcohol in separate tubes for transport back to Carleton University for later analysis.

During brood collections, I did not capture the parents for tissue samples for the following reasons. My primary goal was to collect broods in their entirety to assess their individual genetic structure and to ascertain if brood mixing occurs in wild convict cichlid broods. My main concern was to ensure that neighbouring broods were minimally disrupted. Any attempt at collecting the parents (after collecting the fry) would have resulted in an increased likelihood of disturbing neighbouring broods and causing fry to scatter. This would potentially have created artificial mixing events with neighbouring broods, thereby compromising the integrity of my dataset. Parents could not be collected before collecting the fry because the unprotected fry would either have been eaten by nearby fish predators or may have been scattered (and 'lost') along the river floor. Indeed, Alonzo et al. (2001) demonstrated that the removal of parents causes complete brood destruction by brood predators within a few minutes. Moreover, it would be logistically difficult to collect parents as many areas were not 'seinable', parents and their brood are highly mobile, and adults are difficult if not impossible to catch with dip-nets. 


\section{Body Length Measurements and Microsatellite Genetic Analyses}

Upon return to Carleton University, the standard body length (from tip of nose to end of the caudal peduncle) of all fry within each brood was measured to the nearest 0.01 $\mathrm{mm}$ from digital photographs (Canon PowerShot A620). These photos were taken under a Zeiss Discovery V8 microscope (at 10X magnification) and measured using digital image processing software (AxioVision, Carl Zeiss, Germany), to ensure highly accurate and precise body size measurements. To straighten out each fish for an accurate body measurement, the body of each fry was placed parallel between two sterile glass slides and the top slide was gently pressed to straighten out the fry's body. This process did not alter the size measurements, which I confirmed by comparing these measurements to those taken separately with callipers during pilot measurements. Each fish was given a brood-specific individual identification (e.g. Al represents individual \#1 from Brood 'A') and transferred to an individual tube ('screw cap' microcentrifuge tube) filled with $95 \%$ ethanol for storage. For eight fry (B25, B27, D3, QQ36, QQ44, QQ97, WW71, WW108), it was impossible to accurately measure their body length due to body damage. Although these individuals were included in the genotype analysis, they were excluded from the analysis of fry body length within and between broods.

Four polymorphic microsatellite loci (Acit1, Acit2, Acit3, and Acit4) were used to assess genetic brood composition. I optimised these microsatellite markers for the convict cichlid from pre-existing Midas cichlid (Amphilophus citrinellus) microsatellite markers (see Noack et al. 2000). The details of the microsatellite marker optimisation and all genetic protocols (DNA extraction, PCRs and microsatellite fragment analysis) are 
provided in Chapter 7 (and in Lee-Jenkins et al. 2011) and, as such, are not re-described here. For 14 fry (B2, B9, B10, B18, B21, B25, B30, L16, L19, M4, M13, N47, N69, UU55), DNA extractions did not yield successful PCR amplifications; these individuals were therefore excluded from all analyses (note that brood sizes were adjusted accordingly).

\section{Data Analysis}

The analysis of this large sample of wild broods was done in a systematic 'bottom-up' approach, from a brood-by-brood level to a within-pool comparison of broods. The first step (a within-brood analysis) was to identify and categorize different genotypes within each brood. Within each brood, I grouped individuals into geneticallydistinct sibsets (= sibling groups). I used the software KINALYZER (Berger-Wolf et al. 2007; Ashley et al. 2009) to group individuals into sibsets within each brood. I then manually checked the output of each analysis to ensure that the most conservative groupings were used. This manual check also served as a double-check for any allele calling or binning errors. KINALYZER software works on the principle of Mendelian inheritance of alleles of co-dominant genetic markers, and is specifically designed to

group data into sibsets when no parental genotype information is available (Berger-Wolf et al. 2007; Ashley et al. 2009). From the results of this sibship categorization process, I was then able to reconstruct the inferred parental genotypes that would have been necessary to yield the observed sibsets (see Chapter 7 (Table 7.3) and Lee-Jenkins et al. 2011 for a more detailed example of this procedure). 
Because genetic data were not obtained from parents, I could not identify with certainty which fry were the 'host fry' (genetic offspring of the parents guarding the brood) and 'foreign fry' (fry from a different brood). Consequently, I inferred 'host fry' identity based on the reasonable assumption that the majority of the brood (i.e. the sibset that comprised the majority of the brood) were the offspring of the guarding parents. Although the lack of genetic information from the parents is not ideal, my genetic data on the sampled broods nonetheless unambiguously demonstrated instances of brood mixing in the Rio Cabuyo (see Results section below), where genotype grouping of fry (into sibsets) matched across the four loci (for an example of brood 'analysis', see Chapter 7 and Lee-Jenkins et al. 2011). In most instances of brood mixing, there was a predominant sibset genotype group. Where no one sibset was predominant in a brood, this brood was not included in host versus foreign fry type comparisons, and was noted in the results. Foreign fry that could not be accurately grouped into a sibset (comprised of $\geq 3$ fry) were placed in the "Mixed Foreign Fry" ('FF Mix') category. This latter group represents foreign fry that were more than likely not related to one another (or could potentially be related to one other individual in the group) and may potentially represent 'stray' foreign fry.

Each constructed sibset was compared within its focal brood at each locus separately, where the genotypes of the inferred parents (for host and foreign sibsets) were compared to determine if extra-pair copulations could have occurred. A potential extrapair copulation occurred when two sibsets shared a parental genotype at each of the four microsatellite loci. There were some instances (twice) where only two foreign fry were 
left to be grouped and a sibset grouping of these two fry resulted in parental genotypes consistent with extra-pair copulations. These two broods were also noted as potential extra-pair copulations (see Table 8.1 - Brood U and Brood EE).

Thus, my brood-by-brood analysis allowed me to ascertain: i) if brood mixing occurred within a brood, ii) the prevalence of mixed broods in the study population, iii) the relative proportions of each distinct sibset within a brood, iv) if sibset body size classes were evident within a brood (when genotype data was coupled with the body-size measurements), and v) if extra-pair copulations could have potentially occurred.

After all the sample broods were genotyped and categorized into sibsets (with parental genotypes constructed), I made within-pool comparisons to determine if mixing events (could have) occurred with fry from other broods collected in the same pool. Within each pool, I first compared all the inferred parental genotypes of host and foreign fry sibsets to any of the genotypes of the 'mixed foreign fry', and then compared all inferred parental genotypes of all brood sibsets within each sampled pool.

\section{Host versus Foreign Fry Body Size Comparisons}

Once fry were grouped into their sibsets, I compared the body size range of foreign fry (FF) sibsets and 'mixed' foreign fry (FF Mix) to the body size range of the inferred host fry (HF); see Table 8.1). For FF sibsets, if the body size range fell within the body size range of the host fry, then they were categorized as being of the same size. If the body size range of FF was above the body size range of the host fry, then the FF sibset was categorized as larger $(=\lg )$ than the host fry. Similarly, if the body size range of a FF 
sibset was below the range of the host fry, it was categorized as smaller $(=\mathrm{sm})$ than the host fry. Foreign fry in the mixed category (FF Mix) were individually compared to the host fry body size range. If a foreign fry was $\geq 0.5 \mathrm{~mm}$ below or above the body size range of host fry, it was noted as 'sm' or ' $\mathrm{lg}$ ', respectively; otherwise, the foreign fry was categorized as 'same'. Ranges were compared rather than mean body length because all of the fry together (HF, FF sibset(s), FF Mix) form a single brood and because it is the differences in the body size of fry within a brood that determines their relative vulnerability to predation and the level of intra-brood competition and aggression (Fraser et al. 1993; Wisenden \& Keenleyside 1994).

To statistically compare the body lengths of inferred host fry and foreign fry over the entire data set (with 'mixed' foreign fry included), I used a linear mixed-effect model. Specifically, I used the the 'Imer' function in the lme4 package of ' $R$ ', with p-values based on Markov-chain Monte Carlo sampling ('pvals.func' function in R: Bates \& Maechler 2009). Body length was my dependent variable and fry type (HF or FF) was my predictor variable, with both brood identity and pool as random factors in the analysis. Only mixed broods and broods that had a predominant genotype (= inferred host fry) were used in this analysis. Where broods potentially contained foreign fry sibsets originating from an extra-pair copulation, these sibsets were excluded and only mixed foreign fry (ones not from an extra-pair copulation) were used in this analysis ( $n=9$ of the 13 broods). 


\section{RESULTS}

My genetic data revealed that brood mixing is common in the Rio Cabuyo convict cichlid population, wherein mixed broods represented $78 \%$ of the 50 broods sampled (Table 8.1). Moreover, the degree of mixing varied, as mixed broods comprised between 4 to $58 \%$ foreign fry (in broods without potential extra-pair copulations). Unmixed broods varied in body length and overall represented the full body size spectrum of freeswimming fry under parental care (Table 8.2). Moreover, unmixed broods were evident across pools with different brood densities. The outgroup brood collected from the Rio Potrero contained only one sibset (i.e. no mixing evident)

Of the 39 mixed broods, 13 broods (or $26 \%$ of all broods sampled) contained a 'foreign fry' sibset that could have been the result of an extra-pair copulation. Two of these broods (Brood XX \& LL) contained two foreign fry sibsets that could have both been from extra-pair copulations (Table 8.3). Brood LL represented an example where the host fry sibset, foreign fry sibset \#1 and foreign fry sibset \#2 all shared parental genotypes consistent with one shared parent. However, Brood XX represented an example where foreign fry sibset \#1 shared the opposite host fry parental genotypes from foreign fry sibset \#2. All of the potential foreign fry sibsets that were consistent with possible extra-pair copulation groupings from the 13 broods were in the same body size range as the inferred host fry, which would be consistent with these sibsets being the same age (see Table 8.3). 
Table 8.1. The brood composition of 50 convict cichlid broods collected from 12 pool areas in the Rio Caburo, Costa Rica. Of the 50 broods, 39 contained foreign fry. Sibling groups of foreign fry (FF) were found in many broods (=FF Sibsets; e.g. Set1) and fry that could not be accurately placed into a sibling group are represented by [FF Mix]. The body size (BL) range of these foreign fry groupings was compared to the body size range of the inferred host fry and categorized as smaller than ( $=\mathrm{sm})$, same size as ( $=$ same) or larger than (=lg) the host fry (HF) sib-set.

\begin{tabular}{|c|c|c|c|c|c|c|}
\hline Pool & $\begin{array}{l}\text { \# of } \\
\text { Broods }\end{array}$ & $\begin{array}{l}\text { Brood W } \\
\text { (\# of fry) }\end{array}$ & $\begin{array}{l}\text { Q6 of Brood HF } \\
\text { ( } \# \text { HF) }\end{array}$ & $\begin{array}{l}\text { Foreign Fr Composition } \\
\text { FF Sibsets \& [FF Mfix] with ( } \# \text { fr) }\end{array}$ & $\begin{array}{l}\text { FF BL relative to HF BL } \\
=\text { sin, same, Ig }\end{array}$ & $\begin{array}{l}\text { Min } \# \\
\text { Families }\end{array}$ \\
\hline \multirow[t]{5}{*}{1} & \multirow{5}{*}{5} & $A(15)$ & $100 \%(15)$ & $\mathrm{N} / \mathrm{A}$ & NiA & 1 \\
\hline & & $\overline{R R(56)}$ & $\overline{60.7 \%(34) *}$ & $\operatorname{Set} I(10) * \operatorname{Set} 2(7),[\mathrm{Mix}(5)]$ & same, sm $[\operatorname{sm}(1)$, same $(4)]$ & $5.5 *$ or 6 \\
\hline & & $S S(44)$ & $97.7 \%(43)$ & {$[\mathrm{Mix}(1)]$} & [same - at smallest end] & \\
\hline & & $\mathrm{TT}(52)$ & $80.8 \%(42)$ & Set1 (3), $[\operatorname{Mix}(0)]$ & same, $[\operatorname{sm}(1)$, same $(4), \lg (2)]$ & 6 \\
\hline & & $\mathrm{UU}(61)$ & $78.7 \%(48)^{*}$ & $\operatorname{Set}]()^{*}, \operatorname{Set} 2(3),[\mathrm{Mix}(3)]$ & same, same, [same(3), slightly lg(1)] & $4.5^{*}$ or 5 \\
\hline \multirow[t]{4}{*}{2} & \multirow[t]{4}{*}{4} & $\mathrm{~B}(32)$ & $96.9 \%(31)$ & Mix (1)] & [same] & 2 \\
\hline & & $V(33)$ & $51.5 \%(17)$ & Set1 (12), Set $2(3)$, Mix (1)] & sm, same, [same] & 4 \\
\hline & & WW (109) & $93.6 \%(102)$ & Set1 $(7)$ & same & 2 \\
\hline & & $\mathrm{xx}(35)$ & $34.3 \%(12) * ?$ & Set $1(10) *$ Set $2(7) *,[\mathrm{Mix}(6)]$ & same, same, [same] & $?$ \\
\hline \multirow[t]{4}{*}{3} & \multirow[t]{4}{*}{4} & $\mathrm{C}(22)$ & $81.8 \%(18)$ & Setl (3), $\operatorname{Mix}(1)]$ & sm. [same] & 3 \\
\hline & & $D(36)$ & $55.6 \%(20)$ & Set1 (0), Set (3) , Mix (7)] & same, large [same $(5), \lg (2)]$ & 7 \\
\hline & & $E(38)$ & $47.4 \%(18)^{*}$ & Set $](16)^{*},[\mathrm{Mix}(4)]$ & same'slighth sm, [same- slightly sm] & 3.5 or 4 \\
\hline & & $F(12)$ & $100 \%(12)$ & N/A & $\mathrm{N} / \mathrm{A}$ & 1 \\
\hline \multirow[t]{2}{*}{4} & \multirow[t]{2}{*}{2} & $G(14)$ & $35.7 \%(5) ?$ & Setl (4), Set2 (3), $\operatorname{Mix}(2)]$ & same, sm \& same, [sm(1) \& same(1)] & 4 \\
\hline & & $Q 0(97)$ & $100 \%(97)$ & $\mathrm{N} / \mathrm{A}$ & $\mathrm{N} / \mathrm{A}$ & 1 \\
\hline \multirow[t]{7}{*}{5} & \multirow[t]{7}{*}{7} & $\mathrm{H}(20)$ & $100 \%(20)$ & $\mathrm{N} / \mathrm{A}$ & NA & 1 \\
\hline & & $\mathrm{I}(24)$ & $79.2 \%(19)$ & Set1 (4), [Mix (1)] & sm \& same, [sm] & 3 \\
\hline & & $\mathrm{J}(15)$ & $100 \%(15)$ & $N / A$ & N/A & 1 \\
\hline & & $\overline{\mathbf{K}(13)}$ & $92.3 \%(12)$ & Mix (1)] & [same- slightly $\mathrm{sm}$ ] & $1.5 *$ or 2 \\
\hline & & $L(34)$ & $58.8 \%(20)$ & Setl (8), Set (4), Mix (2)] & lg, same, [same] & 4 \\
\hline & & $M(17)$ & $23.4 \%(4) ?$ & Set1 (3), Mix (10)] & $\lg [\operatorname{same}(8) \& \lg (2)]$ & $7 ?$ \\
\hline & & $\mathrm{N}(73)$ & $100 \%(73)$ & NA & $\mathrm{N} / \mathrm{A}$ & 1 \\
\hline
\end{tabular}


Table 8.1. contimed....

\begin{tabular}{|c|c|c|c|c|c|c|}
\hline Pool & $\begin{array}{l}\text { \# of } \\
\text { Broods }\end{array}$ & $\begin{array}{l}\text { Brood ID } \\
\text { ( } \# \text { of fru) }\end{array}$ & $\begin{array}{l}\text { \% of Brood HF } \\
\text { (स HF) }\end{array}$ & $\begin{array}{l}\text { Foreign Fry Composition } \\
\text { FF Sibsets \& [FF Mfix] with ( } \# \text { frv) }\end{array}$ & $\begin{array}{l}\text { FF BL relative to HF BL for each } \\
\text { FF set \& [FF Mix] =sm, same, lg }\end{array}$ & $\begin{array}{l}\text { Min \# } \\
\text { Families }\end{array}$ \\
\hline 6 & 2 & $\begin{array}{l}\mathrm{O}(27) \\
\mathrm{P}(52) \\
\end{array}$ & $\begin{array}{l}51.9 \%(14)^{*} \\
59.6 \%(31) \\
\end{array}$ & $\begin{array}{l}\text { Set }\left[(12)^{*}[\operatorname{Mix}(1)]\right. \\
\text { Set] }(12),[\operatorname{Mix}(9)]\end{array}$ & $\begin{array}{l}\text { sm \& same, [same] } \\
\text { slightly sm \& same, [same(3) \& } \lg (6)]\end{array}$ & $2.5^{*}$ or 3 \\
\hline 7 & 3 & $\begin{array}{l}Q(61) \\
R(32) \\
S(58)\end{array}$ & $\begin{array}{l}67.2 \%(41) \\
71.9 \%(23) \\
50 \%(29)\end{array}$ & $\begin{array}{l}\text { Set1 (12), [Mix (8)] } \\
\text { Set1 (6), [Mix (3)] } \\
\text { Set1 (20), Set2 (4), Set3 (3), [Mix(2)] }\end{array}$ & $\begin{array}{l}\text { same, [same] } \\
\text { same } \& \text { slightly } \lg \text { [ }[\operatorname{sm}(1) \& \text { same(2)] } \\
\text { same \& } \mathrm{lg} \text { lg. same, [same] }\end{array}$ & $\begin{array}{l}6 \\
4 \\
5\end{array}$ \\
\hline 8 & $T$ & $T(12)$ & $100 \%(12)$ & N/A & N/A & 1 \\
\hline 9 & 4 & $\begin{array}{l}U(34) \\
V(22) \\
W(23) \\
X(24) \\
\end{array}$ & $\begin{array}{l}94.1 \%(32)^{*} \\
72.7 \%(16)^{*} \\
65.2 \%(15) \\
70.8 \%(17)^{*}\end{array}$ & $\begin{array}{l}\text { Setl }(2)^{*} \text { ? } \\
\text { Set1 }(5)^{*},[\mathrm{Mix}(1)] \\
\text { Set1 }(4),[\operatorname{Mix}(4)] \\
\text { Setl }(6)^{*},[\operatorname{Mix}(1)]\end{array}$ & $\begin{array}{l}\text { same } \\
\text { same, [lg] } \\
\operatorname{sm},[\operatorname{sm}(2) \& \operatorname{same}(2)] \\
\text { same, [lg] }\end{array}$ & $\begin{array}{l}1.5^{*} \text { or } 2 \\
2.5^{*} \text { or } 3 \\
4 \\
2.5^{*} \text { or } 3 \\
\end{array}$ \\
\hline 10 & 4 & $\begin{array}{l}\text { AA (11) } \\
\text { BB (68) } \\
Y(45) \\
Z(30) \\
\end{array}$ & $\begin{array}{l}54.5 \%(6)^{* ?} \\
61.8 \%(42) \\
86.4 \%(39) \\
100 \%(30) \\
\end{array}$ & $\begin{array}{l}\text { Set1 }(5)^{*} \\
\text { Set1 (10), Set2 (9), Set3 (3), [Mix (4)] } \\
\text { Set1 (4), } \operatorname{Mix}(2)] \\
\text { N/A }\end{array}$ & $\begin{array}{l}\text { same } \\
\text { lg, same \& lg, same \& lg, [same] } \\
\text { same, [same] } \\
\text { N/A }\end{array}$ & $\begin{array}{l}1.5 \text { or } 2 \\
6 \\
3 \\
1\end{array}$ \\
\hline 11 & 9 & $\begin{array}{l}\mathrm{CC}(7) \\
\mathrm{DD}(8) \\
\mathrm{EE}(20) \\
\mathrm{FF}(56) \\
G G(20) \\
\mathrm{HH}(33) \\
\text { II (14) } \\
\text { JJ(78) } \\
\text { KK (43) }\end{array}$ & $\begin{array}{l}\text { partial (5)* } \\
\text { partial }(4) * \\
90.0 \%(18)^{*} \\
100 \%(50) \\
90 \%(18) \\
39.4 \%(13)^{*} \\
71.4(10) \\
\frac{100 \%(78)}{81.4 \%(35)^{*}}\end{array}$ & $\begin{array}{l}{[\operatorname{Mix}(2)]} \\
{[\operatorname{Mix}(4)]} \\
\operatorname{Setl}(2)^{*} \\
\text { N/A } \\
{[\operatorname{Mix}(2)]} \\
\text { Setl }(6)^{*}, \operatorname{Set} 2(10),[\operatorname{Mix}(4)] \\
\text { Set1 }(3),[\operatorname{Mix}(1)] \\
\text { N/A } \\
\text { Setl }(8)^{*}\end{array}$ & $\begin{array}{l}\text { same } \\
\text { same } \\
\text { same } \\
\text { N/A } \\
{[\mathrm{sm}]} \\
\text { same, sm, [lg] } \\
\text { same, [same- slightly lg] } \\
\text { N/A } \\
\text { same- slightly lg }\end{array}$ & $\begin{array}{l}2 \\
3 \\
1.5 * \text { or } 2 \\
1 \\
2 \\
4.5^{*} \text { or } 5 \\
3 \\
1 \\
1.5^{*} \text { or } 2\end{array}$ \\
\hline 12 & 5 & $\begin{array}{l}I(73) \\
\text { MM (21) } \\
\text { NN (16) } \\
O O(31) \\
\text { PP (31) }\end{array}$ & $\begin{array}{l}60.3 \%(44)^{*} \\
100 \%(21) \\
81.3 \%(13) \\
41.9 \%(13) \\
64.5 \%(20)\end{array}$ & $\begin{array}{l}\text { SetI }(18)^{*}, \operatorname{Set} 2(5)^{*},[\mathrm{Mix}(0)] \\
\text { N/A } \\
\text { Setl }(3) \\
\text { Setl }(6), \operatorname{Set} 2(4),[\mathrm{Mix}(8)] \\
\text { Set1 }(0), \operatorname{Mix}(5)]\end{array}$ & $\begin{array}{l}\text { same, same, [same] } \\
\text { NAA } \\
\text { sm } \\
\text { lg, same, [sm(1), same(4)\& } \lg (3)] \\
\text { same. [same] }\end{array}$ & $\begin{array}{l}7 \\
1 \\
2 \\
7 \\
5\end{array}$ \\
\hline
\end{tabular}


Table 8.2. The body size distribution of unmixed broods (containing no foreign fry), which represent $22 \%$ of total number of wild convict cichlid broods sampled. Body lengths $(\mathrm{BL})$ ranged across the entire developmental spectrum from newly freeswimming fry ( $\sim 5 \mathrm{~mm})$ to fry approaching independence ( $\sim 10$ to $13 \mathrm{~mm})$. Even pools with a relatively high number of broods contained unmixed broods.

\begin{tabular}{llllll}
\hline $\begin{array}{l}\text { Brood } \\
\text { ID }\end{array}$ & $\begin{array}{l}\text { Pool } \\
\text { ID }\end{array}$ & $\begin{array}{l}\text { \# Broods } \\
\text { in Pool }\end{array}$ & $\begin{array}{l}\text { \# of Fry } \\
\text { in Brood }\end{array}$ & $\begin{array}{l}\text { Mean } \pm \text { s.e. BL } \\
\text { in m m }\end{array}$ & $\begin{array}{l}\text { Min to Max BL \& } \\
\text { (range) in mm }\end{array}$ \\
\hline $\mathrm{A}$ & 1 & 5 & 15 & $6.90 \pm 0.07$ & $6.35-7.42(1.07)$ \\
\hline $\mathrm{F}$ & 3 & 4 & 12 & $11.26 \pm 0.12$ & $10.55-11.48(1.23)$ \\
\hline $\mathrm{QQ}$ & 4 & 2 & 97 & $5.44 \pm 0.02$ & $5.02-5.85(0.83)$ \\
\hline $\mathrm{H}$ & 5 & 7 & 20 & $8.51 \pm 0.07$ & $7.49-8.92(1.43)$ \\
\hline $\mathrm{J}$ & 5 & 7 & 15 & $8.70 \pm 0.07$ & $8.24-9.17(0.93)$ \\
\hline $\mathrm{N}$ & 5 & 7 & 73 & $4.94 \pm 0.02$ & $4.59-5.23(0.64)$ \\
\hline $\mathrm{T}$ & 8 & 1 & 12 & $7.75 \pm 0.05$ & $7.54-8.05(0.51)$ \\
\hline $\mathrm{Z}$ & 10 & 4 & 30 & $7.99 \pm 0.07$ & $6.83-8.62(1.79)$ \\
\hline $\mathrm{FF}$ & 11 & 9 & 56 & $6.63 \pm 0.02$ & $6.03-7.03(1.0)$ \\
\hline $\mathrm{JJ}$ & 11 & 9 & 78 & $7.02 \pm 0.02$ & $6.57-7.38(0.81)$ \\
\hline $\mathrm{MM}$ & 12 & 5 & 21 & $6.22 \pm 0.03$ & $6.04-6.52(0.48)$ \\
\hline
\end{tabular}


When making inter-brood comparisons within each sampled pool, siblings were found in different focal broods in seven instances. In three of these cases, individuals identified as 'mixed' foreign fry in their focal brood (1 FFMix Brood I, 1 FFMix Brood O, 2 FFMix Brood GG) were siblings with individuals forming a foreign fry sibset in a neighbouring brood (FFsetl Brood L, FFsetl Brood P, and FFset 1 in Brood HH, respectively). In one case, a 'mixed foreign fry' (from UU) was the sibling of individuals who were host fry in a different brood (Brood RR). These two broods were not closest to each other at time of collection in Pool 2, but rather were approximately $9 \mathrm{~m}$ apart. A foreign fry sibset of four individuals in Brood $\mathrm{Y}$ were siblings with a foreign fry sibset (of 10 individuals) in Brood BB. Moreover, in two cases, a foreign fry found in a brood was the sibling of host fry from another brood in the same pool. In these examples, Broods OO and PP were both donor and recipient broods. These two broods were neighbouring broods (closest to each other) out of the five broods collected in Pool 12. Taken together, these data indicate that a fry from a given focal brood can find itself in the brood of nearby adults that are not his parents within the same pool.

For the host fry versus foreign fry body size comparisons, eight of the 39 mixed broods were excluded from this analysis. Three broods did not have a predominant sibset (Broods $\mathrm{G}, \mathrm{AA}, \mathrm{M}$ ) and two broods only represented partial brood samples (CC \& DD). Of the broods with potential extra-pair copulations, 3 broods only contained potential half-sibs (to the host fry) with no 'true' foreign fry (EE, KK, U). The remaining extrapair copulation broods were examined using their 'true' foreign fry sibsets or mixed foreign fry only. 
Table 8.3. The mean ( \pm s.e.) body length of host fry (HF) and associated potential extrapair copulation (EPC) sibsets, representing a total of 13 out of 50 broods sampled.

\begin{tabular}{lllllll}
\hline $\begin{array}{l}\text { Brood } \\
\text { ID }\end{array}$ & $\begin{array}{l}\text { Pool } \\
\text { ID }\end{array}$ & $\begin{array}{l}\text { \# of } \\
\text { Fry }\end{array}$ & $\begin{array}{l}\text { \# of } \\
\text { 'HF' }\end{array}$ & $\begin{array}{l}\text { Mean } \pm \text { s.e. BL } \\
\text { of HF }(\mathbf{m m})\end{array}$ & $\begin{array}{l}\text { \# of } \\
\text { 'EPCs' }\end{array}$ & $\begin{array}{l}\text { Mean } \pm \text { s.e. } \\
\text { of EPC ( mm) }\end{array}$ \\
\hline RR & 1 & 56 & 34 & $6.46 \pm 0.02$ & 10 & $6.55 \pm 0.03$ \\
\hline UU & 1 & 61 & 48 & $5.86 \pm 0.02$ & 7 & $5.85 \pm 0.03$ \\
\hline XX & 2 & 35 & 12 & $5.53 \pm 0.05$ & 10 & $5.57 \pm 0.04$ \\
& & & & & 7 & $5.60 \pm 0.06$ \\
\hline E & 3 & 38 & 18 & $6.51 \pm 0.03$ & 16 & $6.53 \pm 0.05$ \\
\hline $\mathrm{O}$ & 6 & 27 & 14 & $7.63 \pm 0.03$ & 12 & $7.21 \pm 0.09$ \\
\hline $\mathrm{U}$ & 9 & 34 & 32 & $5.43 \pm 0.02$ & 2 & $5.36 \pm 0.19$ \\
\hline $\mathrm{V}$ & 9 & 22 & 16 & $6.24 \pm 0.04$ & 5 & $6.35 \pm 0.09$ \\
\hline $\mathrm{X}$ & 9 & 24 & 17 & $8.44 \pm 0.07$ & 6 & $8.56 \pm 0.15$ \\
\hline $\mathrm{AA}$ & 10 & 11 & 6 & $8.75 \pm 0.07$ & 5 & $8.83 \pm 0.13$ \\
\hline $\mathrm{EE}$ & 11 & 20 & 18 & $5.11 \pm 0.05$ & 2 & $5.12 \pm 0.16$ \\
\hline $\mathrm{HH}$ & 11 & 33 & 13 & $10.18 \pm 0.10$ & 6 & $10.14 \pm 0.10$ \\
\hline $\mathrm{KK}$ & 11 & 43 & 35 & $5.90 \pm 0.02$ & 8 & $6.00 \pm 0.05$ \\
\hline $\mathrm{LL}$ & 12 & 73 & 44 & $5.12 \pm 0.02$ & 18 & $5.10 \pm 0.04$ \\
& & & & & 5 & $5.12 \pm 0.10$ \\
\hline
\end{tabular}


Distinct intra-brood 'size classes' of fry were evident in 18 of 31 broods (58\%) with foreign fry. In these broods, there were examples of both smaller and larger foreign fry, where 11 broods (35\%) contained foreign fry that were smaller than host fry and 10 broods $(32 \%)$ contained foreign fry that were larger than host fry ( 3 broods contained both smaller and larger foreign fry). Of these 31 broods, 26 broods (84\%) contained foreign fry that were of similar size to host fry (see Table 8.1 and Figure 8.1). When all body size data were grouped and examined together, body size did not differ between host and foreign fry (linear-mixed effects model (lmer): $t=-0.422, \mathrm{df}=1081, \mathrm{MCMC} p$ $=0.9254)$. Body size did appear to vary more between host and foreign fry as mean host fry body size increased, and most foreign fry were smaller than host fry after the latter reached $8 \mathrm{~mm}$ in body length (Figure 8.1 ). 


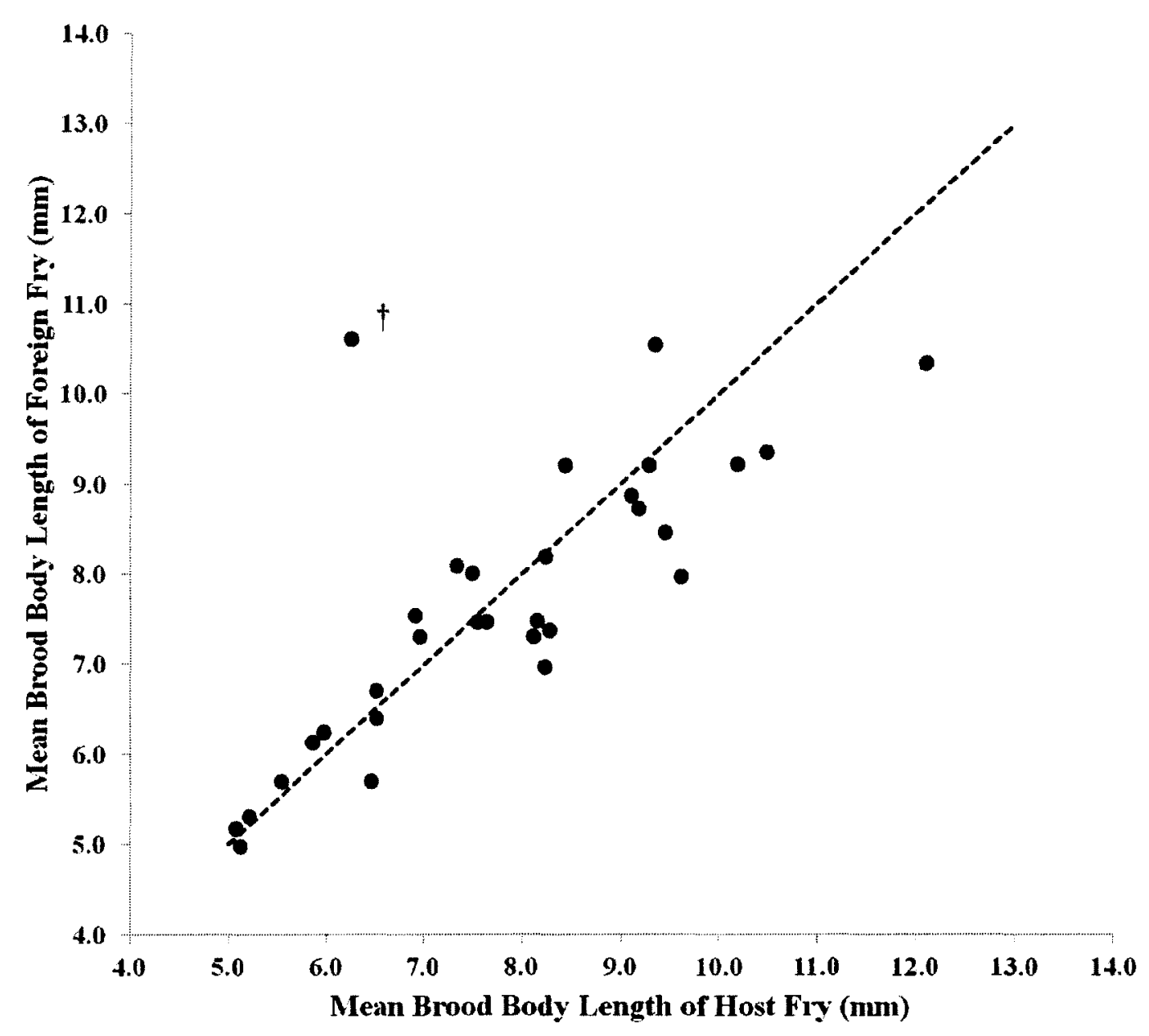

Figure 8.1. Relationship between the mean brood body length of foreign fry and that of host fry within 31 mixed broods. The diagonal dashed line is the line of equivalence $(x=$ $y$ ), where the mean body lengths of foreign fry and host fry within individual broods are identical. The variation around this line increases with increasing body length [not including the outlier Brood V at $(\dagger)$, which had only one foreign fry]. Points above the line indicate that mean foreign fry body length was greater than host foreign fry body length, whereas points below the line indicate that mean foreign fry body length was less than that of host fry. 


\section{DISCUSSION}

Alloparental care may be adaptive if parents that care for foreign or 'fostered' young gain net fitness benefits from doing so. For example, by adopting foreign young, parents could potentially gain reproductive experience (Riedman 1982), appear more attractive or gain access to potential mates (Martin 1989), or exploit fostered young to gain fitness advantages for their own offspring (Natase \& Sherry 1997). Alternatively, alloparental care could be costly and may result from the misidentification of foreign young as one's own young (Riedman 1982; Wisenden 1999). Understanding the evolution of this behaviour can be complex, depending on both environmental constraints and selective pressures (Riedman 1982).

My microsatellite genotyping results here indicate that natural mixing events in the convict cichlid are more prevalent than originally predicted by previous behavioural observations, at least in the Rio Cabuyo (Wisenden \& Keenleyside 1992). More specifically, my results showed that 39 out of 50 wild broods $(78 \%)$ contained foreign fry compared to $15 \%$ of 232 broods inferred to have foreign fry in Wisenden \& Keenleyside's (1992) field study. The prevalence $(78 \%)$ of brood mixing observed in the current study is much higher than prevalence values reported for many bird species (e.g. 22 - 37\%: Brown 1998; Faircloth et al. 2005). Moreover, the degree of mixing within mixed convict cichlid broods varied widely, ranging from 2\% (e.g. Brood SS 1 of 45 fry) to $58 \%$ (e.g. Brood OO 18 of 31 fry) of the brood containing foreign fry.

The high prevalence and high degree of brood mixing in wild convict cichlids suggest that parental convict cichlids may gain a fitness advantage by caring for mixed 
broods over unmixed broods. Evidence for an adaptive advantage to caring for mixed broods has been found in Canada Geese, Branta canadensis, where 'host' goslings survived longer than adopted goslings in mixed broods and 'host' offspring in mixed broods survived longer than those in unmixed broods (Natase \& Sherry 1997). Mixed broods may also be advantageous because they are often larger than unmixed broods (Codenotti \& Alvarez 1998; Natase \& Sherry 1997). In the convict cichlid system, the high prevalence of brood mixing could be a result of the intense predation pressure in the Rio Cabuyo population (personal observations; Fraser et al. 1993; Wisenden \& Keenleyside 1994). The gradual loss of fry through predation is inevitable during the parental care period, even with both parents guarding the brood (Wisenden 1994). As a brood decreases in membership size, group theory predicts that it may be beneficial for parents to acquire foreign fry into their brood to increase group size and thus dilute the risk of predation upon their own offspring (safety in numbers; Krause \& Ruxton 2002). By adopting smaller foreign fry in their brood, which would be easier targets for fish predators, parents could increase the survival of their own larger offspring on average (differential predation effect; Krause \& Ruxton 2002). Indeed, Wisenden \& Keenleyside (1994) demonstrated such an anti-predation advantage by manipulating convict cichlid broods in the field. Their study revealed that the survival rate of larger (host) fry increased when smaller 'foreign' fry were experimentally placed into a brood. Moreover, it would be advantageous for female convict cichlid parents to accept or actively adopt foreign fry as their brood size declines over the parental care period. Wisenden et al. (2008) demonstrated that parental investment provided by males was correlated to brood 
size and not brood age. Therefore, females may be manipulating male parental care by adopting foreign fry to increase their brood size and thereby reducing the likelihood of male desertion. In so retaining her mate, a female enjoys male assistance with the defence of her brood against predators, as biparental defence is more effective than uniparental defence in the convict cichlid (Wisenden \& Keenleyside 1992). Lastly, adopting foreign young may enhance the level of parental care for the entire brood. For example, in the Greater Rhea, Rhea americana, males that adopted unrelated young were found to be 'better parents' because they were more vigilant and protective of young than nonadopting fathers (Codenotti \& Alvarez 1998).

While the adoption of smaller foreign fry could potentially be advantageous for parental convict cichlids, my genotyping results indicate that for 18 broods (out of 31 ) containing size-class differences between host and foreign fry, 11 of these broods had a distinct size class of smaller foreign fry and 10 broods contained larger foreign fry ( 3 broods had both smaller and larger foreign fry). Moreover, the body sizes of host and foreign fry did not differ when compared over all mixed broods. Therefore, it appears that preferential adoption of smaller young did not occur. Parental convict cichlids in the Rio Cabuyo population may only dilute the predation risk on their offspring through the adoption of similar-sized fry or, alternatively, perhaps they cannot distinguish between their young and foreign young when they are of similar body length. Previous studies have indicated that cichlid fish parents can recognize their own free-swimming young (Noble \& Curtis 1939; Myrberg 1966); however, these studies have primarily compared offspring to heterospecific young rather than to conspecific foreign young. Testing 
whether convict cichlid parents can distinguish their own offspring from the young of other conspecific parents would be a logical extension of my current study. Finally, there is also the possibility that some host fry groupings were incorrect (i.e. the assumption that the largest sibset represents host fry may not always be true).

The pattern of acceptance of foreign fry based on their body size is likely dependent on the relative developmental stage (body size) of host fry (Fraser et al. 1993; Fraser \& Keenleyside 1995; Fraser 1996), accounting for fry vulnerability to predation and inter-fry aggression. Fraser (1996) created a model based on empirical data from series of brood adoption behavioural manipulations (Fraser et al. 1993; Fraser \& Keenleyside 1995). The model predicts that, around $7 \mathrm{~mm}$ in standard body length, host fry would not only benefit from their parents' adoption of smaller or same-sized fry in the brood but would also benefit from group dilution effects if parents allow larger fry (within 2-mm size difference) into the brood. Therefore, at this particular developmental stage, parents will be less restrictive on which foreign fry to accept based on their body size because host fry are more robust and stronger swimmers once they reach $7 \mathrm{~mm}$ in length (see Fraser 1996 for model details). In general, my data conform with the predictions of Fraser's (1996) model. Larger foreign fry (relative to host fry) were clearly evident when host fry were $\geq 7 \mathrm{~mm}$ in body length (except for one outlier: see Figure 8.1), but parents apparently still accepted similar-sized and smaller foreign fry into their brood as their own (host) young increased in length beyond $7 \mathrm{~mm}$. Thus, in natural brood mixing events, parental convict cichlids appear to control the size of foreign fry that they 
accept into their brood. Of course, brood mixing under natural conditions will be constrained by the availability of nearby donor broods.

In the current study, I also found genetic evidence for extra-pair copulations in $26 \%$ of wild convict cichlid broods, a phenomenon that has not hitherto been confirmed in this species. This finding is somewhat surprising because convict cichlids form socially monogamous pair-bonds and breed in isolated cave-like breeding territories which they form by excavating sand from underneath large rocks (Wisenden 1995). The female lays adhesive eggs onto the cave ceiling, the male subsequently enters the cave to fertilize the eggs, and the female then remains in the cave caring for her eggs while the male guards the territory and the entrance to the brooding cave (Keenleyside et al. 1990; Wisenden 1995; personal observations). In this type of breeding territory, it should therefore be very difficult for a sneaker male to enter the cave in order to fertilize recently-spawned eggs and, as such, the breeding caves of the convict cichlid are believed to rule out sperm competition (Wisenden 1995). Appropriate breeding cave territories are somewhat limited in nature and are guarded by the mated male and female throughout the parental care period (Wisenden 1995). If some or all of the $26 \%$ of broods are indeed from extrapair copulations (EPC) in the current study, then it remains unknown whether these EPCs are the result of a sneaker male in the breeding territory, bigamous males within their own breeding territory, and/or females potentially laying eggs in multiple caves. I cannot determine the origin of these potential EPCs copulations without parental genetic data. Further genetic examination of the natural mating system of the convict cichlid would therefore be a fruitful avenue for future research. 
Previous experimental studies have alluded to the possibility of short-term male bigamy in convict cichlid populations, particularly when the female sex ratio is high and predation level is low (Keenleyside 1985; Keenleyside et al. 1990). A bigamous convict cichlid male would split his time between two females within his breeding territory. In the wild, even in the presence of abundant predators, this would not likely affect offspring survival until the fry reach the free-swimming stage and need both parents to guard the brood in open habitat (Keenleyside et al. 1990). If male bigamy did occur in the current study, then one of the females may have 'farmed out' her young at a young freeswimming stage, explaining the extra-pair young of similar body sizes. In the case of Brood XX (Table 8.1, where FFsetl shared the opposite host parental genotype from FFset2), male bigamy and a male sneak copulation may have have occurred. For Brood LL (Table 8.1), a breeding male could have had three simultaneous (and synchronous breeding) broods, which could have combined once free-swimming.

The mechanisms underlying natural brood mixing events in the convict cichlid, particularly if these events are active or passive, are unknown (Wisenden et al. 2008). When comparing brood genotypes within the same pool in the current study, siblings were found in different broods in only seven instances. Four of these cases were of fry that were both 'foreign fry' in their sampled broods. The other three cases were of foreign fry that were siblings to 'host fry' of an existing brood at the time of sampling. These results suggest that different brood mixing mechanisms could be at play. In the former cases, the foreign fry may represent a brood that no longer existed at the time of sampling. In the latter cases, these foreign fry potentially represent fry that have become 
separated or lost from their siblings and parents, who are still in their pool, and joined a neighbouring brood. It was surprising that more foreign fry did not match other sibsets within a given pool, especially because broods were sampled at a high frequency during the mating season in the current study. These data suggest that the majority of foreign fry in broods originally belonged to other broods that were deserted by their biological parents. In biparental cichlid fishes, when a female is deserted by her mate she may try to push her offspring into neighbouring broods ('farming out') because it if very difficult for a lone female to defend her brood successfully (Yanagisawa 1985). Another possibility is that 'host' parents actively steal or 'kidnap' foreign fry to increase the membership size of their own brood (McKaye \& McKaye 1977; Wisenden 1999). If a brood is reduced to a small number of young, parental investment theory predicts that parents may abandon the remaining young and save their energy for future reproductive opportunities (CluttonBrock 1991).

My study provides for the first time unequivocal genetic evidence for brood mixing events, and for the genetic and body size structures of broods, in wild convict cichlid fish. The study's results begs the question of the mechanism(s) underlying brood mixing in the wild in this species and potentially other fish species. With contemporary animal tagging technology (Krause et al. 2011), it should prove fruitful if one could tag newly free-swimming cichlid fry from the breeding cave territory and observe resident broods in a pool in nature. This would allow one to track multiple brood mixing events and predation encounters in real time over the entire course of the parental care period and subsequent offspring fitness outcomes. 
Brood mixing is not only interesting in the context of parental care theory. During brood mixing events, not only do parents accept non-descendent fry into their brood, the host fry must likewise accept foreign fry into the brood. As such, the 'brood mate' or shoal choice of fry can potentially play a role in brood mixing. Given that brood mixing is common in wild convict cichlids (current study), fry within a brood are likely to be in social contact with both kin (sibs) and non-kin (foreign fry), and thus likely encounter socially familiar and unfamiliar fry during brood mixing events. Moreover, if siblings become separated during early ontogeny, they may re-encounter each other at a later developmental stage. Familiarity and kinship are both known to influence social interactions and associations between individuals (e.g. Griffiths and Ward 2006). As such, both of these factors may importantly influence the outcome of brood mixing events and the cohesiveness of the brood/group. In the following chapter (Chapter 9), I therefore investigate the effects of social familiarity and kinship on shoal mate choice in free-swimming convict cichlid young.

The genetic evidence for brood mixing in the current study raises questions regarding the evolution of alloparental care and brood mixing in the convict cichlid fish. Brood mixing appears to be quite common, but varies in the degree of mixing (proportion of foreign fry in the brood) and the number of donor/foreign families involved. Therefore, different mechanisms could underlie brood mixing events. Potential non-exclusive mechanisms include a female parent farming out her young to another brood after male desertion, fry getting lost and joining another brood, active 'kidnapping' of neighbouring fry, or simply mistaken identity of young by the parents (Wisenden 1999). Moreover, 
ambient predation pressure and brood density within a pool also likely influence the prevalence of brood mixing events in nature. However, actual brood mixing mechanisms for the convict cichlid remain unknown (Wisenden et al. 2008). Therefore, future research should examine the aforementioned putative mechanisms of brood mixing in the wild. The research reported in the next two chapters (Chapters 9 and 10) contribute to this quest for further understanding the mechanisms of brood mixing and brood composition for the convict cichlid as a model study system.

\section{ACKNOWLEDGEMENTS (Chapters 7 \& 8)}

Thank you to Jean-Guy Godin, Brian Wisenden and Tony Stumbo who were all involved in the collection of wild broods in Costa Rica. I am most grateful to Adam Densmore who performed the majority of the DNA extraction, PCR and fragment analysis presented in this very large dataset and who helped me fine tune the final optimisation of the DNA extraction method. I would like to extend my deepest thanks to Myron Smith who provided valuable insights into the analysis of this dataset. Moreover, he provided the lab space and equipment in his lab for me to complete this project. Myron and his lab (Kristin, Denis, Isabel, Melissa and Rob) played key roles in training me on the various genetic techniques which allowed me to optimize microsatellites for the convict cichlid. I am most grateful for their patience and for the skills I have now acquired. 


\section{CHAPTER 9}

Concurrent effects of familiarity and kinship on social affiliations in convict cichlid (Amatitlania siquia) young

This chapter is currently under peer-review by the journal Behaviour. 


\begin{abstract}
How cues associated with social familiarity and genetic relatedness interact to influence the formation of social associations among individuals, and thus group composition and dynamics, is poorly understood. Here, I investigated the concurrent effects of social familiarity and kinship on social affiliations in free-swimming convict cichlid fish young or 'fry' (Amatitlania siquia) by pitting the cues of social familiarity and kinship against each other in a four-way choice apparatus. Individual focal fish were given a simultaneous choice to associate ('shoal') with conspecifics that were either socially familiar and kin (full sibs), socially unfamiliar and kin, socially familiar and not kin, or socially unfamiliar and not kin. Stimulus shoal preference differed depending on the body length of the focal fish; smaller fry exhibited no preference, whereas larger (more mobile) fry significantly preferred to associate with familiar kin. In the convict cichlid system, where brood mixing occurs in the wild, a preference to associate with familiar kin may confer fitness benefits to individuals, especially when fry become more mobile as they grow and encounter predators more often. My results contribute to further our understanding of the mechanisms of brood mixing events in the wild and the roles of familiarity and kinship in the formation of social associations in general.
\end{abstract}




\section{INTRODUCTION}

With whom individuals associate early in life can importantly influence future group association preferences, ability to discriminate kin from non-kin, cooperative behaviour, and choice of mates, for example (e.g. Holmes 1995; Mateo 2004; Thünken et al. 2007a, $b$; but see also Mateo 2010). Kin selection theory predicts that preferentially associating with kin confers mutual fitness benefits (Hamilton 1964; West Eberhard 1975), such as enhanced cooperation (Komdeur \& Hatchwell 1999; West et al. 2007), reduced aggression (Utne-Palm \& Hart 2000; Seppä et al. 2001) and reduced foraging competition (Höjesjö et al. 1998) among individuals in social groups. Furthermore, in species with extended parental care, wherein kin (siblings) are together for long periods, social familiarity may develop between young (e.g. Holmes 1995; Komdeur \& Hatchwell 1999; Coffin et al. 2011). In fishes, preferentially associating with familiar individuals can confer antipredation benefits through increased group cohesion or evasive manoeuvres (Chivers et al. 1995; Griffiths et al. 2004) and increased social learning rates within the group (Swaney et al. 2001; Ward \& Hart 2005). Similarly, preferences for familiar individuals occurs in other animal taxa (e.g. Holmes 1995; Coffin et al. 2011), and in some instances can also interact with a preference for kin (e.g. Holmes 1995). Therefore, both kinship and social familiarity can influence social associations and thus the fitness of individuals living in social groups.

In social systems wherein dispersal is limited and young are surrounded only by siblings, using social familiarity to recognize kin may be reliable (Waldman 1987; Komdeur \& Hatchwell 1999; Mateo 2004). However, in other systems where brood 
mixing (e.g. cichlid fishes, Wisenden \& Keenleyside 1992) or adoption (e.g. geese, Kalmbach 2006) occurs, young may be surrounded by both kin and non-kin during early life stages. Therefore, young could potentially also become familiar with individuals who are not kin. In such cases, it remains unclear whether social familiarity and kinship are equally important in the formation and expression of social association preferences. From a kin recognition perspective, the use of an innate kin discrimination mechanism (e.g. self-referent phenotype matching or 'recognition alleles'; Mateo 2004) may be more effective than reliance on social familiarity to accurately recognize kin and behave preferentially towards them. Thus, in social systems with brood mixing or adoption events, social familiarity and kinship may play either independent or synergistic roles in social association preferences among individuals. However, how cues associated with social familiarity and genetic relatedness interact to influence the formation of social associations among individuals, and thus group composition and dynamics, is still poorly understood.

Social familiarity and kinship, in the context of group associations, have been studied extensively in fishes (reviewed by Ward \& Hart 2003; Griffiths \& Ward 2006) and commonly so in the context of kin recognition by phenotype matching when investigated together (e.g. Hain \& Neff 2006; Le Vin et al. 2010). In some behavioural studies (e.g. Frommen \& Bakker 2004), the effects of familiarity and kinship on social affiliations are not clear, as reported preferences for kin may have been confounded by familiarity. In other studies (e.g. Gerlach et al. 2007), combinations of kinship and familiarity cues were not fully examined, and consequently explaining observed results 
based on kinship or familiarity is rendered difficult. To my knowledge, no study has concurrently tested different combinations of social familiarity and kinship cues to elucidate the relative role each of these two factors, and their interaction, may have on social association preferences.

Here, I experimentally disentangled the potential influences of social familiarity and kinship on the development and expression of social affiliations in free-swimming young of the convict cichlid fish (Amatitlania siquia). As mentioned above, these two factors are sometimes confounded in behavioural studies. My study's objectives were (i) to investigate using a balanced design the potential effects of different combinations of kinship and social familiarity (visual and olfactory) cues on shoal-mate choice in young cichlid fish, and (ii) to examine whether social association preferences were dependent on the body length of focal fish, which is correlated with their age (stage of development). Moreover, in fishes, body size influences behaviour and physiology (Noakes \& Godin 1988; Fuiman \& Magurran 1994; Godin 1997) and is therefore an important factor to consider in behavioural ecology studies.

The monogamous, biparental convict cichlid is an ideal model species to address the above objectives. In Chapter $8, \mathrm{I}$ established that brood mixing and alloparental care occur frequently in nature, whereby parents accept and care for non-descendant or 'foreign' free-swimming young (fry) into their brood (e.g. Rio Cabuyo, Costa Rica; Wisenden \& Keenleyside 1992; Lee-Jenkins et al. 2011). The period of biparental care of fry is extended, typically lasting between four to six weeks (Wisenden 1995), which allows ample time for young within a brood to become increasingly socially familiarized 
with one another in early ontogeny. An extended period of social association among individuals appears necessary for social familiarity to develop in fishes (e.g. 12 days in the guppy, Poecilia reticulata; Griffiths \& Magurran 1997a). As convict cichlid fry age and become larger, the brood unit becomes increasingly mobile (personal observations; Fuiman \& Magurran 1994) and, as a consequence, brood mixing events are more likely to occur. Brood mixing results in individual fry encountering, associating and potentially becoming familiarized with non-kin (fry from another mated pair). Furthermore, as mated pairs and their broods tend to remain in the same stream pool throughout the parental care period (Wisenden \& Keenleyside 1992), the potential exists for fry to encounter siblings, with whom they may not have had time to familiarize with previously, if separated earlier in ontogeny. Therefore, as young could be confronted with potential shoal mates who are familiar or unfamiliar, kin or non-kin, it remains unclear what role these two social relationship factors play on shoaling decisions in free-swimming convict cichlid young. Lastly, because convict cichlid fry experience high predation rates in nature (Wisenden \& Keenleyside 1992; Fraser \& Keenleyside 1995), there is strong selection pressure on them to shoal to reduce individual risk of predation (Krause \& Ruxton 2002).

Convict cichlid fry experience major developmental changes during the period of parental care, when their body size generally reflects their chronological age (Wisenden \& Keenleyside 1992). When they first become free swimming, fry are typically 4 to 5 $\mathrm{mm}$ in standard body length and are relatively weak swimmers (Fraser \& Keenleyside 1995). During the free-swimming stage, as body musculature develops, fry reach a plateau in their swimming speed and acceleration at approximately $8 \mathrm{~mm}$ in length (B.D. 
Wisenden, unpublished data and personal communication), and are between 10 and 12 $\mathrm{mm}$ in length at the time of independence from parental care (Fraser \& Keenleyside 1995). In fishes in general, young gradually develop physically, expand their behavioural repertoire and improve their swimming ability, all of which result in increased burst swimming performance and antipredator avoidance behaviour, during early ontogeny (Noakes \& Godin 1988; Fuiman \& Magurran 1994; Godin 1997).

Many behavioural studies have used binary-choice combination(s) to examine preferences for kin and/or familiars (e.g. Griffiths \& Ward 2006; Frommen et al. 2007b, 2007c; Le Vin et al. 2010). However, in nature, social-affiliation decisions are likely to be more complex. Here, I presented individual free-swimming fry with a simultaneous four-way choice of groups of familiar kin (FK), unfamiliar kin (UFK), familiar non-kin (FNK) and unfamiliar non-kin (UFNK) to more comprehensively assess the potential effects of familiarity and kinship (where 'kin' are siblings) cues on their choice of shoal mates. These cue combinations are ecologically relevant in that they represent the different social/kin relationship combinations (i.e. brood types) potentially encountered by free-swimming convict cichlid fry in the wild, as brood mixing has been found to occur in this species in nature (Chapter 8; Wisenden \& Keenleyside 1992; Lee-Jenkins et al. 2011).

Alternative predictions can be made based on the relative importance given to social familiarity and kinship in social partner associations and group choice. I predicted that, if familiarity alone is important, then both stimulus FK and FNK shoals should be equally the most preferred by focal fry. In contrast, if kinship alone is important, then FK 
Chapter 9 - Social Familiarity \& Kinship

and UFK shoals should be equally the most preferred groups. If familiarity and kinship are both important factors for social associations, then the FK stimulus shoal should be the most preferred of the four available stimulus shoal types. Moreover, if focal fish body size influences shoal-mate preferences (as is the case in several fish species, Hoare et al. $2000 \mathrm{~b}$ ), I predicted that larger fish would exhibit stronger preferential social associations, because of their superior swimming ability and mobility, than smaller conspecifics.

\section{METHODS}

\section{Source of Subjects and Breeding of Adults}

I obtained experimental fry subjects from the successful spawning of mated pairs of convict cichlids in the laboratory. These adult cichlids were outbred and descendants of wild convict cichlids collected (in 2008) in the Rio Cabuyo, Costa Rica and laboratorybred convict cichlids (distant descendants of adults collected in the same Rio Cabuyo population). Each mating pair was housed in an aquarium $(771 ; 77 \mathrm{~cm} \mathrm{x} 32 \mathrm{~cm} \mathrm{x} 32 \mathrm{~cm}$; $\mathrm{L} \times \mathrm{W} \times \mathrm{H}$ ) filled with aged, dechlorinated and continuously filtered tap water that was maintained at $24-27^{\circ} \mathrm{C}$. Each aquarium contained a gravel substratum, an artificial plant for cover, and a clay flower pot as a spawning site. The aquaria were illuminated overhead with fluorescent tubes on a $13 \mathrm{~h} \mathrm{L:11} \mathrm{h} \mathrm{D} \mathrm{cycle} \mathrm{and} \mathrm{were} \mathrm{visually} \mathrm{isolated} \mathrm{from}$ each other with opaque screens. The adult fish were fed ad libitum with frozen brine shrimp (Hikari ${ }^{\circ}$ Bio-Pure Brine Shrimp) and pelleted fish food (Hikari ${ }^{\circ}$ Cichlid Floating Pellets) once daily. During the course of my experiment, water in each aquarium was changed (by siphoning $25-50 \%$ of the water volume and replacing it with aged, treated 
tap water) once weekly to stimulate breeding. A total of 21 breeding pairs of adults were available to produce experimental fry.

\section{Rearing of Experimental Subjects}

Once any two mating pairs had spawned within a day of each other, and within 24 h of egg hatching, I removed equal numbers of young from each of the two broods (e.g. 60 from Pair $\mathrm{A}$ and 60 from Pair B) from their respective breeding aquarium using a sterile 1-ml pipette to form split-brood groups. I then placed one group of young from Pair A and one group from Pair B into each of two separate rearing aquaria until they were used in the experimental trials described below. This split-brood rearing design allowed us to expose future focal fish to the visual and chemical cues of FK, FNK, UFK and UFNK for approximately 5 days during the wriggler-embryo stage, followed by between $26-42$ days during the free-swimming fry stage (see Figure 9.1 ). It was not possible to collect the young during the egg stage, as the eggs could not be removed successfully from the spawning substratum in the parental breeding aquarium without suffering high mortality rates. Although the eggs from any given brood were necessarily incubated in the same breeding aquarium until hatching, it is unlikely that the embryos became familiar with each other as kin during the egg stage because chemical cues are seemingly not transmitted between eggs within a brood in cichlid fishes (Noble \& Curtis 1939; Myrberg 1964). However, large free-swimming convict cichlid fry under parental care can recognize the water from aquaria housing their parents and brood mates using chemosensory cues (Wisenden \& Dye 2009). 
Each rearing aquarium $(11.21 ; 31 \mathrm{~cm} \times 18 \mathrm{~cm} \times 21 \mathrm{~cm})$ contained a natural gravel substratum and was divided into three compartments (each $10 \mathrm{~cm}$ in length) with clear, perforated $(0.7 \mathrm{~mm}$ holes) plastic dividers (Figure 9.1). These dividers allowed for the transmission of both chemical and visual cues between compartments, but prevented freeswimming fry from leaving their compartment. A gravel-filled 96-ml black plastic cup (base internal diameter $=4.5 \mathrm{~cm}$; top internal diameter $=7.0 \mathrm{~cm}$ ) was placed on the bottom of each compartment, into which I pipetted the newly-hatched young upon their transfer from their respective home breeding aquarium. These cups allowed the young to readily aggregate (which occurs naturally during parental care) and served as a shelter during the free-swimming stage.

In each rearing aquarium, I placed future focal fish in the central compartment and kin (siblings) in one of the two outer compartments and non-kin in the other outer compartment. The fry in the two outer compartments later served as stimulus shoals in the experimental choice trials. This arrangement thus allowed future focal fish to view and smell both future stimulus kin and non-kin during the experimental rearing period. The proportions of fry in each compartment always summed to an equal proportion of fry originating from mated Pair A and Pair B, ensuring that the focal fry would be exposed to similar amounts of chemosensory cues from kin and non-kin in each rearing aquarium (see Figure 9.1 for details). 


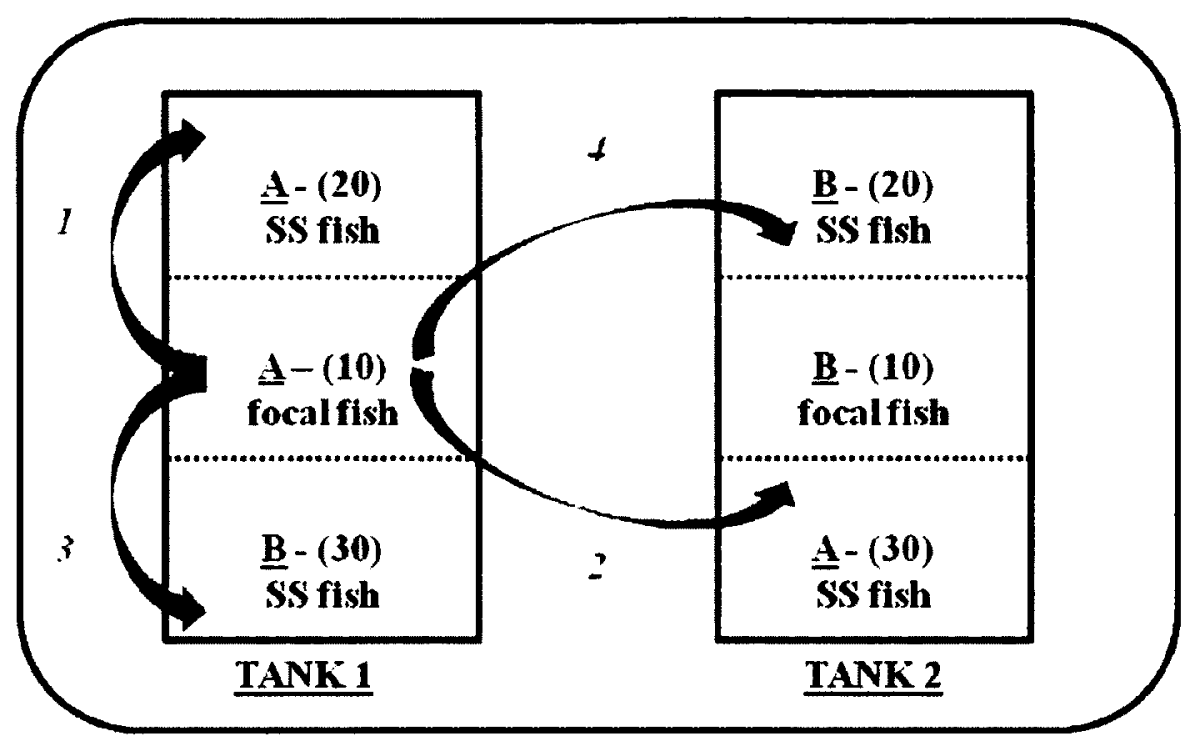

Figure 9.1. An example of the set-up of paired rearing aquaria, contained in a water bath, in which newly-hatched young from hypothetical breeding Pair ' $\underline{A}$ ' and Pair ' $\underline{B}$ ' (a set) were placed and reared until tested for their social association preferences. The numbers in brackets indicate the number of young in a particular compartment of the aquarium; each aquarium contained an equal number of fish from each kin group. These numbers were chosen such that the compartment with the largest number of stimulus fish would not be crowded. The particular end compartment in which the stimulus fish (SS) were introduced was randomized. When focal fish from the central compartment of TANK 1 were tested individually in the choice apparatus, they were given a choice to associate with each of four shoals constituted (indicated by the arrows) using stimulus fish (SS) reared in the other two compartments of the aquarium, as denoted by the numbered arrows ( 1 = FK, 2 = UFK, 3 = FNK, 4 = UFNK). 
Each of the two outer compartments of the rearing aquarium contained an air stone which circulated water throughout the tank, ensuring that focal fry were exposed to chemical cues from both kin and non-kin (thorough water mixing in the rearing aquaria was confirmed using a food colour dye test). The paired rearing aquaria (= a set) were contained within a heated water bath in a $30-1$ plastic bin, such that the water temperature experienced by fry within a set was identical. The long sides of each rearing aquaria were covered externally with opaque gray screens to block visual contact between fish in the two aquaria in the water bath. The water temperature of the rearing aquaria (across all sets) ranged between 24.5 and $26.0^{\circ} \mathrm{C}$.

Once the young fish reached the free-swimming, exogenous feeding stage (approximately 5 days post-hatch), they were fed ad libitum live brine shrimp (Artemia franscisciana) nauplii once daily in their rearing aquarium. I continually replaced evaporative water loss in the water bath and rearing aquaria with treated, aged tap water, and removed any solid waste or dead fry using a sterile 1-ml pipette.

\section{Experimental Apparatus and Protocol}

Free-swimming focal fry from a given set were tested for their social association preferences once they and the stimulus fry were $26-42$ days old $(=6.0-9.0 \mathrm{~mm}$ standard body length (SL); where day 1 = start of free-swimming stage), which falls within the age and body size ranges of young convict cichlids still under parental care in the wild (Fraser \& Keenleyside 1995). At this age/size range, they are sufficiently robust for dip-net handling. Individual focal fish were presented with the simultaneous choice of 
four stimulus shoals of three conspecific fry each (all body size-matched) to socially associate (i.e. 'shoal') with in a four-way choice apparatus (Figure 9.2). Each stimulus shoal differed in kinship and social familiarity relative to the focal fish, namely (i) FK, (ii) UFK, (iii) FNK and (iv) UFNK to the focal fish. At the end of each arm of the choice apparatus, a stimulus shoal compartment $(5 \times 5 \mathrm{~cm})$ was delineated and separated from the remainder of the arm with a clear, perforated plastic divider, allowing for the transmission of both visual and chemical cues between the resident stimulus shoal and focal fish.

Prior to the onset of any given trial, I selected fry from the paired rearing tanks to constitute four stimulus shoals. To form each stimulus shoal type, three fry were carefully dip-netted from each of the end compartments of the two rearing tanks and placed in a cup containing $75 \mathrm{ml}$ of aged tap water. Because aggression can occur between convict cichlid fry that differ in length by $1 \mathrm{~mm}$ or more (Fraser et al. 1993) and because body size has been shown to influence shoaling preferences in fishes (reviewed by Hoare et al. $2000 \mathrm{~b}$ ), all stimulus fry and focal fry were size-matched by eye (to minimize stress) prior to the trial; post-trial measurements confirmed that the standard body lengths of fry did not differ between the four types of stimulus shoals (one-way ANOVA: $F=1.01, \mathrm{df}=3$, $947, p=0.39$ ). Once all four stimulus shoals had been selected, most of the water in each cup was discarded and the stimulus fish carefully poured into their corresponding arm compartment of the apparatus (Figure 9.2), which was predetermined using a random sequence generator (Random.org). All four stimulus shoals were then left undisturbed to acclimatize to the apparatus and to resume regular swimming activity for $10 \mathrm{~min}$. 
Following this period, a focal fry was placed in a clear, plastic perforated cylinder (4.7 $\mathrm{cm}$ diameter) in the centre of the apparatus and allowed to view/smell the four stimulus shoals in each arm of the apparatus for 15 min (Figure 9.2). Following this viewing period, the cylinder was lifted, allowing the focal fish to freely swim in the apparatus and to associate with any of the four stimulus shoals for a 30 -min choice trial. The fish were filmed from above using a digital camcorder (SONY model HDR-HC7). A total of 79 focal fish, originating from seven matched sets and from 12 different mated pairs, were similarly tested individually.

Pilot dye tests, in which a different food colour dye was released in each arm compartment once the stimulus shoals were in place, confirmed that the dyes had reached the central cylinder, but there was no mixing of water between arms, by the end of the viewing period. Therefore, the focal fish were exposed to both chemical and visual cues originating from each of the four stimulus shoals, but the shoal-specific chemical cues had not yet mixed within the apparatus, prior to the start of the trial.

Blind to the identity of the stimulus shoals, I quantified the time that the focal test fish spent associating with each of the four stimulus shoals using JWatcher v1.0 (Blumstein et al. 2006; Blumstein \& Daniel 2007). The focal fish was deemed to be 'shoaling' with a stimulus shoal when it entered the particular arm of the apparatus containing that shoal, was facing $\left(0 \pm 90^{\circ}\right)$ the shoal and was within $2.5 \mathrm{~cm}$ from the screen (i.e. the half of the choice section of the arm closest to the stimulus shoal). The latter distance corresponds to about 3-4 focal fish body lengths, which falls within the range of inter-individual distances observed in fish shoals in nature (Pitcher \& Parrish 
1993). However, focal fry exhibited strong shoaling tendencies in the apparatus, and typically interacted with the stimulus shoal in a given arm immediately in front of the compartment screen, within 1 body length of the stimulus fish (i.e. moving up and down the screen whilst facing the shoal; Figure 9.2).

At the end of each trial, the experimental apparatus, compartment screens and central cylinder were vigorously rinsed with tap water. Focal fish were always naïve to the experimental apparatus. However, at the end of an experimental day, stimulus fish were returned to the corresponding compartments of their rearing aquarium (so as to avoid depleting the number of fish available and markedly changing the relatively amounts of chemical cues in the aquarium over time), and thus could have been reused as stimulus shoal fish on subsequent experimental days. Within a given day of experimentation, only one focal fish per rearing aquarium was tested to minimize stress on all the fish in the aquarium.

\section{Statistical Analyses}

As previously mentioned, a total of 79 focal fry were tested. I was reliant on the breeding timings of the laboratory mating pairs (to produce two kin groups of identical age for a given set), which yielded focal fry from seven different sets (pairings of two families) and originating from 12 different mated pairs (where two families had to be used twice). Of these focal fry, four to 12 individuals were used from each family (mean $\pm \mathrm{SE} ; 6.6 \pm 0.8$ ); this corresponded to a range of eight to 17 focal fry tested in a given set $(11.3 \pm 1.2)$ 


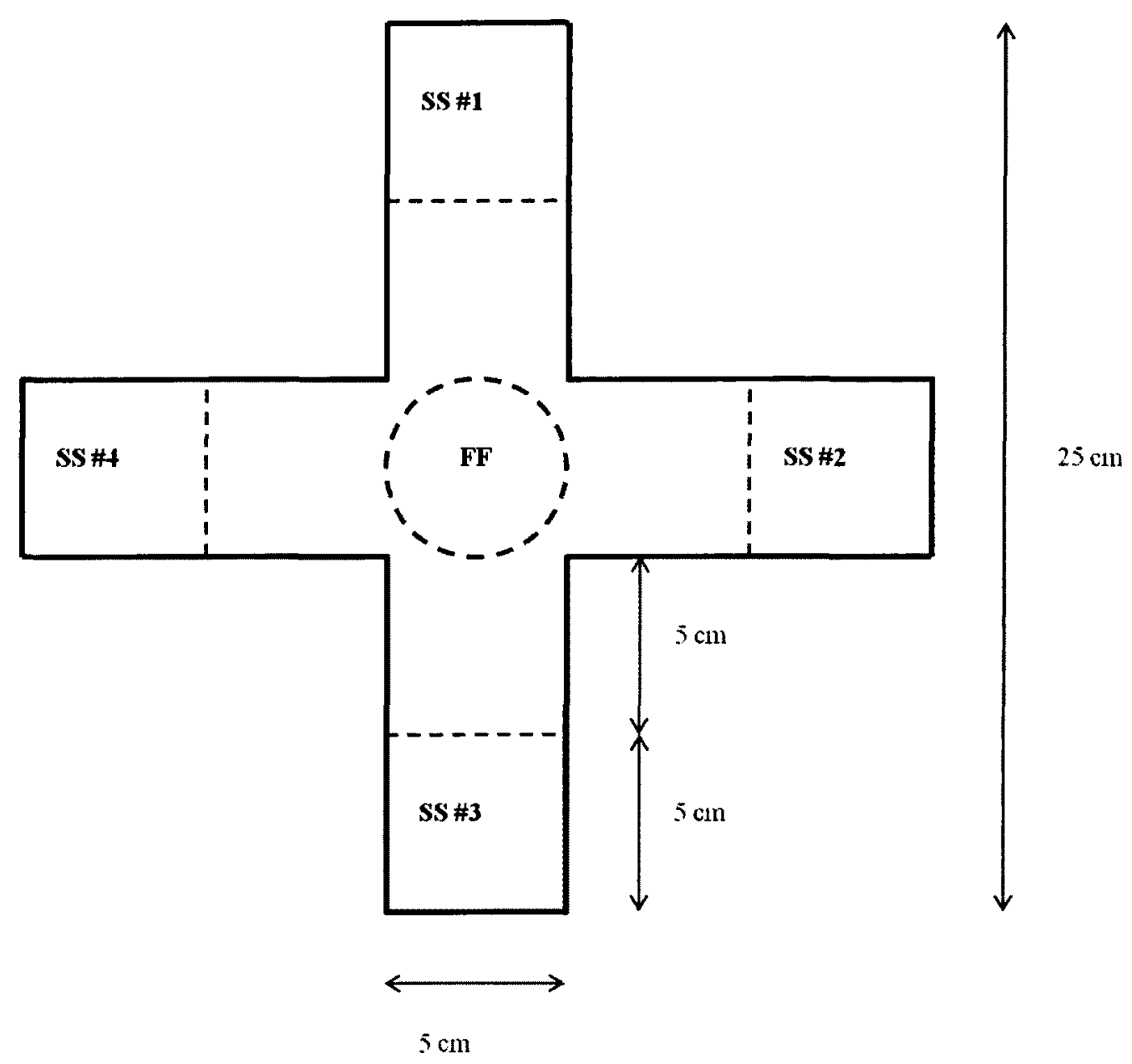

Figure 9.2. Top view of the experimental four-way choice apparatus. For each trial, the order of the stimulus shoal types (FK, UFK, FNK and UFNK) was randomized with respect to their placement into the end compartment of each arm of the apparatus (SS\#1, SS\#2, SS\#3, SS\#4). The dashed lines in the arms indicate the locations of clear perforated screens, which allowed the transmission of visual and chemical cues between the stimulus shoals and the focal fish. The central cylinder was used to temporarily hold the focal test fish (FF) during a viewing period, allowing for its receipt of visual and chemical cues originating from each of the four stimulus shoals. 
Because focal fish were not independent from one another across trials (i.e. some were from the same mated pair as oppose to being from 79 different broods), I performed a series of analyses to determine if this affected my results. First, I ascertained whether family group identity affected the time focal fish spent shoaling with each type of stimulus shoal separately using a one-way ANOVA test. For each ANOVA separately, the proportion of total shoaling time that individual focal fish spent shoaling with a particular stimulus shoal was the response variable and focal fish family identity (i.e. which mated pair the focal fish came from) was the predictor variable. All proportions were arc-sine transformed and met the assumptions of normality and homogeneity of variance. There was no effect of focal fish family identity on the mean proportion of shoaling time spent with any of the four stimulus shoal types (one-way ANOVA results ranges: $F=0.46$, to $1.41, \mathrm{df}=11,67,0.81>p>0.15$ ). Given this result, data from all focal fish were pooled across families for subsequent analyses. Second, using a linear mixed-effects model, I tested for the potential effects of focal fish age and body length (fixed predictor factors) on the proportion of their shoaling time spent with FK (response variable) when accounting for the effects of focal fish family and set (random predictor variables). In the current study, as expected, the body length of focal fish was positively correlated with their chronological age (Pearson's correlation: $r=0.36, \mathrm{n}=79, p=$ $0.001)$. I selected familiar kin (FK) as the target shoal type for the response variable in the model because it is likely the shoal type most commonly encountered by convict cichlid fry in nature. This analysis indicated that focal fish body length, but not age, affected the proportion of time shoaling with FK when accounting for the random effects 
of focal fish family and rearing set (linear-mixed effects model: Log-Likelihood Value $=$ $\left.15.88, \mathrm{AIC}=32.24, \mathrm{df}=65, t_{\text {body length }}=2.26, p_{\text {body length }}=0.028, t_{\text {age }}=-0.31, p_{\text {age }}=0.76\right)$. This result confirmed my a priori expectation that body length (and thus state of development) would influence shoaling behaviour.

To ascertain whether the body size of focal fish influenced the shoal choice of focal fish, I subdivided the data set into two a priori categories based on the standard body length of focal fish (small $=6.0-7.5 \mathrm{~mm}$; large $=8.0-9.0 \mathrm{~mm}$ ) for further analyses. This categorization is not arbitrary, but rather biologically and ecologically relevant. As mentioned above, convict cichlid fry reach a developmental plateau in swimming velocity and acceleration at $8 \mathrm{~mm} \mathrm{SL}$, which coincides with greater mobility as they approach independence from parental care (B.D. Wisenden, unpublished data and personal communication; Wisenden \& Keenleyside 1994). Moreover, the diameter of convict cichlid broods in nature also reaches its maximum when fry are $8 \mathrm{~mm}$ SL (B.D. Wisenden, unpublished data and personal communication). This ontogenetic transition in mobility and swimming performance coincides with reduced vulnerability to predation in wild convict cichlid fry of 8-10 mm SL (Wisenden \& Keenleyside 1994; Fraser \& Keenleyside 1995).

For my main shoal-choice analyses, for each of these two data subsets separately, I first compared the proportion of time focal fry spent shoaling with each stimulus shoal separately against the proportion of shoaling time expected by chance (i.e. null proportion of 0.25 ) using two-tailed, one-sample $t$-tests (with Bonferroni correction; $\alpha=0.05 / 4=$ $0.0125)$. All proportion data were arc-sine transformed to meet the assumptions of 
normality and homogeneity of variance. Data were compared to the null-expectation because focal fish were given a simultaneous four-way choice, and consequently time spent within a trial of fixed duration with one stimulus shoal was not independent of the time spent with the other stimulus shoals. Therefore, the use of either a repeatedmeasures ANOVA or a Friedman's test here would be inappropriate.

In conjunction with the above analysis of shoal-choice preference, I determined for each trial separately which stimulus shoal the focal fish spent the most time associating with (deemed the preferred stimulus shoal). I then used the $G$-test of independence to compare the frequencies of preferred stimulus shoal of the small and large focal fry to ascertain whether body size influenced their shoal-mate preference. Lastly, for each size class of focal fry separately, I compared the observed frequencies of the preferred stimulus shoal in a trial to those expected by chance (i.e. $1: 1: 1: 1)$ using goodness-of-fit $G$-tests.

Finally, I compared the first stimulus shoal visited by focal fry from the two body-size classes using the $G$-test. To compare the mobility of small and large focal fish within the apparatus and their shoal-sampling frequencies, I recorded the number of switches (= the number of times the focal fish changed 'arms' in the apparatus) and also, for the focal fish that sampled all four stimulus shoals, I recorded time elapsed from the start of a trial until the focal fish 'sampled' (visited) all four stimulus shoals.

All statistical tests were performed using SPSS v19, except the $G$-tests which were performed following Zar (2010) and the linear mixed-effects model analysis which was performed in ' $R$ ' ( $v$ 2.11.1) using the 'nlme' package and the 'Ime' function. 


\section{RESULTS}

The proportion of shoaling time that small fry spent with each stimulus shoal type did not differ from that expected by chance for three of four the stimulus shoal types (one-sample $t$-tests: for UFK, $t=0.47, \mathrm{df}=48, p=0.64$; for $\mathrm{FNK}, t=-1.95, \mathrm{df}=48, p=$ 0.06 ; for UFNK, $t=-0.17, \mathrm{df}=48, p=0.87$; Figure 9.3), however, smaller focal fish spent significantly less time with FK than that expected by chance (one-sample $t$-test: for $\mathrm{FK}, t=-3.85, \mathrm{df}=48, p=0.0004)$. In comparison, the proportion of time that the larger fry spent shoaling with each of the four stimulus shoal types did not differ from chance (for FK, $t=0.13, \mathrm{df}=29, p=0.90$; for UFK, $t=-1.64, \mathrm{df}=29, p=0.11$; for FNK, $t=-$ 2.51, $\mathrm{df}=29, p=0.02$; for UFNK, $t=-0.01, \mathrm{df}=29, p=0.99 ;$ Figure 9.3).

However, when examining the data based on the most preferred stimulus shoal in each trial, small and large fish differed significantly in their stimulus shoal preferences ( $G$-test of independence: $G=9.48, \mathrm{df}=3, p=0.024$; Figure 9.4). More specifically, the small focal fry showed no preference for any of the stimulus shoal types $(G=1.28, \mathrm{df}=3$ $n=49, p>0.50 ;$ Figure 9.4), whereas the larger focal fry significantly preferred to associate with FK conspecifics than expected by chance $(G=10.71, \mathrm{df}=3, \mathrm{n}=30,0.01$ $<p<0.025$; Figure 9.4). The first stimulus shoal visited did not differ between stimulus shoal types for either small $(G=5.32, \mathrm{df}=3, \mathrm{n}=49, p>0.05 ; \mathrm{FK}=10, \mathrm{UFK}=17, \mathrm{FNK}$ $=7, \mathrm{UFNK}=15)$ or large focal fish $(G=3.60, \mathrm{df}=3, \mathrm{n}=30, p>0.75 ; \mathrm{FK}=11, \mathrm{UFK}=$ $9, \mathrm{FNK}=5, \mathrm{UFNK}=5$ ).

Of the 79 focal fish tested, 58 sampled all four arms of the apparatus, 12 sampled three arms, 6 sampled two arms and 3 sampled only one arm. Large focal fry were more 
mobile in the apparatus and sampled the stimulus shoals more frequently than smaller fry. More specifically, the number of arms visited by focal fry was positively correlated to their body length $(r=0.27, \mathrm{n}=79, p=0.016)$, and the number of switches between arms $(10.25 \pm 0.94$, range $=0-45)$ was correlated with both their body length $(r=0.23, p=$ $0.047)$ and age $(r=0.30, p=0.007)$. For those focal fish that sampled all four arms, the time elapsed to visit all four stimulus shoals $(13.82 \pm 1.11 \mathrm{~min}$, range $1.63-29.44)$ and the number of arm switches exhibited were negatively correlated with each other $(r=-$ $0.521, \mathrm{n}=49, p<0.01)$ 


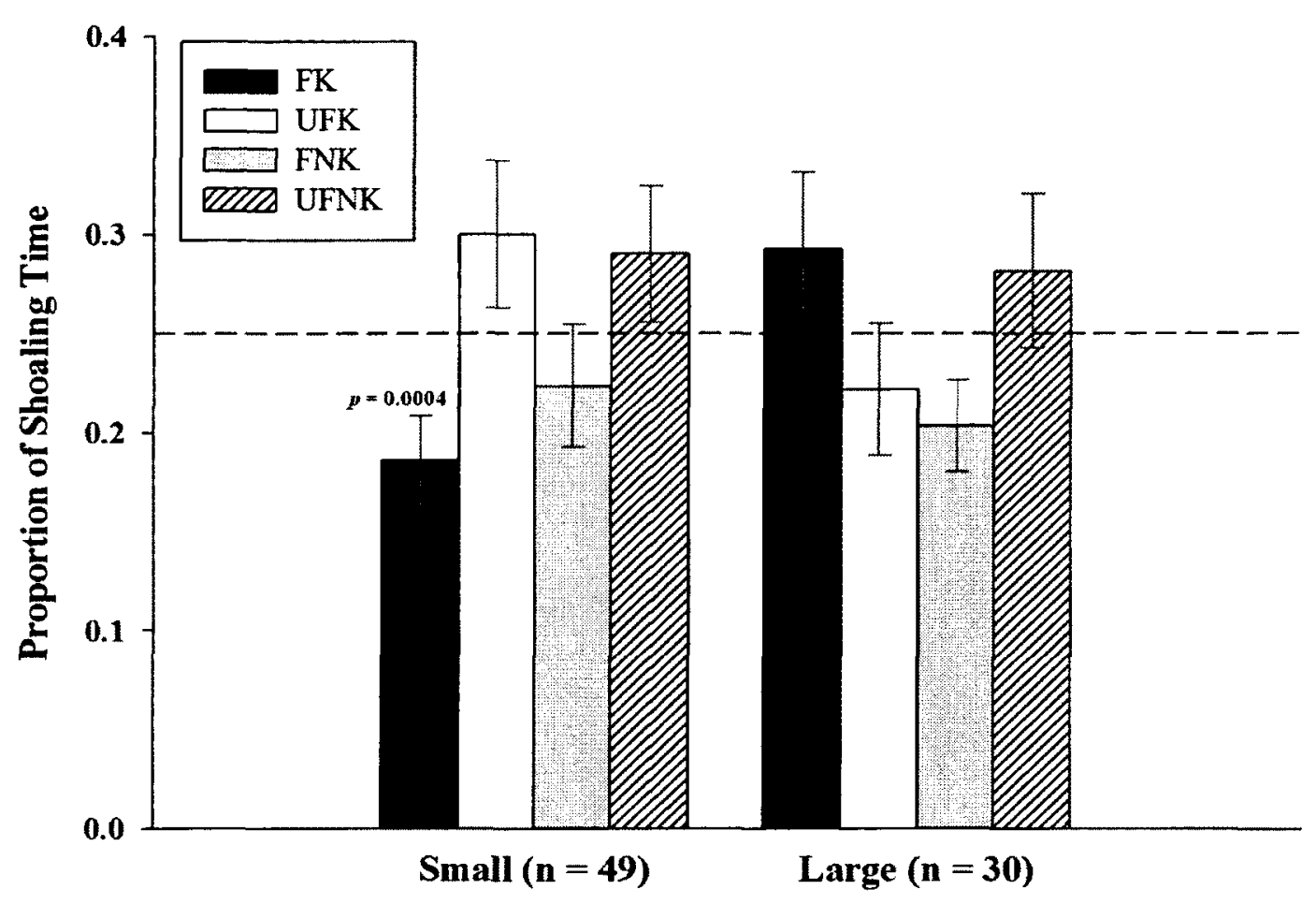

Focal Fish

Figure 9.3. Mean ( $\pm \mathrm{SE}$ ) proportion of shoaling time that small $(6.0-7.5 \mathrm{~mm}, \mathrm{SL})$ and large $(8.0-9.0 \mathrm{~mm})$ focal fry spent with each of the four stimulus shoal types (denoted in the inset box). Each mean value shown was compared against a proportion of 0.25 (indicated by dashed horizontal time) expected by chance using the one-sample $t$-test. Although all proportion data were arc-sine transformed prior to statistical analysis, the results shown here are for untransformed data. Any significant difference (with Bonferroni correction, $\alpha=0.0125$ ) from that expected by chance are shown on the figure. 


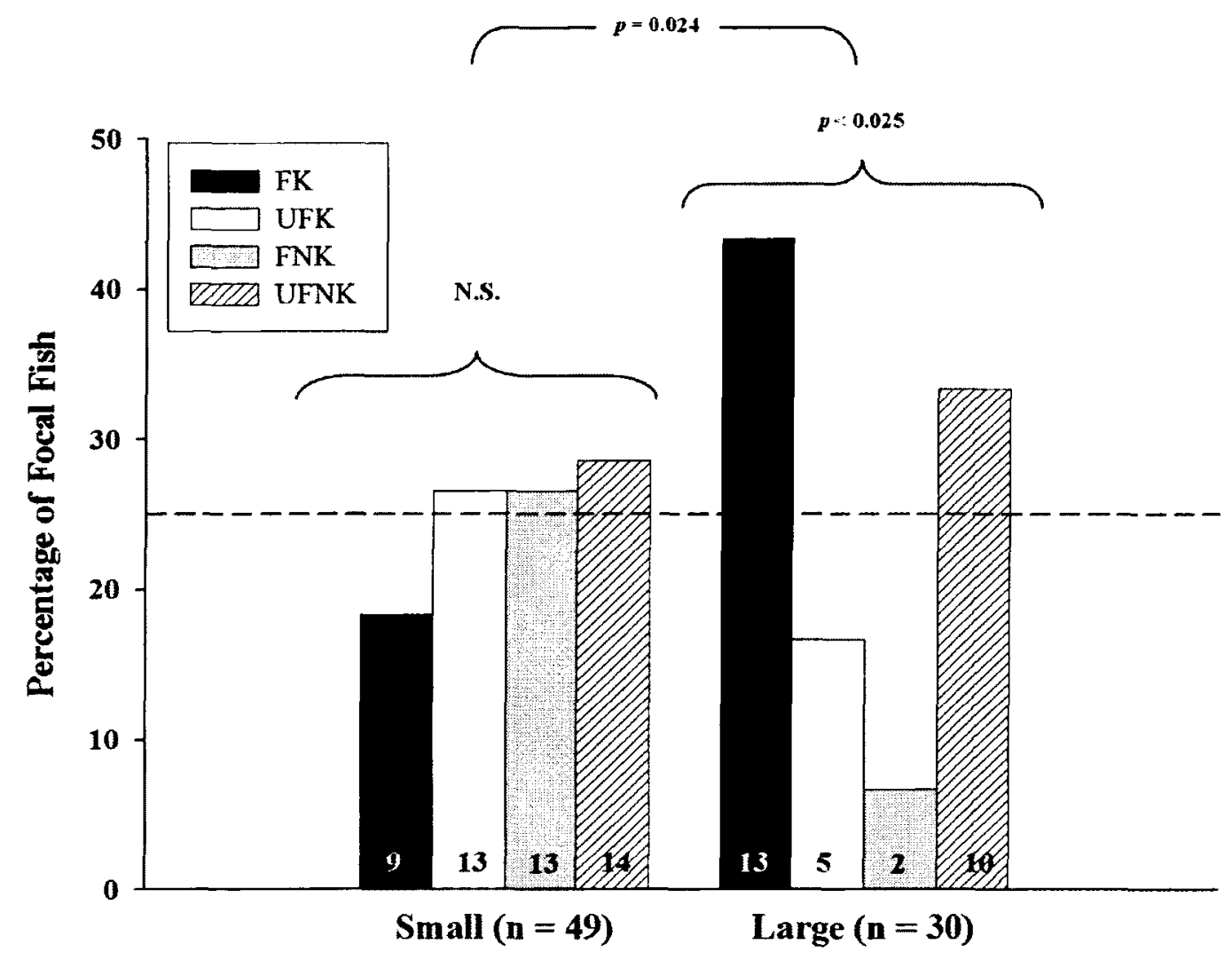

Focal Fish

Figure 9.4. Percentage (and actual number inside histogram bars) of small (6.0 - 7.5 $\mathrm{mm})$ and large $(8.0-9.0 \mathrm{~mm})$ focal fry that exhibited a preference to affiliate with a particular stimulus shoal out of the four stimulus shoal types presented (denoted in the inset box). The preferred shoal is the one that the focal fry spent the most time shoaling with in a given trial. The distribution patterns of preferred stimulus shoal types exhibited by small and large focal fry were compared using the $G$-test of independence $(\alpha=0.05)$. For each fish body-size category separately, the observed frequency distribution of preferred shoal types was compared against a null distribution expected by chance (denoted by the horizontal dashed-line) using the goodness-of-fit $G$-test ( $\alpha=0.05$ ). 


\section{DISCUSSION}

Recognizing kin from non-kin and familiar from unfamiliar individuals has important implications for inter-individual behavioural interactions and for social group formation, structure and dynamics (e.g. Waldman 1987; Ward \& Hart 2003; Mateo 2004). Yet, whether and how cues associated with kinship and familiarity interact to influence affiliative behaviour remain poorly understood. Here, I presented individual convict cichlid young with a simultaneous four-way choice of socially associating with small shoals of similar-size conspecifics that differed in one of four different combinations of relatedness (kin vs. non-kin) and familiarity (familiar vs. unfamiliar) cues. Although this type of choice test is more complex and cognitively challenging than the more commonly-used dichotomous choice test, it is ecologically relevant for young convict cichlids in their natural habitats, where they are potentially exposed simultaneously to the aforementioned combinations of cues associated with genetic relatedness and social familiarity because of brood mixing events (Chapter 8; Wisenden \& Keenleyside 1992; Lee-Jenkins et al. 2011). A similar situation presumably occurs in other precocial species that experience communal breeding, brood adoption, brood parasitism or crêching behaviour (e.g. Codenotti \& Alvarez 1998; Wisenden 1999; Öst et al. 2005; Kalmbach 2006) and wherein newly-hatched mobile young affiliate with each other for some time before becoming independent.

I showed that the shoal-choice behaviour of young convict cichlids depended on their body length, which was positively correlated with their chronological age. Based on the most preferred stimulus shoal, small fry did not exhibit a clear choice for any of the 
four stimulus shoal types presented simultaneously. In contrast, larger and more mobile fry significantly preferred to associate with familiar kin (FK) over the other stimulus shoal types. Keeping kinship constant in the comparisons, the large fry preferred familiar kin (FK) over unfamiliar kin (UFK), but unfamiliar nonkin (UFNK) over familiar nonkin (FNK). Orthogonally, holding familiarity constant, large fry preferred familiar kin (FK) over familiar nonkin (FNK), but unfamiliar nonkin (UFNK) over unfamiliar kin (UFK). Therefore, it appears that cues associated with both relatedness and social familiarity interact in a complex manner to influence social affiliative behaviour in larger (older) convict cichlid fry during the parental care period, but not in smaller (younger) conspecifics. Social familiarity (F) seems to act synergistically with relatedness (sibling) cues $(\mathrm{K})$ to influence social association behaviour in larger fry, resulting in the expression of a significant preference for familiar kin (FK).

Interpretation of shoal choice differs depending on the measure used to define shoal preference. This discrepancy, when comparing proportion of shoaling time with each stimulus shoal versus using the most preferred stimulus shoal, may be an artefact of the type of choice apparatus used (4-way vs. 2-way). When faced with a choice between four different stimulus shoals of conspecifics (as opposed to a binary choice), convict cichlid fry allocated their shoaling time to four groups instead of just two. Consequently, time spent with each of the four stimulus shoals may not have provided sufficient resolution to reveal the true preference of the focal fish. Bateson (2004) noted that, in behavioural choice experiments, the addition of a third choice ' $C$ ' to a binary choice of ' $A$ ' and ' $B$ ' could cause a change in the proportional amount of time an individual would 
spent with B over A, or even alter a pre-existing preference for B over A. As such, in experiments where a series of pairwise binary choices are performed on the possible combinations of two factors, all possible choice combinations are not simultaneously available to a focal animal. Experimental results from a binary-choice test could thus be biased and(or) not be representative of the actual choice conditions faced by the study animal in nature. I chose to use a four-way choice apparatus over a binary-choice one for the biological and ecological reasons mentioned above; similarly, the use of four-way choice apparatuses is not uncommon in studies of mate choice in birds for example (e.g. Forstmeier \& Birkhead 2004). Notwithstanding the limitations of binary-choice tests, it might be informative to carry out a series of binary-choice tests with the convict cichlid fry in a future study to compare with the results of the current experiment.

Complex social associations based on familiarity and(or) kinship have also been reported for another fish species with parental care, the three-spined stickleback (Gasterosteus aculeatus). In binary-choice tests, juvenile sticklebacks prefer to socially associate with FK over UFNK (Frommen \& Bakker 2004; Frommen et al. 2007b, 2007c), indicating that familiarity and(or) kinship play a role in shoal choice in this species. But these fish exhibit no preference when given a choice between FK and FNK, suggesting that familiarity or learned recognition must be used as a form of kin recognition in this species (Frommen et al. 2007b). However, social familiarity alone may play a role in shoal choice in juvenile sticklebacks, entirely separate from kin recognition or association. Mehlis et al. (2008) found that adult female sticklebacks could distinguish unrelated males from their brothers regardless of familiarity. When adult sticklebacks 
were given the choice between UFK and UFNK, outbred adults preferred to associate with UFK (Frommen et al. 2007c). However, juvenile sticklebacks showed no preference for either UFK or UFNK (Steck et al. 1999). Collectively, these results suggest that sticklebacks possess and use an innate kin recognition mechanism, which may take time to develop or is only expressed in the adult phase. In the wild, non-reproductive adult sticklebacks have been found to repeatedly shoal with the same individuals or small 'cliques' (Ward et al. 2002a); whether such non-random social grouping patterns is based solely on kinship, social familiarity or familiarity and kinship is unknown.

Sociality and association preferences develop and change during the lifetime of individuals (Noakes \& Godin 1988; Krause \& Ruxton 2002), as seemingly reflected in the results of the current study and those on the three-spined stickleback summarized above. In the current study, the chronological age of young convict cichlids correlated positively with their body length. Smaller, younger fry showed no significant preference for any of the stimulus shoals (when looking at proportion of shoaling time and most preferred stimulus shoal), but did spend less time affiliating with FK than expected by chance. This result might be owing to the fish's reduced mobility and swimming capabilities early in ontogeny, given that the body size of focal fry was negatively correlated with both frequency of switches (sampling) and number of stimulus shoals visited. In comparison, larger, older fry exhibited a clear preference for FK. The observed differences in affiliative behaviour between these two size/age categories of convict cichlid fry may reflect the development of a kin recognition mechanism as the fish age and develop (e.g. Gerlach et al. 2008). Moreover, larger fry exhibited more switching 
behaviour (sampling of stimulus shoals) than smaller fry in my study. This is likely owing to their greater mobility and swimming capability, rendering them more active in shoal choice, than smaller conspecifics.

My results suggest that, at larger body sizes $(8-9 \mathrm{~mm})$ or later developmental stages, kin discrimination in convict cichlid fry acts in conjunction with a preference for familiar individuals, resulting in the expression of a clear preference for familiar kin. In preferring to associate with familiar kin, larger/older convict cichlid fry may be using an innate kin recognition mechanism, such as self-referent phenotype matching or some kind of recognition allele such as the major histocompatibility complex (Mateo 2004), although this cannot be determined from these current data. More research is therefore required to further elucidate the nature of the kin recognition mechanism in the convict cichlid, as done for the zebrafish, Danio rerio (Gerlach et al. 2008) for example, especially given that brood mixing events can occur during the parental care period and fry are simultaneously exposed to both kin and non-kin.

In the laboratory, convict cichlid young are able to recognize their parents and potentially brood mates using both visual and chemical cues (Wisenden \& Dye 2009). Free-swimming fry $(\geq 9 \mathrm{~mm}$ ) prefer the chemical cues of home tank water (i.e. of parents and brood or FK) compared to both blank water and water from a different set of parents/brood tank (i.e. UFNK) when given the choice in a Y-maze apparatus (Wisenden \& Dye 2009). Moreover, Wisenden \& Dye (2009) demonstrated that when convict cichlid young see their parents, they will reset their 'homing chemical cues' to those in the present surrounding water. These findings indicate that larger convict cichlid young 
are attracted to the scents of their home or biological brood and parents, and can learn and reset the chemical habitat cues associated with the presence of familiar kin. This current study similarly demonstrated a preference for FK in larger fry, but in the absence of guarding parents in this case. The ability of fry to reset a chemical cue signature for 'home' would be important in the wild, because parents and their broods become increasingly mobile across the river floor as fry become larger (personal observations; B.D. Wisenden, personal communication).

Exhibiting a shoal-mate preference for familiar kin at the time of independence from guarding parents could be adaptive. Convict cichlid fry are under intense fish predation pressure in nature (Wisenden \& Keenleyside 1992; Fraser \& Keenleyside 1995). Associating with familiar conspecifics can confer antipredator benefits to individual shoal members (Chivers et al. 1995; Griffiths et al. 2004). Moreover, local predation risk may promote preferential associations with kin, as suggested by the findings of Piyapong et al. (2011) for juvenile Trinidadian guppies in nature. Associating with familiar and(or) kin individuals may also facilitate cooperation (Chivers et al. 1995), reduce aggression (Utne-Palm \& Hart 2000; Seppä et al. 2001), and reduce foraging competition (Höjesjö et al. 1998) among individuals within groups. In fishes, these benefits of preferentially associating with familiar and(or) related conspecifics can result in increased individual growth rate and survivorship (Fraser \& Keenleyside 1995; Godin 1997; Seppä et al. 2001). Being in close proximity to a familiar individual has also shown to increase individual growth rates irrespective of kinship in juvenile red-back salamanders, Plethodon cinereus (Liebgold \& Cabe 2008). 
Future studies should attempt to elucidate further the mechanisms of brood mixing, and its implications for alloparental care (Wisenden 1999), in fishes. Moreover, future work on the convict cichlid system should examine how social association preferences, based on familiarity and kinship, change throughout an individual's lifetime and in varying social contexts, as done for other species (e.g. zebrafish: Gerlach \& Lysiak 2006; guppy: Griffiths \& Magurran 1997a, 1999; Kelley et al. 1999; Piyapong et al. 2011) and whether social association preferences for familiar kin in the juvenile life phases results in inbreeding at the adult stage (e.g. Thünken et al. 2007a,b). My study highlights the importance of differentiating between social association based on kinship (relatedness) and social familiarity when investigating patterns and mechanisms of social affiliation in animals, and that these two factors can interact in an unpredicted non-linear fashion when individuals decide with whom to associate socially.

\section{ACKNOWLEDGEMENTS}

I would like to thank Brian Wisenden for earlier comments on this chapter and Tom Sherratt for his advice on the statistical analyses. 


\section{CHAPTER 10}

Separation anxiety?: Consequences of spatial separation from the family unit in the young of a biparental fish, the convict cichlid (Amatitlania siquia) 


\section{ABSTRACT}

The young of many species rely on the protection provided by their parent(s) to avoid predation. However, if mobile young become separated from their parents and brood mates, they potentially become more exposed and vulnerable to predators. There should thus be strong selection for young to exhibit effective 'homing' abilities and antipredator behaviours when separated from their protective parents. Using complementary field and laboratory experiments, I examined the consequences of spatial separation of young convict cichlid fish (Amatitlania siquia) from their parents and brood mates (= 'family unit'). Individual cichlid young were captured by dipnet and displaced/released at one of four distances $(20,40,60$ or $80 \mathrm{~cm})$ from the home brood. In the field (in Costa Rica), focal fish were less likely, and took longer, to find 'their way home' with increasing displacement distance. Focal fish body length strongly influenced trial outcome; larger fish were more likely to refuge than to return home, and smaller fish were more likely to be eaten by fish predators than to refuge. In the laboratory (in the absence of fish predators), focal fish similarly were less likely, and took longer, to return home the further the displacement distance. Moreover, larger focal fish returned home sooner than smaller fish. My results show that young convict cichlids who are separated from their family unit suffer increased exposure time with increasing separation distance in nature, and that the body size or developmental stage/age of the young appears to mediate their assessment of the ambient risk of predation and(or) their homing response. 


\section{INTRODUCTION}

The threat of predation is one of the most influential selection pressures facing animals in nature (Lima \& Dill 1990; Godin 1997; Lima 1998; Barbosa \& Castellanos 2005). During early ontogenetic stages, young individuals are intrinsically vulnerable to predation because they have yet to fully develop physically (Arnold \& Wassersug 1978; Fuiman \& Magurran 1994; Caro 2005), have incomplete neurosensory systems (Sih \& Kats 1994; Noakes \& Godin 1988), have not fully acquired their antipredator behavioural repertoire (Noakes \& Godin 1988; Fuiman \& Magurran 1994), and(or) their foodbegging behaviour renders them more conspicuous (Magrath et al. 2010), depending on the species. Moreover, when young are still relatively small in size, they are vulnerable to gape-limited predators (Fuiman \& Magurran 1994; McLennan et al. 2004) and typically have a greater number and wider range of predators than in adulthood (Fitzgibbon 1990; Caro 2005). In many species, one or both parents protect their offspring against predators during vulnerable phases of development (e.g. Clutton-Brock 1991; Keenleyside 1991b; Thiel 1999; Caro 2005).

Because young animals are particularly vulnerable to predation, spatial separation from their protecting parents potentially increases their risk of predation (Sih \& Kats 1994; Alemadi \& Wisenden 2002). Thus selection should favour any behaviour in young (or parents) that promotes their safe return to the care of their parents (Morse 1991; Simpson et al. 2005; Wisenden \& Dye 2009). Mobile young, can become separated from their parent(s) during the parental care period, particularly, where parent(s) and offspring are a mobile unit, as in some ungulate (Fitzgibbon 1990) and bird (Codenotti \& Alvarez 
1998; Simpson et al. 2005) species, and in substrate-brooding cichlid fishes (Keenleyside $1991 b$; Wisenden \& Dye 2009). In these taxa, young can become separated from the parent(s) and brood mates during territorial conflicts between neighbouring parental adults, predator attacks on the brood or when feeding in one area whilst the remainder of the brood continues moving elsewhere (Keenleyside 1991b; Codenotti \& Alvarez 1998; Simpson et al. 2005; Wisenden \& Dye 2009). The local 'homing' ability of young (defined herein as the ability of young to find their way back to their parent(s)) during spatial separation from parents is likely a critically time-sensitive response because the further away and the longer the time spent away from the 'refuge' of parental protection, the more likely an individual is to encounter a predator and the greater the risk of predation (cf. Lima \& Dill 1990).

The antipredator and 'homing' responses of a young animal may depend on its relative developmental stage or age. Antipredator responses are known to change throughout ontogeny in many species (Noakes \& Godin 1988; Kullberg \& Lind 2002; Brown 2003; Kelley \& Magurran 2003; Caro 2005), owing in part to developmental sensory-motor processes (Noakes \& Godin 1988) and learning about local predators (Griffin et al. 2000; Brown 2003; Kelley \& Magurran 2003). Furthermore, in many taxa, juveniles disperse from their natal territory or nesting area once independent of parental care (e.g. Keenleyside 1991 b; Dingemanse et al. 2003; Johnson et al. 2009; Serrano \& Tella 2012); older individuals may therefore be less inclined to return to parental care than younger conspecifics. However, parent-offspring conflict theory predicts that young will attempt to maximize parental care benefits and thus may stay as long as possible with 
parents (Trivers 1972). Therefore, it is not clear whether the likelihood to return home once separated from parents wanes as young develop.

In addition to the potential influence of developmental stage/age, the ability of young to successfully return 'home' could also be affected by a number of extrinsic factors, such as predation pressure in the home environment (Vives 1988), the structural complexity of the local habitat (Morse 1991; Wisenden \& Dye 2009), and the quality and type of care behaviours exhibited by the parent(s) (Blomqvist et al. 1997; Reddon 2012). For example, in substrate-brooding cichlid fishes, parents may exhibit 'calling' movement behaviours when mobile young ( $=$ fry) stray away from them (Keenleyside $1991 b$; Wisenden \& Dye 2009), which in turn typically elicits a clustering response in the fry around the calling parent (Keenleyside 1991b; Lavery et al. 1990), and(or) they may retrieve stray young in their mouth and return them to the brood when they are small (Vives 1988; Keenleyside 1991b).

The behaviour of mobile young following spatial separation from guarding parent(s), and their risk of predation whilst separated, remain poorly characterized. The Central American convict cichlid fish, Amatitlania siquia, is an excellent model system for investigating the homing ability, and vulnerability to predation, of mobile dependent young that might become separated from their parents during the parental care period. The convict cichlid is a socially-monogamous, biparental substrate-brooding species. Parental fish care for their young from the egg stage, throughout the free-embryo, endogenous-feeding "wriggler" stage and for up to six weeks after the start of the mobile, exogenously-feeding free-swimming stage (Wisenden 1995). Biparental care in this 
species primarily involves both parents vigorously defending their young against abundant piscivorous predators in their natural habitats (Hay 1978; Wisenden \& Keenleyside 1994; Wisenden 1995; Alemadi \& Wisenden 2002). Such parental defence is critical to the survival of the young in cichlid fishes (Keenleyside 1991b); a brood of convict cichlid fry that is not guarded by parents is typically eaten in its entirety by fish predators within just a few minutes in the wild (Keenleyside \& Wisenden 1992; Alonzo et al. 2001).

As free-swimming young convict cichlids develop and increase in body size, the brood or family unit (= brood and guarding parents) becomes increasingly mobile (Wisenden \& Dye 2009), and the young typically travel and forage during the day along the river substratum, up to about $14 \mathrm{~m}$ from the parental breeding territory, whilst guarded by their parents (Wisenden 1995). Moreover, as fry become larger, they follow their parents from a greater distance (Baerends \& Baerends-Van Roon 1950). In the wild, some fry stray and become separated from their family unit (Keenleyside $1991 b$ ). Under such a situation of increased vulnerability to predation (Keenleyside 1991b), a fry's antipredator behaviour and ability to return to its parents and brood mates will likely affect its survivorship (Wisenden et al. 2008; Wisenden \& Dye 2009). Stray convict cichlid fry are predisposed (at least under laboratory conditions) to return to their parents and brood mates (Wisenden \& Dye 2009), and larger fry (8-9 mm body length) prefer to socially associate with familiar siblings (see Chapter 9). This preferential association may facilitate the fry's return to their family unit, thereby contributing to the integrity of the brood during the parental care period. Alternatively, they may encounter and join 
neighbouring broods to gain protection from predators (Keenleyside 1991b); if so, then such joining events could explain the high prevalence $(78 \%)$ of brood mixing in the wild (Lee-Jenkins et al. 2011; Chapter 8).

Investigating the behaviour of young animals when spatially separated from their family unit should provide general insights into an important potential consequence of such separation (i.e. increased vulnerability to predators), the ontogeny of their riskassessment and antipredator behaviours (Lima 1998), and the phenomenon of brood mixing (Riedman 1982; Keenleyside 1991b; Codenotti \& Alvarez 1998; Lee-Jenkins et al. 2011). Although we have some knowledge of the differential vulnerability to predators (e.g. Dickman \& Lynman 1991; Rohner \& Krebs 1996) and the antipredator responses (e.g. Noakes \& Godin 1988; Fuiman \& Magurran 1994; Sih \& Kats 1994; Alemadi \& Wisenden 2002; Fraker 2008) of young animals, I am not aware of any experimental study that has examined the 'homing' ability of young animals when separated from their mobile family unit in species with extended parental care.

The objective of this current study was therefore to gain a better understanding of the behaviour of convict cichlid fry that are spatially separated from their parents and brood mates and the fitness consequences of such separation. I performed complementary field and laboratory experiments that simulated the physical separation of individual young from their family unit. Individual convict cichlid young were separated from their family and displaced/released at varying distances from their home brood. The field experiment ascertained some of the fitness consequences of separation from the family unit in the wild. The second experiment was carried out in a more homogenous laboratory 
environment, where external variables (such as predators, habitat structure, brood movement, and parental retrieval) could be controlled, to characterize the behavioural response of young to displacement from the family unit. Because many behavioural and physiological traits vary with body size in fishes (Noakes \& Godin 1988; Clarke \& Johnston 1999; Hoare et al. 2000b), I considered it as a factor potentially mediating the post-displacement behaviour of convict cichlid fry social affiliations in both experiments.

I predicted that fry released close their brood unit should be more likely to find their way 'home' (and return home sooner) than fry that are released at further distances. Moreover, I predicted that larger (older) fry should be more likely to return to the brood unit, owing to their increased mobility and more developed sensory systems (Noakes \& Godin 1988; Fuiman \& Magurran 1994), than smaller (younger) conspecifics. Findings from the current study will elucidate the consequences of mobile young straying from their family unit while under parental care, and more generally, the ontogeny of homing and predator avoidance behaviours in young animals.

\section{METHODS}

\section{Field Experiment}

\section{Field Sites}

This experiment was carried out in the Rio Cabuyo (located in the Reserva Biologica Lomas Barbudal) and the nearby Rio Potrero, Costa Rica (approximately $10^{\circ} 27^{\prime} \mathrm{N}, 85^{\circ} 20^{\prime} \mathrm{W}$ ) between March $25^{\text {th }}$ and April $5^{\text {th }}$, 2010. I necessarily used two field populations because the densities of fishes (in general) and the number of breeding pairs 
of convict cichlids in particular were unusually low in both rivers that year. During the long dry season (November to May), these river systems consist of long, rectangularshaped pools separated from the adjacent pool by a short riffle section. The substratum in these pools typically consists of sand and leaf litter, with rocks along the banks providing breeding cave habitats. There are many fish species in the two rivers, including convict cichlids, other cichlids (Neetroplus nematopus, Amphilophus longimanus, Parachromis dovii), characins (Astyanax aeneus), catfish (Rhamdia nicaraguensis), and large poecilids (Poeciliopsis turrubarensis). All of these fishes are potential predators on young convict cichlids (personal observations).

\section{Experimental Subjects}

Guarding parents and their brood were visually located in both rivers while snorkelling. Once guarding parent(s) and their brood were located, the brood unit was observed and videotaped in situ (using an Olympus Stylus $1030 \mathrm{SW}$ underwater camera) for approximately $1 \mathrm{~min}$ to record approximate brood size, behaviour of the brood and parents, any fish predators in the vicinity, and local habitat features. After this observation period, four focal fry were carefully collected from the focal brood with a dip-net, with minimal disruption to the brood. Each of these fry was measured using a ruler whilst held in a translucent dip-net (to minimize handing) and placed in numbered, clear $25-\mathrm{ml}$ Falcon $(\mathrm{C}$ tube $(3.0 \mathrm{~cm}$ diameter, $11.5 \mathrm{~cm}$ length) filled with river water. The number on the tubes corresponded to a predetermined distance from the brood (determined by Random.org) at which the focal fry was to be released during the 
subsequent trial period. The experiment comprised four distance treatments (see below). The treatment sequence was randomized for each trial set because trial order, and thus time away from brood, could potentially affect the ability of young to find their way back to the brood unit. After all fry were measured, the Falcon tubes were sealed (i.e. visually and chemically isolated) and temporarily immersed in the river to keep water temperature constant until use. During the fry collecting and measuring pre-trial stage, a second observer monitored the focal brood unit to ensure disruption was minimal and to track any movement of the brood. All of the focal fry measurements were performed while in the river (on a floating platform) to minimize time elapsed from collection to the onset of a trial (which was always $<5 \mathrm{~min}$ ). Although focal test fish ranged from 5 to $11 \mathrm{~mm}$ in standard body length, their mean length was similar across the four displacement distance treatments (one-way ANOVA: $F=0.032, \mathrm{df}=3,99, p=0.992$; mean \pm s.e., $20 \mathrm{~cm}: 8.2 \pm$ $0.38 \mathrm{~mm}, 40 \mathrm{~cm}: 8.3 \pm 0.38 \mathrm{~mm}, 60 \mathrm{~cm}: 8.3 \pm 0.39 \mathrm{~mm}$, and $80 \mathrm{~cm}: 8.4 \pm 0.38 \mathrm{~mm})$. Within this size range, wild convict cichlid young are still under parental care (Wisenden \& Keenleyside 1994).

\section{Experimental Protocol}

The four focal fry collected from a given brood were displaced and released into the river at one of four distances from their brood unit, namely, $20 \mathrm{~cm}, 40 \mathrm{~cm}, 60 \mathrm{~cm}$, or $80 \mathrm{~cm}$. These distances fall well within the range of movement of parental convicts and their young on any given day in the Rio Cabuyo (Wisenden 1995). One fry per focal brood was released at each of the above treatment distances. All fry were collected prior 
to the start of a trial to minimize pseudoreplication and disturbance to the brood. Any given trial (comprising the four distance treatments) typically lasted $1 \mathrm{~h}$ (from the collection of focal fish to the completion of the last distance treatment). A long stick obtained from the river (with $20 \mathrm{~cm}$ interval markings) was used to measure release distances to minimize startle responses of guarding parents and their broods.

After the focal fry were measured and placed into their corresponding Falcon $\mathrm{C}$ tubes, the first treatment was initiated. The corresponding release distance was measured, and marked with a labelled river rock on the substrate and the capped Falcon $($ tube was carefully inverted approximately $10 \mathrm{~cm}$ off the substrate and held stationary at that location for $30 \mathrm{~s}$. This procedure allowed the focal fish to visually assess its surroundings, while not providing too much time to attract predators to the area or for the brood unit to move away (established during pilot work). Following this initial viewing period, the cap was unscrewed slowly and the tube slowly lifted away from the cap. If the focal fish would not leave the cap after $5 \mathrm{~min}$, or if during this time the brood moved out of sight, the tube was replaced lightly over the cap and the treatment restarted near the brood (this occurred on $20 \%$ of the completed treatment trials, two of these trials were discarded because the focal fish never moved). During pilot work, replacing the cap and slowly reinverting the tube was a way to stimulate focal fish to move out of the tube cap. While the focal fish was in the cap, it was not attacked by predators or approached by parents. Fry were only approached or attacked post-release once they were swimming in the water column or stationary on the river substrate. When lifting the tube away from the cap, focal fry would either temporarily remain stationary in the cap or immediately swim out 
of the tube. Once the fry swam away from the tube's cap, a timer was started by the second observer. The release location of focal fish relative to the current was as consistent as possible given the heterogeneous landscape of the river bottom. Focal fry were always released downstream and/or across current from the brood in such a way that allowed for maximal visibility and receipt of chemical cues between them (as visual and chemical cues are important for homing in young convict cichlids; Wisenden \& Dye 2009).

The released focal fry would typically either swim in the lower half of the water column or hide in the leaf substratum. The focal fry and brood unit were tracked by two observers, and were observed until one of the following trial endpoints occurred: (i) the focal fish hid (e.g. in leaf litter) and was not observed for five continuous minutes, (ii) the focal fish was eaten by a predator, (iii) the focal fish safely returned to the brood unit, or (iv) the focal fish was visually lost by both observers. Pilot work completed in the Rio Cabuyo indicated that once a fry remained hidden for $5 \mathrm{~min}$, it was typically lost from sight (likely had moved along the substrate under the leaf litter) and unlikely to emerge from its refuge. If the brood moved between consecutive treatments within a trial, I placed a river rock with flagging tape on the spot where the brood was initially located. The next distance treatment commenced in the same fashion until all focal fish (at all four distance treatments) had been tested. Once a trial ended, I measured the distance travelled by the focal fish. At the end of a trial, I used the flagged river rocks to measure the distance travelled by the brood during the course of the trial as a measure of brood mobility. I also recorded water current velocity at the surface, the turbidity, depth and 
temperature of the water, area of the pool, duration of the trial (time taken from fry collection to the end of the last treatment), and any other notable features (e.g. local fish density, predator approaches during a trial, etc.). Water current velocity averaged $4.8 \pm$ $1.4 \mathrm{~cm} \cdot \mathrm{s}^{-1}$ (range $=0$ to $25 \mathrm{~cm} \cdot \mathrm{s}^{-1}$ ) during the experiment, but was low or nil for the majority of focal broods (mode $=0 \mathrm{~cm} \cdot \mathrm{s}^{-1}$ ), and the water was clear during all trials.

\section{Statistical Analysis}

A total 100 focal fry from 25 broods were tested; 17 of these broods were from the Rio Cabuyo and 8 from the Rio Potrero. Observations for three focal fish were necessarily aborted, because two of them did not move out of the tube and, for the third one, the focal brood unit had disappeared from sight on the fourth distance treatment of the trial. All of these focal fish were from the Rio Potrero and were from distance treatments $(20,40$ and $80 \mathrm{~cm})$ and different broods. In addition, three focal fish were lost from sight by both observers in the Rio Cabuyo; these were from distance treatments 20 , 40 , and $80 \mathrm{~cm}$, respectively, and originated from different broods. Therefore, data from these six focal fish were excluded from the final data set for statistical analysis.

I used a multinomial logit regression model, specifically the 'mlogit' package in $\mathrm{R}$ (Version 2.1.11; http://www.r-project.org), to test for the potential effect of three predictor variables [distance treatment, focal fish body length and river (Potrero/Cabuyo)], on the 'outcome' of a trial (a discrete, nominal response variable). The variable of 'river' was subsequently removed from the model because it did not significantly contribute to the model. Within a given trial, there were three possible 
categorical outcomes for a fry released at a given distance from its home brood unit namely, returned successfully to the brood, hid in refuge (and did not reappear for $5 \mathrm{~min}$ ), or eaten by a predator.

In addition, I used a Cox proportional hazards regression analysis to test for any effect of focal fry release distance ("Treatment"; categorical variable) and focal fish body length ("FFSize"; continuous variable) on the likelihood of the focal fry returning to its family unit and the elapsed return time. This analysis was used as it accounts for cases where focal fish did not find their way home (i.e. right-censored data) and allows covariables to be examined in the model. The analysis was performed using the Survival ('survfit') package and the 'coxph' function in R. A series of Cox proportional hazards models were initially compared: Model $1=$ Treatment + FFSize + Treatment ${ }^{*}$ FFSize + cluster(Family), Model 2 = Treatment + FFSize + cluster(Family). However, in model 2 , FFSize violated the proportional hazards assumption. Therefore, for subsequent analyses, a FFSize time-dependent covariate was created and added to the models ('FFSize:Time'). For all models, focal fish family (= Family) and river ("River": Rio Potrero or Rio Cabuyo) were used as clustering variables. To select the 'best-fit' model, I compared the Akaike Information Criterion (AIC) scores for each model, where the model with the lowest AIC was selected. As previously mentioned, the assumption of proportional hazards was tested. For each model, this was performed using the cox.pzh function in R.

I also characterized the mobility of individual brood units by comparing the developmental stage of young within the brood (inferred from the mean body length of the four focal fish taken from that brood) to the distance the brood travelled during the 
course of a trial using a general linear model (GLM). The data meet the assumptions of normality and homoscedasticity.

\section{Laboratory Experiment}

\section{Experimental Subjects}

Fry were obtained from breeding pairs of adults (originating from the Rio Cabuyo population) in the laboratory at Carleton University (see Chapter 9 for details of the holding conditions for these fish). A total of 22 different brood units (or families) were tested, with four focal fish from each brood similarly released at one of four distances treatments $(20,40,60$ and $80 \mathrm{~cm})$ from the home brood. Across all sets, brood units and focal fry were tested at varying ages/body sizes (randomly chosen for a given test brood) such that an equal variety of broods with focal fry body sizes $(5.5$ to $9.5 \mathrm{~mm}$ in standard length) were tested overall. The mean body length of focal fry did not differ across the distance treatments (one-way ANOVA: $F=0.005, \mathrm{df}=3,87, p=1.0 ; 20 \mathrm{~cm}: 7.7 \pm 0.25$ $\mathrm{mm}, 40 \mathrm{~cm}: 7.7 \pm 0.28 \mathrm{~mm}, 60 \mathrm{~cm}: 7.7 \pm 0.27 \mathrm{~mm}, 80 \mathrm{~cm}: 7.7 \pm 0.26 \mathrm{~mm}$ ), and similar to body lengths of the focal fry tested in the field (see Field Experiment above).

\section{Experimental Apparatus}

The experimental apparatus comprised a long rectangular glass tank (184 x $60 \times 26$ $\mathrm{cm} ; \mathrm{L} \mathrm{x} \mathrm{W} \mathrm{x} \mathrm{H;} \mathrm{Figure} \mathrm{10.1)} \mathrm{that} \mathrm{was} \mathrm{divided} \mathrm{into} \mathrm{three} \mathrm{compartments} \mathrm{with} \mathrm{clear,}$ perforated plastic partitions; one of two end compartments $(22 \times 60 \mathrm{~cm})$ contained the parents and brood mates of a focal test fry, and a large central testing compartment $(140 \mathrm{x}$ 
$60 \mathrm{~cm}$ ) into which a focal test fry would be released and observed. In a given trial, one of the two end compartments was randomly selected to house the parents and home brood of the focal test fry and the opposite end compartment remained empty (i.e. contained no fish). Each end compartment was similar in that they contained a submersible water heater and airstone along the back wall, a central clay pot for shelter and an artificial plant at the 'front wall' (see Figure 10.1). The partitions between compartments were secured to the sides of the tank with silicon so that no gaps existed between the dividers and the tank walls, preventing any fry from escaping the end compartments. The bottom of the entire tank was covered with a $1.5-\mathrm{cm}$ layer of fine, white gravel as substratum, resembling the sandy substrate found in their natural rivers in Costa Rica. The tank was filled with aged tap water $\left(15 \mathrm{~cm}\right.$ depth) maintained at $24.5 \pm 0.05^{\circ} \mathrm{C}$. The tank was drained completely at the end of each trial and the water replaced and aged for $24 \mathrm{hr}$. Vertical lines were drawn at $5-\mathrm{cm}$ intervals on the front and back walls of the central compartment, and thin bamboo skewers $(25 \mathrm{~cm}$ in length) were partially buried into the substrate at $10-\mathrm{cm}$ intervals (parallel to the end walls) with a $10-\mathrm{cm}$ portion exposed (Figure 10.1), to facilitate the recording of focal fry movement and the identification of the location of release of the focal fry (depending on the four displacement distance treatments. The end walls of the tank were covered on the inside with black plastic board. The entire apparatus was located within a blind constructed of black polyethylene plastic to minimize any external disturbances. The behaviour of the focal fish was observed from above the blind though a screened observation port. 


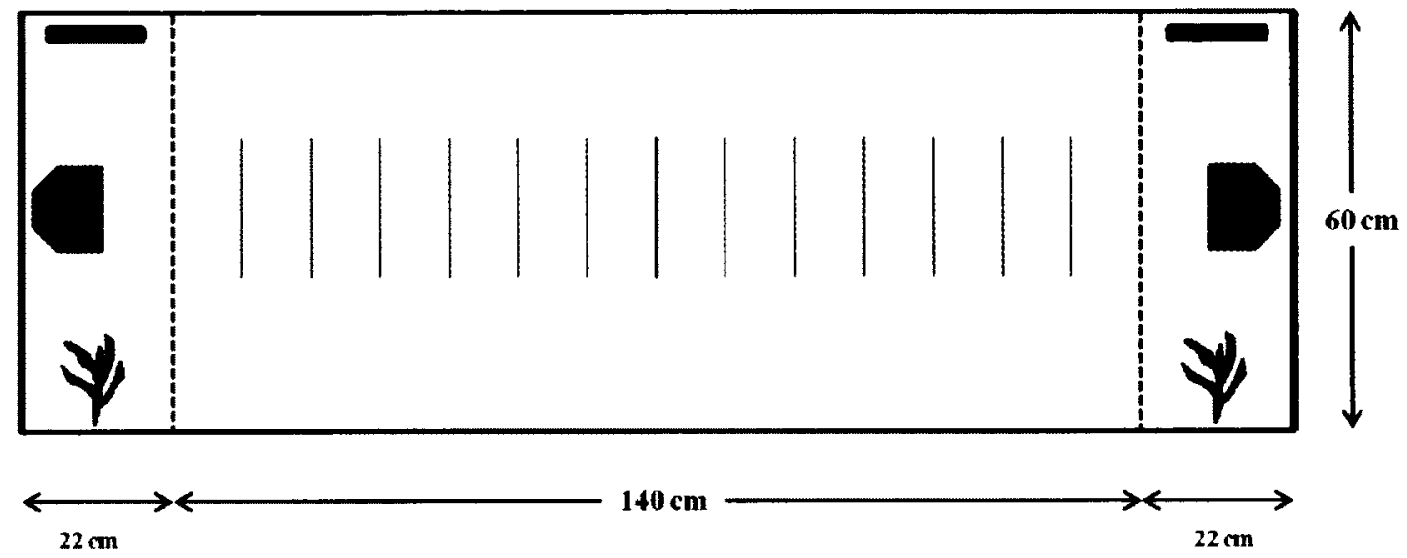

Figure 10.1. Top-down view of the laboratory experimental apparatus where each end compartment contained an artificial plant, clay pot and water heater. One of the two end compartments (randomized for each trial) housed the parents and brood mates of the focal fry. The central compartment was the testing/displacement area and was separated from the end compartments by clear, perforated dividers. During a trial, focal fish were displaced to one of four distances $(20,40,60$ or $80 \mathrm{~cm})$ from the edge of the end compartment containing its parents and home brood. Thin bamboo skewers (vertical lines in the central compartment) were partially buried in the gravel substratum of the central test compartment at $10-\mathrm{cm}$ intervals. 


\section{Experimental Protocol}

The protocol followed was generally similar to the one used in the Field Experiment (see above); four displacement distance treatments $(20,40,60$ and $80 \mathrm{~cm}$ from the end compartment containing the parents and brood mates of the focal fry) and one focal fry from each focal brood was tested at each distance in any given trial.

Between 09:00 - 11:00 hrs on the day of a trial, the parents of a focal brood $(\mathrm{n}=$ 22) and 20 randomly-selected fry from that brood were dip-netted into an opaque bucket containing treated aged tap water $(\sim 1 \mathrm{~L})$ and transferred into one of the two end compartments of the experimental tank (hereafter termed the 'home compartment'); the designated home compartment was selected randomly a priori to the trial. The parents and their brood were left undisturbed to acclimatize for $5 \mathrm{~h}$. Following this period, four visually size-matched focal fry were carefully dip-netted from their home compartment and temporarily placed into a cup containing experimental tank water (taken from the centre of the tank). Each individual focal fry was then measured and placed in a separate 25-ml Falcon@ tube (as described for the Field Experiment above) until testing.

Prior to the onset of the trial, the air stones in both end compartments were shut off and a clear, perforated plastic cylinder $(7 \mathrm{~cm}$ diam.) was placed in the central compartment at the first distance treatment (treatment order determined at random). For a given distance treatment, a focal fry was carefully poured from its tube into the cylinder from a vantage location behind the observation blind, so as to not disturb the parent fish and brood in their end compartment. The focal fish was allowed a 1-min viewing period (similar to that in the Field Experiment) before the cylinder was lifted and the test fish 
allowed to swim freely in the central compartment. The behaviour of the focal fish was recorded using a digital voice recorder (Olympus Digital Voice Recorder VN-5200PC). The observation period ended when either the focal fish returned 'home' (i.e. when it approached and nipped at the divider of the end compartment containing its parents and brood mates) or until $30 \mathrm{~min}$ had elapsed. At the end of the observation period, the focal fish was dip-netted and the cylinder placed at the next distance treatment location in the central compartment. The three other displacement distance treatments were similarly and sequentially carried out in pre-determined random order. Each displacement distance treatment was replicated with 22 focal fish, each from a different family. At the end of the trial, the standard length of both parents and all stimulus fry within the focal brood were measured.

The audio tape recordings were later transcribed, and the total distance travelled by each focal fish in the central compartment and the time elapsed to return to its home compartment were recorded.

\section{Statistical Analysis}

As for the Field Experiment, I used a Cox proportional hazards regression analysis to compare the likelihood and time to return of focal fry to their home brood between the different displacement distance treatments. Similarly, I created a FFSize time-dependent co-variable which was added to the model, because initially there was a violation of the proportional hazards assumption. I used AIC values to compare fitted models. 
I also wanted to determine if the body size of the focal fish and the distance initially separated from its home brood affected the (approximate) length of the path taken by focal fish to reach home. Thus, I calculated a 'Path Ratio measure', which was simply the total length of the path traveled by the focal fish divided by the treatment distance. A ratio value of 1 would indicate that the focal fish took the most direct (linear) return route to the brood. The larger the path ratio value, the less direct the return travel of the focal fish (controlling for displacement distance). I used a linear mixed-effects model, using the 'nlme' package and the 'Ime' function in $R$, to see if focal fish body length predicted the path ratio. In the model, displacement distance treatment (categorical predictor) and focal fish length (continuous predictor) where the variables and brood identity was added as a random factor. Path ratio was log-square-root transformed to meet the assumptions of normality and homoscedasticity. The models were again compared using AIC values to determine the 'best-fit' model.

\section{RESULTS}

\section{Field Experiment}

Of the 25 broods tested, $60 \%$ of the broods had at least one focal fish that returned to the brood, $84 \%$ had at least one focal fish that took refuge in the leaf litter, and $32 \%$ had at least one focal fish that was eaten during a trial. Correspondingly, of a total of 94 focal fish tested and included in the final data set, $25 \%$ of them returned to the brood, $62 \% \mathrm{hid} /$ refuged and $13 \%$ were eaten by fish predators. The predators were convict cichlids, other cichlid fishes (Neetroplus nematopus, Amphilophus longimanus) and the 
characin, Astyanax aeneus, which captured 6,2,3 and 1 focal test fish, respectively. Of the 58 focal fish that immediately refuged in the substratum leaf litter upon release, none was observed to return to their home brood within the trial period.

Trial outcome, or the likelihood of a displaced focal fish refuging or returning safely to its family unit, depended on both the focal fish's body length and the initial displacement distance separating it from the home brood (multinomial logit regression: Log-likelihood $=-64.48, \chi^{2}=41.99, p<0.001$; Table 10.1, Figures 10.2 and 10.3). The proportion of focal fish safely returning to their family unit progressively declined, whereas the proportion of fish refuging in the leaf letter progressively increased, with increasing separation distance from the home brood (Figure 10.2). More specifically, focal fish were more likely to return to the brood than to seek refuge in leaf litter at $20 \mathrm{~cm}$ $(t=-2.42, p=0.015$; Table 10.1), but more likely to seek refuge than to return to the brood at $60 \mathrm{~cm}(t=2.35, p=0.019)$ and no fish returned to the brood at the $80 \mathrm{~cm}$ displacement distance.

Corroborating the above results, the Cox proportional hazards regression analysis revealed that the distance treatment significantly affected the elapsed time and likelihood of a focal fish returning to the brood, and that the time-dependent focal fish body size variable was marginally significant (overall Wald Test: $z=9.88, \mathrm{df}=4, p=0.043$; Tables $10.2 a$ and 10.3a, Figure 10.3). Fish displaced and released $20 \mathrm{~cm}$ away from their home brood were 1.7 times $(z=-1.06, p=0.29)$ and 3.3 times $(z=-2.17, p=0.03)$ more likely to return to the brood than fish released either at $40 \mathrm{~cm}$ or $60 \mathrm{~cm}$, respectively. Model 
parameters could not be estimated for fish released at $80 \mathrm{~cm}$ from the brood (Table 10.3a), as no focal fish was observed to return to its home brood (Figure 10.3).

In general, larger focal fish were significantly more likely to seek refuge than to return to the brood or to be eaten by predators compared with smaller conspecifics, irrespective of displacement distance (Table 10.1). For every 1-mm increase in body length, individual focal fish were 1.5 times more likely to seek refuge than to return to the brood $(t=2.33, p=0.02$; Table 10.1) and twice as likely to hide than to be eaten $(t=-$ $3.35, p=0.0008$ ). However, the main effect of the body length of focal fish (FFSize) on the likelihood to return to the home brood was not significant (Cox proportional hazards regression analysis: $z=0.012, p=0.99$ ) when correcting for the constant proportional hazards assumption, but the effect of the time-dependent focal fish size variable (FFSize:Time) was marginally significant $(z=-2.02, p=0.043)$. This result suggests that the body length of displaced focal fish influenced their behaviour only early in the trial (i.e. first $10 \mathrm{~s}$ ) following release, but not over the remainder of the trial.

The mobility of the focal family unit in the river (distance the brood travelled during a trial) tended to increase (glm: $t=2.00, \mathrm{n}=25, p=0.057$ ) with increasing mean body length of focal fish within a brood. 


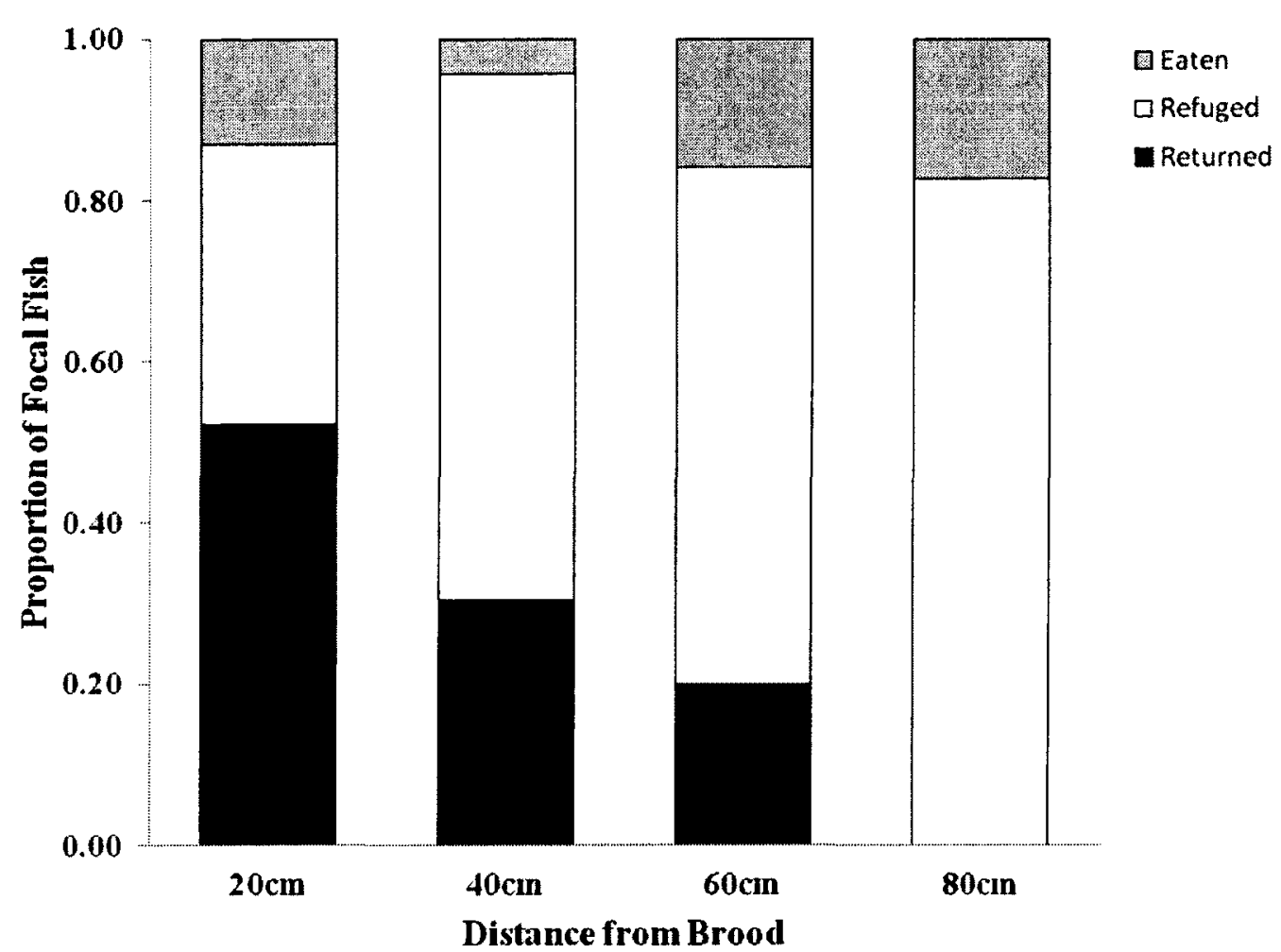

Figure 10.2. Proportion of focal fish displaced from their home brood that either returned safely to brood, hid/refuged in to leaf litter or were eaten by fish predators upon release into the river at different displacement distances from their home brood and guarding parents. Four focal fish from each of 25 focal broods were displaced and released at each distance treatment. Replicate sample sizes were 23, 23, 25 and 23 focal fish for the distance treatment, $20,40,60$ and $80 \mathrm{~cm}$, respectively; two focal fish in each of treatments 20,40 and $80 \mathrm{~cm}$ were either lost from sight or the brood disappeared during a trial. 
Table 10.1. Results from a multinomial logit regression model (Log-likelihood $=-64.48, \chi^{2}=41.99, p<0.0001$ ), for three possible trial outcomes: returned successfully to the brood (Returned), hid/refuged in leaf litter (Refuged), or eaten by a predator (Eaten). The predictor variables were treatment (distance released from brood) and focal fish body length (FFSize) were included in the model. The comparisons in the model were an outcome compared to (vs.) the reference outcome within all possible outcome combinations and predictors. Significant differences are boldfaced. None of the focal fish returned to the brood when released from $80 \mathrm{~cm}$, therefore accurate p-values and coefficients could not be computed (italicised and indicated by $\mathrm{NA}$ ).

\begin{tabular}{|c|c|c|c|c|c|c|c|}
\hline Variable & Outcome Coinparison & Estimate & $\operatorname{Exp}(E s t)$ & Exp(-Est) & Std. Error & t-value & $p$ value \\
\hline \multirow{3}{*}{ Imt- $20 \mathrm{~cm}$} & Refuged vs. Returned & -3.78 & $2.29 \mathrm{e}-02$ & 43.82 & 1.56 & -2.42 & 0.015 \\
\hline & Eaten vs. Returned & 1.41 & 4.11 & $2.44 e-01$ & 1.84 & 0.77 & 0.44 \\
\hline & Eaten vs. Refiged & 5.19 & 179 & $5.57 \mathrm{e}-03$ & 1.86 & 2.79 & 0.0053 \\
\hline \multirow[t]{3}{*}{$\operatorname{Tmt}-40 \mathrm{~cm}$} & Refuged vs. Returned & 1.26 & 3.51 & $2.84 \mathrm{e}-01$ & 0.68 & 1.85 & 0.064 \\
\hline & Eaten vs. Refuged & -1.98 & $1.38 \mathrm{e}-01$ & 7.24 & 1.31 & -1.51 & 0.13 \\
\hline & Eaten vs. Returned & -0.72 & $4.86 \mathrm{e}-01$ & 2.05 & 1.28 & -0.56 & 0.57 \\
\hline \multirow[t]{3}{*}{$\operatorname{Tm} t-60 \mathrm{~cm}$} & Refuged vs. Returned & 1.70 & 5.48 & $1.83 e-01$ & 0.72 & 2.35 & 0.019 \\
\hline & Eaten vs. Returned & 0.99 & 2.70 & $3.72 e-01$ & 0.97 & 1.03 & 0.30 \\
\hline & Eaten vs. Refuged & -0.71 & $4.92 e-01$ & 2.03 & 0.97 & -0.73 & 0.47 \\
\hline \multirow[t]{3}{*}{$T \mathrm{mt}-80 \mathrm{~cm}$} & Refuged vs. Returned & $N A$ & $N A$ & $N A$ & $N A$ & $N A$ & NA \\
\hline & Eaten vs. Retumed & $N A$ & $N A$ & $N A$ & $N A$ & $N A$ & $N A$ \\
\hline & Eaten vs. Refuged & -0.90 & $4.05 \mathrm{e}-01$ & 2.46 & 0.99 & -0.91 & 0.36 \\
\hline \multirow[t]{3}{*}{ FFSize } & Refuged vs. Returned & 0.39 & 1.47 & $6.77 e-01$ & 0.17 & 2.33 & 0.02 \\
\hline & Eaten vs. Returned & -0.33 & $7.18 \mathrm{e}-01$ & 1.39 & 0.23 & -1.47 & 0.14 \\
\hline & Eaten vs. Refuged & -0.72 & $4.88 \mathrm{e}-01$ & 2.05 & 0.21 & -3.35 & 0.0008 \\
\hline
\end{tabular}




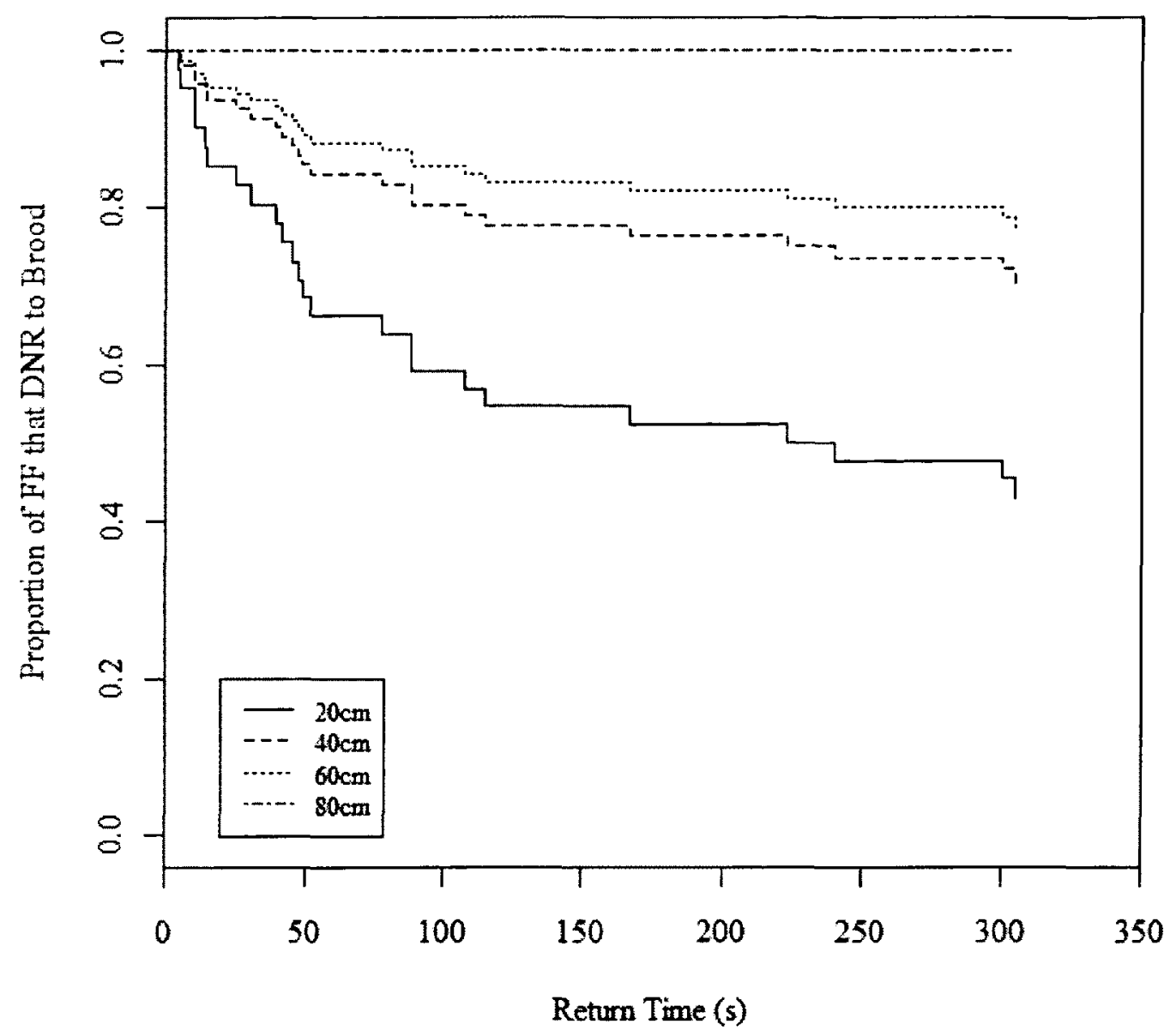

Figure 10.3. 'Survival' plot of the proportion of displaced focal fish (in the field experiment) that did not return to their home brood (=DNR) as a function of time since being released into the river at different distances from the brood (where the longest time to return was $310 \mathrm{~s}$ ). The four curves represent the four different displacement distances $(20,40,60$ or $80 \mathrm{~cm} ; n=23,23,25$, and 23 , respectively) from which focal fry were released relative to the location of the home brood 
Chapter 10 - 'Homing' Ability in Convict Cichlid Young

\section{Laboratory Experiment}

In the relative homogeneous environment of the experimental tank, 78 (or $88.6 \%$ ) of the 88 focal fish tested returned home following displacement from their brood mates and parents, considerably more than in the more complex and risky environment of their natural riverine habitats (see Field Experiment above). The remaining 10 (11.4\%) focal fish that did not return (DNR) were necessarily censored in the Cox proportional hazards analysis.

The initial response of displaced focal fish (remain immobile on the substratum or swim in the water column) immediately after release from the cylinder (i.e. at the onset of the trial) was not predicted by either their body length or distance displaced from the brood (generalized linear mixed-effects model for binary data; all $p$-values $>0.30$ ). However, the distance from which a displaced focal fish was released from its home brood, its body length and the time-dependent body length covariate, all contributed significantly to the likelihood of returning and the time taken to return to the brood in the laboratory test tank (overall Wald Test: $z=43.03, \mathrm{df}=5, p<0.0001$; Tables $10.2 b$ and $10.3 b$, Figure 10.4). In general, focal fish were less likely to return to their home brood and parents, and took longer to return, the further away they were displaced from their home brood, and overall, larger fish were more likely to return than smaller ones. More specifically, focal fish that were displaced at $20 \mathrm{~cm}$ from their family unit were 1.8 times $(z=-1.85, p=0.064 ;$ Table 10.3b), 2.8 times $(z=-3.50, p=0.0005)$ and 3.8 times $(z=-$ $4.07, p=0.00005$ ) more likely to return home than fish displaced at 40,60 and $80 \mathrm{~cm}$ from the brood, respectively. Focal fish body size also affected the likelihood of returning 
to the brood; for every $1-\mathrm{mm}$ increase in body length, focal fish were 1.5 times more likely to return $(z=2.96, p=0.0031)$. However, the effect of body size on the likelihood of returning to the brood decreased with time elapsed or the longer the trial progressed ( $z$ $=-3.88, p=0.0001)$ and stopped affecting the likelihood of returning after $7 \mathrm{~min}$ had elapsed.

For those focal fish that returned home, the path ratio (length of path taken home divided by the shortest linear path length to the brood) was not predicted either by their body length or distance displaced from the brood. The best-fit model only contained focal fish body length as a variable, but this effect was not significant (linear mixed-effects model: $t=-1.64, \mathrm{df}=55, p=0.11$. 
Table 10.2. Comparisons of Cox proportional hazards models and associated AIC values for the combinations of the predictor variables (displacement distance, focal fish body length, and the time-dependent covariate of focal fish body length) for field (a) and lab (b) data. Focal fish family was a cluster variable for both the field and lab models, and river was a second cluster variable for the field data. Model 3 was the best-fit model (lowest AIC value*) in both cases. All $\triangle \mathrm{AIC}$ values here are the differences in AIC value compared to the best fit model 3.

a)

\begin{tabular}{llc}
\hline Model & AIC & AAIC from lowest AIC \\
\hline Tmt*FFSize + Tmt + FFSize + FFSize:Time & 245.57 & 3.62 \\
Tmt*FFSize + Tmt + FFSize & 248.09 & 6.14 \\
Tmt + FFSize + FFSize:Time & $\mathbf{2 4 1 . 9 5 *}$ & - \\
Tmt + FFSize & 244.37 & 2.42 \\
Tmt & 244.38 & 2.43 \\
\hline
\end{tabular}

b)

Model

Tmt*FFSize + Tmt + FFSize + FFSize:Time

Tmt*FFSize + Tmt + FFSize

Tmt + FFSize + FFSize:Time

Tmt + FFSize

Tmt

\section{AIC}

$\triangle \mathrm{AIC}$ from lowest AIC

574.03

584.19

$570.09 *$

580.04

578.11
14.1

9.95

3.94

-

8.02 
Table 10.3. Results from the best-fit Cox proportional hazards model for the field (a) and lab (b) data (Field data: overall Wald $z=9.88, \mathrm{df}=4, p=0.043$; Lab Data: overall Wald $z=43.03, \mathrm{df}=5, p<0.0001)$. Distance treatment was a significant variable contributing to the return rate of focal fry to the brood in both the field and lab experiments, and FFSize was a significant variable in the lab experiment. The hazards ratio is represented by $\exp (\operatorname{coef})$ and $\exp (-\operatorname{coef})$. Note that none of the focal fish returned to the brood when released at $80 \mathrm{~cm}$ in the field; consequently, the model parameters for this treatment could not be calculated.

a) Model $=$ Treatment + FFSize + FFSize:Time + cluster(Family) + cluster(River)

\begin{tabular}{|c|c|c|c|c|c|c|}
\hline Variable & $\begin{array}{l}\text { coef } \\
(=\beta)\end{array}$ & $\exp (\operatorname{coef})$ & $\exp (-\operatorname{coef})$ & robust se & $z$ (Wald) & $p$-value \\
\hline 20 vs. $40 \mathrm{~cm}$ & -0.510 & 0.600 & 1.666 & 0.483 & -1.058 & 0.2903 \\
\hline 20 vs. $60 \mathrm{~cm}$ & -1.196 & 0.302 & 3.308 & 0.552 & -2.168 & 0.0301 \\
\hline 20 vs. $80 \mathrm{~cm}$ & $N / A$ & $N / A$ & $N / A$ & $N / A$ & $N / A$ & $N / A$ \\
\hline FFSize & 0.001 & 1.001 & 0.999 & 0.119 & 0.012 & 0.991 \\
\hline FFSize:Time & -0.016 & 0.984 & 1.016 & 0.008 & -2.017 & 0.0437 \\
\hline
\end{tabular}

b) Model $=$ Treatment + FFSize + FFSize:Time + cluster(Family)

\begin{tabular}{lllllll}
\hline Variable & $\begin{array}{l}\text { Coef } \\
(=\mathfrak{B})\end{array}$ & $\exp ($ coef) & $\exp (-$ coef) & robust se & $z$ (Wald) & $p$-value \\
\hline 20 vs. $40 \mathrm{~cm}$ & -0.596 & 0.551 & 1.815 & 0.322 & -1.851 & 0.0642 \\
20 vs. $60 \mathrm{~cm}$ & -1.014 & 0.363 & $\mathbf{2 . 7 5 8}$ & 0.300 & -3.499 & $\mathbf{0 . 0 0 0 5}$ \\
20 vs. $80 \mathrm{~cm}$ & -1.339 & 0.262 & $\mathbf{3 . 8 1 5}$ & 0.329 & -4.071 & $\mathbf{0 . 0 0 0 0 5}$ \\
FFSize & 0.372 & $\mathbf{1 . 4 5 1}$ & 0.689 & 0.126 & 2.959 & $\mathbf{0 . 0 0 3 1}$ \\
FFSize:Time & -0.061 & 0.940 & $\mathbf{1 . 0 6 3}$ & 0.016 & -3.882 & $\mathbf{0 . 0 0 0 1}$ \\
\hline
\end{tabular}




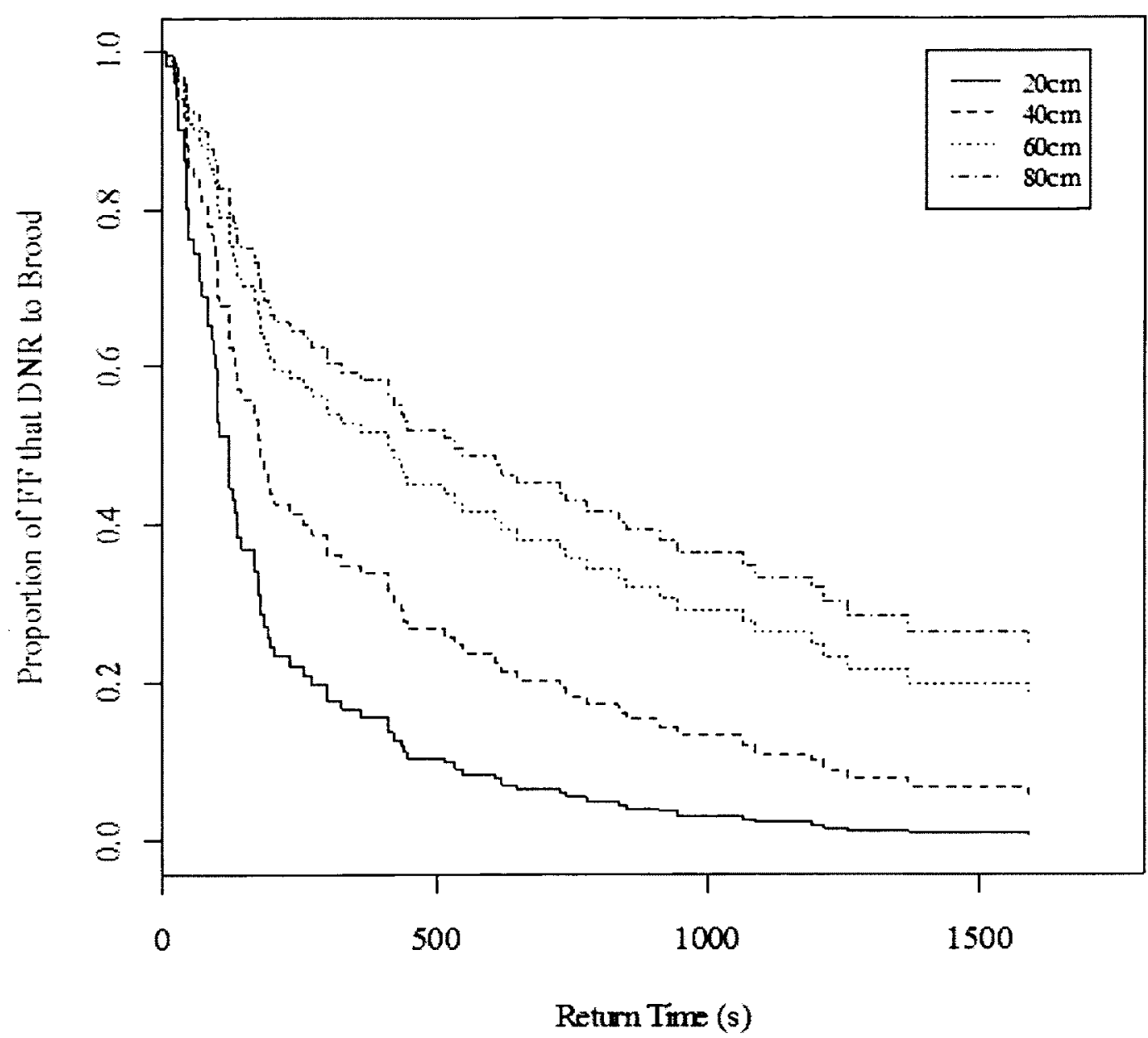

Figure 10.4. 'Survival' plot of the proportion of displaced focal fish (in the laboratory experiment) that did not return to their home brood and parents (= DNR) as a function of time since being released into the experimental tank at different distances from the brood (where the longest time to return was $1800 \mathrm{~s}=30-\mathrm{min}$ trial). The four curves represent the four different displacement distances $(20,40,60$ or $80 \mathrm{~cm} ; \mathrm{n}=22$ for each treatment) from which focal fry were released relative to the location of the home tank compartment. 


\section{DISCUSSION}

In species wherein parents care for mobile dependent offspring, the young may occasionally stray and become separated from their parents and brood mates (e.g. Fitzgibbon 1990; Codenotti \& Alvarez 1998; Simpson et al. 2005; Wisenden \& Dye 2009). During such separations, a young animal is without parental protection and is thus particularly vulnerable to predation (Sih \& Kats 1994; Alemadi \& Wisenden 2002; Alonzo et al. 2001). The magnitude of this risk is presumably in part a function of the distance separating young from their protective parent(s) (cf. Lima \& Dill 1990) and the developmental stage of the young (Noakes \& Godin 1988; Kelley \& Magurran 2003). However, the behaviour of mobile young following separation from their family unit (= brood and guarding parents), and their risk of predation whilst separated, remain poorly characterized in general. Here, to address this knowledge deficit, I simulated separation between parents and young by experimentally displacing in both the field and laboratory individual young convict cichlids at varying distances from their family unit, and quantified their subsequent behaviour and fate (returned safely back 'home', refuged in leaf litter, or captured by a predator).

Young convict cichlids that were displaced from their family unit were increasingly less likely to return to their family, and took longer to return if they did so, with increasing distance of displacement from the home brood, as predicted. In the fish's natural riverine environment (field experiment), focal fish that were displaced near (20 $\mathrm{cm}$ ) their home brood were significantly more likely to return home than to seek refuge in the substratum leaf litter. In comparison, focal fish were increasingly more likely to 
refuge than to return home when displaced further away from their family. Collectively, these novel results suggest that young convict cichlids that were separated from their family unit assessed their immediate ambient risk of predation to be increasingly higher with increasing separation distance and behaved appropriately by adopting more cautious, less conspicuous behaviour (i.e. hiding in leaf litter, rather than swimming in the water column) when increasingly further away from the safety of their family unit. Activity in open habitat can increase an individual's risk of predation (Lima \& Dill 1990; Godin 1997) and the duration of exposure to predators is a major component of an individual's risk of predation (Lima \& Dill 1990), which presumably is an increasing function of separation distance from the family unit for a young dependent cichlid. Therefore, hiding from predators instead of remaining active and visible in the water column would appear to be adaptive in reducing individual vulnerability to predation in young convict cichlids that are separated from their family unit. Refuging and remaining immobile are effective antipredator strategies (Lima \& Dill 1990; Godin 1997), which can be adopted by mobile, dependent young animals that are separated from their parents (e.g. Caro 2005).

Given that body size affects numerous behavioural and physiological traits in animals (Noakes \& Godin 1988; Clarke \& Johnston 1999; Hoare et al. 2000b) and vulnerability to predation (Noakes \& Godin 1988; Godin 1997), it was expected that the behaviour of convict cichlid young separated from their family unit would be mediated by their body length. Moreover, because body length is correlated with age in young convict cichlids (Chapter 9), larger and older young may have encountered and experienced more predators, and thus may assess and respond to local predation hazards, 
differently than smaller and younger conspecifics. The expectation of size-mediated behavioural responses was met in the relatively homogeneous environment of the laboratory where the likelihood of a displaced young returning to its family unit increased, and the time taken to return to the family decreased, significantly with increasing body length, suggesting that larger fish felt safer and were thus more active and (or) swimming faster in the open water column than smaller conspecifics. The tortuosity of the travel path (= path ratio measure) of fish that returned to their family unit did not vary with body length. These results additionally suggest that homing motivation does not wane with increasing body length (age) and approaching age of independence, in young convict cichlids.

In contrast, in the convict cichlid's more complex natural environment where ambient predation intensity is high (e.g. Hay 1978; Wisenden \& Keenleyside 1994; Wisenden 1995; Wisenden \& Dye 2009), the body length of displaced focal fish only weakly and ephemerally affected the likelihood of returning to the family unit. Nonetheless, larger focal fish were significantly more likely to hide (in leaf litter) than to return to their family unit than smaller fish in the wild, irrespective of separation distance, and smaller fish were more likely to be eaten than to refuge. This suggests that larger fish assessed their individual risk of predation to be greater than smaller fish or that, because of developmental constraints (Noakes \& Godin 1988), smaller fish were not able to accurately assess ambient predation risk. The difference in the importance of fish body size in mediating behaviour between the laboratory and natural environments is likely attributable to differences in the biotic and abiotic features of these two types of 
environment (e.g. predators present and refugia available in the wild but not in the laboratory environment) and, consequently, the focal fish's perception of the local risk of predation. For example, it is known that differential prior exposure and experience with predators affects the approach ('homing') response of young convict cichlids towards their parents in the laboratory (Vives 1988).

The observed decreasing likelihood of displaced convict cichlid young returning to their family unit with increasing separation distance from the family likely reflects either a decreasing willingness of the separated young to risk predation by swimming longer distances in dangerous open habitat in the absence of parental protection (as argued above) or sensory constraints on the young's ability to locate its parents and brood mates at increasing distances from them. I suggest that both mechanisms are operating concurrently, as they are not mutually exclusive. Young convict cichlid use both parental visual and chemical cues (Lavery et al. 1990; Wisenden \& Dye 2009) to locate, recognize and approach their parents. It is reasonable to assume that the availability or intensity of such cues would wane with increasing distance away from the family unit, which would most likely adversely affect the ability of separated young to return to their family. Separated young cichlids may additionally use familiar habitat landmark cues (Wisenden \& Dye 2009), if they are still within their parents' territory, to home back to their family unit, as other fishes can recognize chemical habitat cues when forming preferential social associations with conspecifics (Ward et al. 2005) and parental spiders in locating their nest and young (Morse 1991), for example. In some taxa (e.g. Clutton-Brock 1991; Caro 2005), including substrate-guarding cichlid fishes (Vives 1988; Keenleyside 1991b), stray 
mobile young that do not return to their family unit on their own may be retrieved by a parent.

The current study demonstrated for the first time, using the convict cichlid as a model system, that the likelihood of stray dependent young returning to their family is a negative non-linear function of separation distance, and that it can be mediated by the individual's body size or developmental stage/age. Stray young that do not promptly find their way back to their family unit or are not retrieved by a parent undoubtedly face a much greater risk of predation than otherwise. Seeking refuge by these vulnerable stray young should mitigate their immediate risk of predation, but at the cost of lost foraging opportunities and growth (Lima \& Dill 1990; Godin 1997); the current study showed that the likelihood of refuging increases with increasing separation distance between the displaced young and its family and can also be mediated by body size or developmental stage/age. As an alternative antipredator strategy, stray young may opportunistically join another nearby family if encountered and if accepted by the attending parental adult(s). The latter joining behaviour of stray young may be one of the mechanisms underlying the phenomenon of brood mixing, and associated alloparental care, in wild brood-guarding cichlid fishes (Keeleyside 1991), including the convict cichlid (Lee-Jenkins et al. 2011, Chapter 8), and in other taxa (e.g. Riedman 1982; Codenotti \& Alvarez 1998). Additional field research on the ecological conditions (e.g. local population density, predation intensity, habitat complexity) leading to the separation of dependent young from their guarding parents and their fate whilst separated should prove fruitful in contributing to 
our further understanding of parent-young interactions, survival rate of separated young, brood mixing and alloparental care in particular.

\section{ACKNOWLEDGEMENTS}

I would like to give my extreme thanks to Sarah Jeswiet for all of her valuable assistance in the field and to Brian Wisenden for his logistical suggestions. Emily Standen and Jeff Dawson kindly allowed me to borrow their large glass tank for my laboratory trials and Tom Hossie was most helpful with the Cox proportional hazards models in R. I would also like to thank Rebecca Warmington and Patrick Barks for all their help with the maintenance of the cichlid breeding pairs in our aquatics lab. 


\section{CHAPTER 11}

\section{Part II -Discussion}

Early life associations in Convict Cichlids 


\section{GENERAL DISCUSSION - PART II}

\section{Summary of Findings}

In Chapter 8, I found that most (78\%) convict cichlid broods in the Rio Cabuyo, Costa were mixed genetically, indicating that convict cichlid fry were commonly interacting with both kin and nonkin within a given brood. This finding also represents the first genetic evidence for alloparental care of young in the convict cichlid. Mixed broods varied in the extent of mixing, with some broods containing a few apparent 'stray' fry whereas others contained a number of foreign fry sibsets. Host and foreign fry within broods were of similar body length on average, suggesting that foreign fry similar in size to their own young were accepted by the attending parental adults into their brood. Moreover, potential extra-pair copulations were identified in $26 \%$ of the broods, which is a novel finding for this socially monogamous species. How extra-pair matings occur in this highly territorial species (during breeding season) remains unknown and should be addressed in future research.

In Chapter 9, I demonstrated that the body size of convict cichlid young influenced their shoal-mate preference; larger fry $(\geq 8 \mathrm{~mm})$ preferred to shoal with familiar kin, whereas smaller fry exhibited no preference. This size-dependent shoaling preference is potentially due to the differences in the swimming abilities of small fry $(<8$ $\mathrm{mm}$ in length) compared to larger ones, which can affect the frequency and nature of their social interactions among conspecifics during early ontogeny (Fuiman \& Magurran 1994). 
In Chapter 10, I showed experimentally, in both the laboratory and field, that the likelihood of a fry separated from its family unit returning successfully to it declined with increasing separation distance. Moreover, smaller fry that were separated from their family were more likely to be eaten by predators than to refuge, and larger fry were more likely to refuge than to return, in their natural habitat. This novel finding suggests that convict cichlid fry of different size or developmental stage have differing risk-assessment strategies or abilities (whilst under parental care).

The mechanisms underlying the phenomenon of brood mixing in the convict cichlid remain unknown. The results of my studies here shed some light on putative brood-mixing mechanisms. Given that wild broods are mobile and can be within $1.5 \mathrm{~m}$ of each other at the height of the breeding season in Costa Rica (Wisenden \& Keenleyside 1992), it is quite likely that broods will occasional encounter one another and potentially mix inadvertently. One possible explanation for the occurrence of 'stray fry' in mixed broods is that these fry became separated from their home brood and lost or hid in leaf litter on the substratum whilst the brood moved further away, and subsequently joined a nearby brood that appeared in their visual field to reduce their risk of predation. Such separation from the family unit could occur during predation events/encounters, during which fry from a brood sometime scatter in multiple directions when the brood is attacked and whilst parents chase the predator(s) away (personal observations in the Rio Cabuyo). As a consequence, dispersed fry that do not return to their family may join or be actively recruited by other adults into their own brood, leading to the occurrence of 'stray' fry within mixed broods. In Chapter 10, I experimentally demonstrated that when 
individual fry were released $80 \mathrm{~cm}$ from their home brood, none of the fry returned to their brood, suggesting that it would advantageous for a separated or lost fry to shoal with any nearby brood to avoid predation.

Results from Chapter 9 indicate that, at $\geq 8 \mathrm{~mm}$ in body length, the majority of fry prefer to associate with socially familiar siblings (kin), which could be important for maintaining the integrity of the brood. As fry grow and become more mobile, the diameter of the brood gradually increases and reaches a maximum when fry are approximately $8 \mathrm{~mm}$ in body length (B.D. Wisenden, unpublished data). When two broods meet or are disturbed in close proximity to one another, the particular brood/shoal preference of fry could affect the outcome of successfully rejoining a brood and the composition of any resultant mixed brood. If most (larger) fry prefer to associate with familiar kin in the wild, then they will likely stay with their own brood (of siblings) and regroup quickly following a predator attack. Smaller fish, which exhibited no particular social association preference, may scatter randomly to nearby broods. In circumstances when a subset of familiar kin becomes separated from their siblings and parents, they may end up joining (through mixing or active parental recruiting) another brood. Alternatively, the occurrence of foreign fry sibsets within some broods could be the result of some fry being 'farmed out' to other broods by their parents or subsets of fry being 'kidnapped' from their family by other parental cichlids (Wisenden 1999).

It is also possible that some fry may have been attracted to neighbouring broods, resulting in brood-mixing events. For the larger focal fish used in Chapter 9, unfamiliar non-kin (UFNK) was the second most preferred group, and the smaller fry demonstrated 
a slight preference for unfamiliar shoals and a decreased amount of time spent with FK. This stimulus shoal type (UNK) represents the most 'novel' one of the four stimulus shoals presented to focal fry, as it contains conspecifics that are both unfamiliar and unrelated and is the opposite of the most preferred stimulus shoal (FK). This observation could explain the observed cases where 'stray' foreign fry occur within a brood in nature, as these fry possibly wandered towards and joined a novel UFNK shoal or brood.

\section{Limitations and Future Directions}

One limitation of my genetic data set is that I could not obtain genetic samples of the parents of the broods collected. While this does not affect my results on the prevalence of brood mixing in the Rio Cabuyo population, it does pose some difficulty in validating the putative occurrence of extra-pair copulations in this population and the analysis of body size of host versus foreign young. My assumption that host fry will always comprise the largest proportion of the brood may not necessarily always hold true. Broods with larger fry will likely be smaller in membership number due to predation events throughout the extended parental care period in the convict cichlid. Parents may then choose to adopt or accept smaller fry in a larger number than their own fry to increase the size of their brood, thereby potentially diluting the risk of predation on their own young. Thus, to further understand the ecology of mixed broods and the mechanisms of brood mixing events in the convict cichlid, it would be ideal to track wild broods throughout the entire parental care period and, if possible, to tag newly emerged freeswimming young and quantify their movements and encounters with other fry in the wild. 
A further avenue of research would be to confirm whether parents can recognize their own offspring so as to shed light on whether brood-mixing events could possibly be due to active adoptions or acceptance of foreign young by parents or to misidentification of young. Future studies could also examine the cohesiveness of mixed versus unmixed broods at different stages of development. I would predict that, at any given stage of development, mixed broods would be less cohesive, and consequently could be more vulnerable to predation (cf. Krause \& Ruxton 2002), compared to unmixed broods on average. Furthermore, the degree of 'mixing' within a brood could have implications for its internal structure, the transmission of social information throughout the brood, and individual predation risk.

In conclusion, my findings in this second thesis section collectively contribute to a greater understanding of brood-mixing events and social associations in young convict cichlids under parental care, and provide fruitful avenues for future research on the behavioural ecology of social associations in this and other species. 


\section{CHAPTER 12}

Thesis General Conclusions 


\section{THESIS GENERAL CONCLUSIONS}

My thesis research results provide some novel insights and approaches towards understanding the behavioural ecology of animal social associations in nature. Using complementary laboratory and field studies in Part I, I established that social familiarity does play a role in social group formation in the banded killifish and that killifish apparently form social cliques of individuals (that repeatedly interact with each other) in nature. In a future research program, I would next investigate the potential consequences of such 'clique' associations in the field. For example, how information about the habitat (for example about a high-quality food patch) and how contagious parasites/disease spread through the social network are ecologically important phenomena that require further attention. I would also manipulate the structure of killifish social networks (e.g. by removing larger individuals who have high betweenness values) to investigate how this affects social structure and potential information transfer among network members. Moreover, network structure may have larger implications for decision making within animal groups; for example are collective group decisions made by consensus or are cliques of individuals controlling or 'leading' groups (Conradt \& List 2009; Kerth 2010). Lastly, as previously mentioned, I would work on improving network data collection techniques by gathering nearest-neighbour data rather than more general gambit-of-thegroup data to obtain greater resolution in the analysis of social networks.

In the second part of my thesis, I established using microsatellite genotyping that convict cichlids exhibit a high prevalence of alloparental care and that, regardless of brood mixing, young at later stages of parental care prefer to socially associate with 
familiar kin (at least in the laboratory). I also demonstrated that mobile young at different stages of development exhibit different risk-assessment behaviours when separated from their parents.

Some of my investigative approaches and several of my results are novel. I optimized and applied for the first time microsatellite genetic markers to investigate behaviour in the convict cichlid, a long-standing important model species for animal behavioural studies. By experimentally disentangling the potential effects of social familiarity and kinship using a four-way choice apparatus, I demonstrated that a preference for familiars and kin is not orthogonal and that these two factors appear to be interacting in a more complicated way than hitherto known. While previous studies have examined the influence of social familiarity and kinship on social associations in animals (e.g. Frommen \& Bakker 2004; Frommen et al. 2007b; Le Vin et al. 2010), the effects of kinship and familiarity studies have either been confounded or their results are potentially misleading because of inherent biases in the choice of stimulus shoal pairings in binary designs (Frommen \& Bakker 2004; Frommen et al. 2007b). In future studies, I would examine more closely the variation in social preferences for FK and UFNK in older $(\geq 8$ $\mathrm{mm}$ ) fry in relation to behavioural 'personality' types. For example, it could be that shyer fish prefer FK and bolder ones prefer UFNK, which would generate a preference pattern similar to the one reported in Chapter 9. Croft et al. (2009) demonstrated that in a guppy social network, shy fish formed stronger social connections than bolder individuals; if this was similarly the case for convict cichlid young, then shy individuals could have stronger preferences for FK than bolder conspecifics. 
In conclusion, my main thesis findings advance our understanding of social associations based on familiarity and kinship, and of the interesting phenomena of brood mixing and alloparental care, in group-living animals. Moreover, my thesis places the context of social associations of individuals within the species' life history, and demonstrated the importance of considering key developmental stages of animals in understanding observed social association patterns. Collectively, my findings more broadly and generally contribute to further understanding the ontogeny of social behaviour, the structures of fission-fusion groups, and the fitness advantages and evolutionary consequences of preferentially associating with familiar individuals in fishes in particular and animals in general. 


\section{REFERENCES}

Alemadi, S.D. \& Wisenden, B.D. 2002. Antipredator response to injury-released chemical alarm cues by convict cichlid young before and after independence from parental protection. Behaviour, 139, 603-611.

Alexander, R.D. 1974. The evolution of social behavior. Annual Review of Ecology and Systematics, 5, 325-383.

Alonzo, J., McKaye, K.R. \& van den Berghe, E. 2001. Parental defense of young by the convict cichlid, Archocentrus nigrofasciatus, in Lake Xiloa, Nicaragua. Journal of Aquariculture and Aquatic Sciences, 9, 208-228.

Andersson, B.Y.M., Wiklund, C.G. \& Rundgren, H. 1980. Parental defence of offspring: a model and an example. Animal Behaviour, 28, 536-542.

Arnold, S. \& Wassersug, R. 1978. Differential predation on metamorphic anurans by garter snakes (Thamnophis): social behavior as a possible defense. Ecology, $\mathbf{5 9}$, 1014-1022.

Ashley, M.V., Caballero, I.C., Chaovalitwongse, W., Dasgupta, B., Govindan, P., Sheikh, S.I. \& Berger-Wolf, T.Y. 2009. KINALYZER, a computer program for reconstructing sibling groups. Molecular Ecology Resources, 9, 1127-1131.

Baerends, G.P. \& Baerends-Van Roon, J.M. 1950. An introduction to the study of the ethology of cichlid fishes. Behaviour, 1, 1-243.

Barber, I. \& Wright, H.A. 2001. How strong are familiarity preferences in shoaling fish? Animal Behaviour, 61, 975-979. 
Barbosa, P. \& Castellanos, I. 2005. Ecology of Predator-Prey Interactions. Oxford: Oxford University Press.

Barlow, G.W. 2000. The Cichlid Fishes: Nature 's Grand Experiment in Evolution. Cambridge: Perseus Books.

Bates, D.M. \& Maechler, M. 2009. Ime4: Linear mixed-effects models using S4 classes. $R$ package version $0.999375-32$.

Bateson, M. 2004. Mechanisms of decision-making and interpretation of choice tests. Animal Welfare, 13, S115-S120.

Berger-Wolf, T.Y., Sheikh, S.I, DasGupta, B., Ashley, M.V., Caballero, I.C., Chaovalitwongse, W. \& Putrevu, S.L. 2007. Reconstructing sibling relationships in wild populations. Bioinformatics, $23,49-56$.

Bhat, A. \& Magurran, A.E. 2006. Benefits of familiarity persist after prolonged isolation in guppies. Journal of Fish Biology, 68, 759-766.

Blomqvist, D., Johansson, O.C. \& Götmark, F.B. 1997. Parental quality and egg size affect chick survival in a precocial bird, the lapwing Vanellus vanellus. Oecologia, 110, 18-24.

Blumstein, D.T. \& Daniel, J.C. 2007. Quantifying Behavior the JWatcher Way. Sunderland, Massachusetts: Sinauer Associates.

Blumstein, D.T., Daniel, J.C. \& Evans, C.S. 2006. JWatcher 1.0. Available from http:// www.jwatcher.ucla.edu

Borgatti, S.P. 2002. NetDraw: Graph Visualization Software. Harvard: Analytic Technologies 
Borgatti, S.P., Everett, M.G. \& Freeman, L.C. 2002. Ucinet for Windows: Software for Social Network Analysis. Harvard, MA: Analytic Technologies.

Boyd, S.K., \& Blaustein, A.R. 1985. Familiarity and inbreeding avoidance in the graytailed vole (Microtus canicaudus). Journal of Mammalogy, 66, 348-352.

Brown, C. 2002. Do female rainbowfish (Melanotaenia spp.) prefer to shoal with familiar individuals under predation pressure? Journal of Ethology, 20, 89-94.

Brown, G.E. 2003. Learning about danger: chemical alarm cues and local risk assessment in prey fishes. Fish and Fisheries, 4, 227-234.

Brown, G.E., Bongiorno, T., DiCapua, D.M., Ivan, L.I. \& Roh, E. 2006. Effects of group size on the threat-sensitive response to varying concentrations of chemical alarm cues by juvenile convict cichlids. Canadian Journal of Zoology, 84, 1-8.

Brown, G.E. \& Smith, R.J.F. 1994. Fathead minnows use chemical cues to discriminate natural shoalmates from unfamiliar conspecifics. Journal of Chemical Ecology, 20, 3051-3061.

Brown, J. A. 1985. The adaptive significance of behavioural ontogeny in some centrarchid fishes. Environmental Biology of Fishes, 13, 25-34.

Brown, J.A. \& Colgan, P.W. 1986. Individual and species recognition in centrarchid fishes - evidence and hypotheses. Behavioral Ecology and Sociobiology, 19, 373379.

Brown, K. 1998. Proximate and ultimate causes of adoption in ring-billed gulls. Animal Behaviour, 56, 1529-1543. 
Caro, T. 2005. Antipredator defenses in birds and mammals. Chicago: University of Chicago Press.

Chivers, D.P., Brown G.E. \& Smith, R.J.F. 1995. Familiarity and shoal cohesion in fathead minnows (Pimephales promelas): implications for antipredator behaviour. Canadian Journal of Zoology, 73, 955-960.

Clarke, A. \& Johnston, N.M. 1999. Scaling of metabolic rate with body mass and temperature in teleost fish. Journal of Animal Ecology, 68, 893-905.

Clutton-Brock, T.H. 1991. The Evolution of Parental Care. Princeton: Princeton University Press.

Codenotti, T.L. \& Alvarez, F. 1998. Adoption of unrelated young by greater theas. Journal of Ornithology, 69, 58-65.

Coffin, H.R., Watters, J.V. \& Mateo, J.M. 2011. Odor-based recognition of familiar and related conspecifics: a first test conducted on captive Humboldt penguins (Spheniscus humboldti). PLoS One, 6, e25002.

Conradt, L. \& List, C. 2009. Group decisions in humans and animals: a survey. Philosophical Transactions of the Royal Society of London B, 364, 719-42.

Coolen, I., van Bergen, Y., Day, R.L. \& Laland, K.N. 2003. Species differences in adaptive use of public information in sticklebacks. Proceedings of the Royal Society of London B, 270, 2413-2419.

Côté, I.M. \& Poulin, R. 1995. Parasitism and group size in social animals: a metaanalysis. Behavioral Ecology, 6, 159-165. 
Croft, D.P., James, R. \& Krause, J. 2008. Exploring Animal Social Networks. Princeton: Princeton University Press.

Croft, D.P., James, R., Thomas, P.O.R., Hathaway, C., Mawdsley, D., Laland, K.N. \& Krause, J. 2006. Social structure and co-operative interactions in a wild population of guppies (Poecilia reticulata). Behavioral Ecology and Sociobiology, 59, 644-650.

Croft, D.P., James, R., Ward, A.J.W., Botham, M.S., Mawdsley, D. \& Krause, J. 2005a. Assortative interactions and social networks in fish. Oecologia, 143, 211 219.

Croft, D.P., Krause, J., Couzin, I.D. \& Pitcher, T.J. 2003. When fish shoals meet: outcomes for evolution and fisheries. Fish and Fisheries, 4, 138-146.

Croft, D.P., Krause, J. \& Darden, S.K. 2009. Behavioural trait assortment in a social network: patterns and implications. Behavioral Ecology and Sociobiology, 63, $1495-1503$.

Croft, D.P., Krause, J. \& James, R. 2004. Social networks in the guppy (Poecilia reticulata). Proceedings of the Royal Society of London B, 271, S516-9.

Croft, D.P., Krause, J. \& James, R. 2005b. Predation risk as a driving factor for size assortative shoaling and its implications for sexual segregation in fish. In: Sexual Segregation in Vertebrates: ecology of the two sexes (Ed. by K.E. Ruckstuhl and P. Neuhaus), pp 115-126. Cambridge: Cambridge University Press.

Croft, D.P., Madden, J.R., Franks, D.W. \& James, R. 2011. Hypothesis testing in animal social networks. Trends in Ecology \& Evolution, 26, 502-507. 
Dall, S.R.X., Giraldeau, L.-A., Olsson, O., McNamara, J.M. \& Stephens, D.W. 2005. Information and its use by animals in evolutionary ecology. Trends in Ecology and Evolution, 20, 187-193.

Dewey, M.R. \& Zigler, S.J. 1996. An evaluation of fluorescent elastomer for marking bluegills in experimental studies. Progressive Fish-Culturist, 58, 219-220.

Dingemanse, N.J., Both, A.J., van Noordwijk, A.J., Rutten, A.J. \& Drent, P.J. 2003. Natal dispersal and personalities in great tits (Parus major). Proceedings of the Royal Society London B, 270, 741-747.

Dugatkin, L.A. 1991. Dynamics of the TIT-FOR-TAT strategy during predator inspection in the guppy (Poecilia reticulata). Behavioral Ecology and Sociobiology, 29, 127-132.

Dugatkin, L.A. 1997. The evolution of cooperation. Bioscience, 47, 355-362.

Dugatkin, L.A. \& Alfieri, M. 1991a. Guppies and the tit-for-tat strategy - preference based on past interaction. Behavioral Ecology and Sociobiology, 28, 243-246.

Dugatkin, L.A. \& Alfieri, M. 1991 b. Tit-For-Tat in guppies (Poecilia reticulata): the relative nature of cooperation and defection during predator inspection. Evolutionary Ecology, 5, 300-309.

Dugatkin, L.A. \& Godin, J.-G.J. 1992. Predator inspection, shoaling and foraging under predation hazard in the Trinidadian guppy, Poecilia reticulata. Environmental Biology of Fishes, 34, 265-276. 
Dugatkin, L.A. \& Mesterton-Gibbons, M. 1996. Cooperation among unrelated individuals: reciprocal altruism, by-product mutualism and group selection in fishes. Biosystems, 37, 19-30.

Dugatkin, L.A. \& Wilson, D.S. 1992. The prerequisites for strategic behaviour in bluegill sunfish, Lepomis macrochirus. Animal Behaviour, 44, 223-230.

Dugatkin, L.A. \& Wilson, D.S. 1993. Fish behavior, partner choice experiments and cognitive ethology. Reviews in Fish Biology and Fisheries, 3, 368-372.

Eadie, J.M., Kehoe, F.P. \& Nudds, T.D. 1988. Pre-hatch and post-hatch brood amalgamation in North American Anatidae: a review of hypotheses. Canadian Journal of Zoology, 66, 1709-1721.

Faircloth, B.C., Palmer, W.E., \& Carroll, J.P. 2005. Post-hatching brood amalgamation in Northern Bobwhites. Journal of Field Ornithology, 76, 175-182.

Farmer, N.A., Ribble, D.O. \& Miller, D.G. 2004. Influence of familiarity on shoaling behaviour in Texas and blacktail shiners. Journal of Fish Biology, 64, 776-782.

Fitzgibbon, C.D. 1990. Anti-predator strategies of immature Thomson's gazelles: hiding and the prone response. Animal Behaviour, 40, 846-855.

Forstmeier, W. \& Birkhead, T.R. 2004. Repeatability of mate choice in the zebra finch: consistency within and between females. Animal Behaviour, 68, 1017-1028.

Foster, S.A. 1985. Group foraging by a coral reef fish: a mechanism for gaining access to defended resources. Animal Behaviour, 33, 782-792.

Fraker, M.E. 2008. The dynamics of predation risk assessment: responses of anuran larvae to chemical cues of predators. Journal of Animal Ecology, 77, 638-45. 
Franks, D.W., Ruxton, G.D. \& James, R. 2010. Sampling animal association networks with the gambit of the group. Behavioral Ecology and Sociobiology, 64, 493-503.

Fraser, S. A. 1996. The influence of predators on adoption behaviour in adult convict cichlids (Cichlasoma nigrofasciatum). Canadian Journal of Zoology, 173, $1165-$ 1173.

Fraser, S.A. \& Keenleyside, M.H.A. 1995. Why are larger convict cichlid (Cichlasoma nigrofasciatum) fry sometimes adopted into broods of smaller fry? Behavioral Ecology and Sociobiology, 37, 343-347.

Fraser, S.A., Wisenden, B.D. \& Keenleyside, M.H.A. 1993. Aggressive behaviour among convict cichlid (Cichlasoma nigrofasciatum) fry of different sizes and its importance to brood adoption. Canadian Journal of Zoology, 71, 2358-2362.

Frommen, J.G. \& Bakker, T.C.M. 2004. Adult three-spined sticklebacks prefer to shoal with familiar kin. Behaviour, 141, 1401-1409.

Frommen, J.G., Luz, C. \& Bakker, T.C.M. 2007b. Kin discrimination in sticklebacks is mediated by social learning rather than innate recognition. Ethology, 113, 276282.

Frommen, J.G., Luz, C. \& Bakker, T.C.M. 2007a. Nutritional state influences shoaling preference for familiars. Zoology, 110, 369-376.

Frommen, J.G., Mehlis, M., Brendler, C. \& Bakker, T.C.M. 2007c. Shoaling decisions in three-spined sticklebacks (Gasterosteus aculeatus) - familiarity, kinship and inbreeding. Behavioral Ecology and Sociobiology, 61, 533-539. 
Fuiman, L.A. \& Magurran, A.E. 1994. Development of predator defences in fishes. Reviews in Fish Biology and Fisheries, 4, 145-183.

Gerlach, G., Hodgins-Davis, A., Avolio, C. \& Schunter, C. 2008. Kin recognition in zebrafish: a 24-hour window for olfactory imprinting. Proceedings of the Royal Society of London $B, 275,2165-2170$.

Gerlach, G., Hodgins-Davis, A., MacDonald, B. \& Hannah, R.C. 2007. Benefits of kin association: related and familiar zebrafish larvae (Danio rerio) show improved growth. Behavioral Ecology and Sociobiology, 61, 1765-1770.

Gerlach, G. \& Lysiak, N. 2006. Kin recognition and inbreeding avoidance in zebrafish, Danio rerio, is based on phenotype matching. Animal Behaviour, 71, 1371-1377.

Giraldeau, L.-A., Valone, T.J. \& Templeton, J.J. 2002. Potential disadvantages of using socially acquired information. Proceedings of the Royal Society of London $B, 357,1559-1566$.

Godin, J.-G.J. 1986. Antipredator function of shoaling in teleost fishes: a selective review. Le Naturaliste Canadien, 113, 241-250.

Godin, J.-G.J. 1997. Evading predators. In: Behavioural Ecology of Teleost Fishes (Ed. by J.-G.J. Godin), pp. 191-236. Oxford: Oxford University Press.

Godin, J.-G.J., Alfieri, M.S., Hoare, D.J. \& Sadowski, J.A. 2003. Conspecific familiarity and shoaling preferences in a wild guppy population. Canadian Journal of Zoology, 81, 1899-1904. 
Godin, J.-G.J. \& Morgan, M.J. 1985. Predator avoidance and school size in a cyprinodontid fish, the banded killifish (Fundulus diaphanus Lesueur). Behavioral Ecology and Sociobiology, 16, 105-110.

Gómez-Laplaza, L.M. \& Fuente, A. 2007. Shoaling decisions in angelfish: the roles of social status and familiarity. Ethology, 113, 847-855.

Grant, J.W.A. \& Guha, R.T. 1993. Spatial clumping of food increases its monopolization and defense by convict cichlids, Cichlasoma nigrofasciatum. Behavioral Ecology, 4, 293-296.

Griffin, A.S., Blumstein, D.T. \& Evans, C.S. 2000. Training captive-bred or translocated animals to avoid predators. Conservation Biology, 14, 1317-1326.

Griffiths, S.W. 2003. Learned recognition of conspecifics by fishes. Fish and Fisheries, $4,256-268$.

Griffiths, S.W. \& Armstrong, J.D. 2001. The benefits of genetic diversity outweigh those of kin association in a territorial animal. Proceedings of the Royal Society of London $B, 268,1293-6$.

Griffiths, S.W., Brockmark, S., Höjesjö, J. \& Johnsson, J.I. 2004. Coping with divided attention: the advantage of familiarity. Proceedings of the Royal Society of London B, 271, 695-699.

Griffiths, S.W. \& Magurran, A.E. 1997a. Familiarity in schooling fish: How long does it take to acquire? Animal Behaviour, 53, 945-949. 
Griffiths, S.W. \& Magurran, A.E. 1997b. Schooling preferences for familiar fish vary with group size in a wild guppy population. Proceedings of the Royal Society of London B, 264, 547-551.

Griffiths, S.W. \& Magurran, A.E. 1998. Sex and schooling behaviour in the Trinidadian guppy. Animal Behaviour, 56, 689-693.

Griffiths, S.W. \& Magurran, A.E. 1999. Schooling decisions in guppies (Poecilia reticulata) are based on familiarity rather than kin recognition by phenotype matching. Behavioral Ecology and Sociobiology, 45, 437-443.

Griffiths, S.W., Ojanguren, A.F., Orpwood, J.E., Magurran, A.E. \& Armstrong, J.D. 2007. Familiarity-biased patterns of association shift with time among European minnows. Journal of Fish Biology, 71, 1602-1612.

Griffiths, S.W. \& Ward, A. 2006. Learned recognition of conspecifics. In: Fish Cognition and Behavior (Ed. by C. Brown, K. Laland \& J. Krause), pp 139-165. Oxford: Blackwell Publishing.

Hain, T.J.A. \& Neff, B.D. 2006. Promiscuity drives self-referent kin recognition. Current Biology, 16, 1807-1811.

Hamilton, W.D. 1964. Genetical evolution of social behaviour I, II. Journal of Theoretical Biology, 7, 1-52.

Hay, T. 1978. Filial imprinting in convict cichlid fish Cichlasoma nigrafasciatum. Behaviour, 65, 138-160. 
Hensor, E.M.A., Godin, J.-G.J., Hoare, D.J. \& Krause, J. 2003. Effects of nutritional state on the shoaling trendency of banded killifish, Fundulus diaphanous, in the field. Animal Behaviour, 65, 663-669.

Hinde, R.A. 1976. Interactions, relationships and social structure. Man, 11, 1-17.

Hoare, D.J., Couzin, I.D., Godin, J.-G.J. \& Krause, J. 2004. Context-dependent group size choice in fish. Animal Behaviour, 67, 155-164.

Hoare, D.J. \& Krause, J. 2003. Social organisation, shoal structure and information transfer. Fish and Fisheries 4, 269-279.

Hoare, D.J., Krause, J., Peuhkuri, N. \& Godin, J.-G.J. 2000b. Body size and shoaling in fish. Journal of Fish Biology, 57, 1351-1366.

Hoare, D.J., Ruxton, G.D., Godin, J.-G.J. \& Krause, J. 2000a. The social organization of free-ranging fish shoals. Oikos, 89, 546-554.

Höjesjö, J., Johnsson, J.I., Petersson, E. \& Jarvi, T. 1998. The importance of being familiar: individual recognition and social behavior in sea trout (Salmo trutta). Behavioral Ecology, 9, 445-451.

Holmes, W.G. 1995. The ontogeny of littermate preferences in juvenile golden-mantled ground squirrels: effects of rearing and relatedness. Animal Behaviour, 50, 309322.

Houston, J. 1990. Status of the banded killifish, Fundulus diaphanus, in Canada. Canadian Field-Naturalist, 104, 45-52. 
Hughes, K., Du, L., Rodd, F. \& Reznick, D. 1999. Familiarity leads to female mate preference for novel males in the guppy, Poecilia reticulata. Animal Behaviour, $58,907-916$.

Jarman, P.J. 1974. The social organisation of antelope in relation to their ecology. Behaviour, 48, 215-267.

Johnson, C.A., Frywell, J.M., Thompson, I.D. \& Baker, J.A. 2009. Mortality risk increases with natal dispersal distances in American martens. Proceedings of the Royal Society of London B, 276, 3361-3367.

Johnsson, J.I. 2003. Group size influences foraging effort independent of predation risk: an experimental study on rainbow trout. Journal of Fish Biology, 63, 863-870.

Kalmbach, E. 2006. Why do goose parents adopt unrelated goslings? A review of hypotheses and empirical evidence, and new research questions. Ibis, 148, 66-78.

Keenleyside, M.H.A. 1985. Bigamy and mate choice in the biparental cichlid fish Cichlasoma nigrofasciatum. Behavioral Ecology and Sociobiology, 17, 285-290.

Keenleyside, M.H.A. (ed.) 1991a. Cichlid Fishes: Behavior, Ecology and Evolution. New York: Chapman and Hall.

Keenleyside, M.H.A. 1991b. Parental care. In: Cichlid Fishes: behavior, ecology and eolution (Edited by M.H.A. Keenleyside), pp. 191-208. New York: Chapman and Hall.

Keenleyside, M.H.A., Bailey, R.C., \& Young, V.H. 1990. Variation in the mating system and associated parental behaviour of captive and free-living Cichlasoma nigrofasciatum (Pisces, Cichlidae). Behaviour, 112, 202-221. 
Kelley, J.L., Graves, J.A. \& Magurran, A.E. 1999. Familiarity breeds contempt in guppies. Nature, 401, 661-662.

Kelley, J.L. \& Magurran, A.E. 2003. Learned predator recognition and antipredator responses in fishes. Fish and Fisheries, 4, 216-226.

Kelley, J.L., Morrell, L.J., Inskip, C., Krause, J. \& Croft, D. P. 2011. Predation risk shapes social networks in fission-fusion populations. PLOS ONE, 6, e24280.

Kellogg, K.A., Markert, J.A., Stauffer, J.R. \& Kocher, T.D. 1995. Microsatellite variation demonstrates multiple paternity in lekking cichlid fishes from Lake Malawi, Africa. Proceedings of the Royal Society of London B, 260, 79-84.

Kerth, G. 2010. Group decision-making in fission-fusion societies. Behavioural Processes, 84, 662-663.

Komdeur, J. \& Hatchwell, B.J. 1999. Kin recognition: function and mechanism in avian societies. Trends in Ecology and Evolution, 14, 237-241.

Krause, J. 1994. Differential fitness returns in relation to spatial position in groups. Biological Reviews, 69, 187-206.

Krause, J., Butlin, R.K., Peuhkuri, N. \& Pritchard, V.L. 2000. The social organization of fish shoals: a test of the predictive power of laboratory experiments for the field. Biological Reviews, 75, 477-501.

Krause, J., Croft, D.P. \& James, R. 2007. Social network theory in the behavioural sciences: potential applications. Behavioural Ecology and Sociobiology, 62, 15 27. 
Krause, J. \& Godin, J.-G.J. 1994a. Shoal choice in the banded killifish (Fundulus diaphanus, Teleostei, Cyprinodontidae): effects of predation risk, fish size, species composition and size of shoals. Ethology, 98, 128-136.

Krause, J. \& Godin, J.-G.J. 1994b. Influence of parasitism on the shoaling behaviour of banded killifish, Fundulus diaphanus. Canadian Journal of Zoology, 72, 17751779.

Krause, J. \& Godin, J.-G.J. 1996. Influence of parasitism on shoal choice in the banded killifish (Fundulus diaphanus, Teleostei, Cyprinodontidae). Ethology, 102, 40-49.

Krause, J., Godin, J.-G.J. \& Brown, D. 1996a. Size-assortativeness in multi-species fish shoals. Journal of Fish Biology, 49, 221-225.

Krause, J., Godin, J.-G.J. \& Brown, D. 1996b. Phenotypic variability within and between fish shoals. Ecology, 77, 1586-1591.

Krause, J., Godin, J.-G.J. \& Rubenstein, D. 1998. Group choice as a function of group size differences and assessment time in fish: The influence of species vulnerability to predation. Ethology, 104, 68-74.

Krause, J., Hoare, D.J., Croft, D., Lawrence, J., Ward, A., Ruxton, G. D., Godin, J.G.J. \& James, R. 2000. Fish shoal composition: mechanisms and constraints. Proceedings of the Royal Society of London B, 267, 2011-7.

Krause, J., James, R. \& Croft, D.P. 2010. Personality in the context of social networks. Philosophical Transactions of the Royal Society B, 365, 4099-4106.

Krause, J. \& Ruxton, G.D. 2002. Living in Groups. Oxford: Oxford University Press. 
Krause, J., Ruxton, G.D. \& Godin, J.-G.J. 1999. Distribution of Crassiphiala bulboglossa, a parasitic worm, in shoaling fish. Journal of Animal Ecology, 68, $27-33$.

Krause, J., Wilson, A.D.M. \& Croft, D.P. 2011. New technology facilitates the study of social networks. Trends in Ecology and Evolution, 26, 5-6.

Kullberg, C. \& Lind, J. 2002. An experimental study of predator recognition in great tit fledglings. Ethology, 108, 429-441.

Lachlan, R.F., Crooks, L. \& Laland, K.N. 1998. Who follows whom? Shoaling preferences and social learning of foraging information in guppies. Animal Behaviour, 56, 181-190.

Laland, K.N. \& Williams, K. 1997. Shoaling generates social learning of foraging information in guppies. Animal Behaviour, 53, 1161-1169.

Landeau, L. \& Terborgh, J. 1986. Oddity and the 'confusion effect' in predation. Animal Behaviour, 34, 1372-1380.

Lavery, R.J., Mackereth, R.W., Robilliard, D.R.C. \& Keenleyside, M.H.A. 1990. Factors determining parental preference of convict cichlid fry, Cichlasoma nigrofasciatum (Pisces: Cichlidae). Animal Behaviour, 39, 573-581.

Lee-Jenkins, S.S.Y., Densmore, A.M., Godin J.-G.J. \& Smith, M.L. 2011. Polymorphic microsatellite loci optimised for studies on the convict cichlid fish (Amatitlania siquia). Environmental Biology of Fishes, 92, 261-266.

Lee-Jenkins, S.S.Y. \& Godin, J.-G. J. 2010. Social familiarity and shoal formation in juvenile fishes. Journal of Fish Biology, 76, 580-590. 
Lehmann, J. \& Boesch, C. 2004. To fission or to fusion: effects of community size on wild chimpanzee (Pan troglodytes verus) social organisation. Behavioral Ecology and Sociobiology, 56, 207-216.

Lehtonen, T. 2008. Convict cichlids benefit from close proximity to another species of cichlid fish. Biology Letters, 4, 610-612.

Le Vin, A.L., Mable, B.K. \& Arnold, K.E. 2010. Kin recognition via phenotype matching in a cooperatively breeding cichlid, Neolamprologus pulcher. Animal Behaviour, 79, 1109-1114.

Liebgold, E.B. \& Cabe, P.R. 2008. Familiarity with adults, but not relatedness, affects the growth of juvenile red-backed salamanders (Plethodon cinereus). Behavioral Ecology and Sociobiology, 63, 277-284.

Lima, S.L. 1998. Stress and decision making under the risk of predation: recent developments from behavioral, reproductive, and ecological perspectives. Advances in the Study of Behavior, 27, 215-290.

Lima, S.L. \& Dill, L.M. 1990. Behavioral decisions made under the risk of predation: a review and prospectus. Canadian Journal of Zoology, 68, 619-640.

Lusseau, D. \& Newman, M.E.J. 2004. Identifying the role that animals play in their social networks. Proceedings of the Royal Society of London B, 271, S477-81.

\section{Lusseau, D., Wilson, B., Hammond, P.S., Grellier, K., Durban, J.W., Parsons, K.M.,} Barton, T.R. \& Thompson, P.M. 2006. Quantifying the influence of sociality on population structure in bottlenose dolphins. Journal of Animal Ecology, 75, 14 24. 
Madden, J.R., Nielsen, J.F. \& Clutton-Brock, T.H. 2012. Do networks of social interactions reflect patterns of kinship? Current Zoology, 58, 319-328.

Magrath, R.D., Haff, T.M., Horn, A.G. \& Leonard, M.L. 2010. Calling in the face of danger: predation risk and acoustic communication by parent birds and their offspring. Advances in the Study of Behavior, 41, 187-253.

Magurran, A.E., Seghers, B.H., Shaw, P.W. \& Carvalho, G.R. 1994. Schooling preferences for familiar fish in the guppy, Poecilia reticulata. Journal of Fish Biology, 45, 401-406.

Mathis, A., Chivers, D.P. \& Smith, R.J.F. 1996. Cultural transmission of predator recognition in fishes: Intraspecific and interspecific learning. Animal Behaviour $51,185-201$.

Martin, K. 1989. Pairing and adoption of offspring by replacement male willow ptarmigan: behaviour, costs and consequences. Animal Behaviour, 37, 569-578.

Mateo, J.M. 2004. Recognition systems and biological organization: The perception component of social recognition. Annales Zoologici Fennici, 41, 729-745.

Mateo, J.M. 2010. Self-referent phenotype matching and long-term maintenance of kin recognition. Animal Behaviour, 80, 929-935.

Matschiner, M. \& Salzburger, W. 2009. TANDEM: integrating automated allele binning into genetics and genomics workflows. Bioinformatics, 25, 1982-1983.

McKaye, K.R. \& McKaye, N. M. 1977. Communal care and kidnapping of young by parental cichlids. Evolution, 31, 674-681. 
McLennan, J.A., Dew, L., Miles, J., Gillingham, N. \& Waiwai, R. 2004. Size matters: predation risk and juvenile growth in North Island brown kiwi (Apteryx mantelli). New Zealand Journal of Ecology, 28, 241-250.

McRobert, S.P. \& Bradner, J. 1998. The influence of body coloration on shoaling preferences in fish. Animal Behaviour, 56, 611-615.

Mehlis, M., Bakker, T.C.M. \& Frommen, J.G. 2008. Smells like sib spirit: kin recognition in three-spined sticklebacks (Gasterosteus aculeatus) is mediated by olfactory cues. Animal Cognition, 11, 643-50.

Michener, G.R. 1981. Ontogeny of spatial relationships and social behaviour in juvenile Richardson's ground squirrels. Canadian Journal of Zoology, 59, 1666-1676.

Möller, L.M., Beheregaray, L.B., Allen, S.J. \& Harcourt, R.G. 2006. Association patterns and kinship in female Indo-Pacific bottlenose dolphins (Tursiops aduncus) of southeastern Australia. Behavioral Ecology and Sociobiology, 61, $109-117$.

Morgan, M.J. \& Godin, J.-G.J. 1985. Antipredator benefits of schooling behaviour in a cyprinodontid fish, the banded killifish (Fundulus diaphanus). Zeitschrift für Tierpsychologie, 70, 236-246.

Morse, D. 1991. Homing by crab spiders Misumena vatia (Araneae, Thomisidae) separated from their nests. Journal of Arachnology, 19, 111-114.

Myrberg Jr., A.A. 1964. An analysis of the preferential care of eggs and young by adult cichlid fishes. Zeitschrift für Tierpsycholgie, 21, 53-98. 
Myrberg, A.A. Jr. 1966. Parental recognition of young in cichlid fishes. Animal Behaviour, 14, 565-71.

Nastase, A.J., \& Sherry, D.A. (1997). Effect of brood mixing on location and survivorship of juvenile Canada geese. Animal Behaviour, 54, 503-507.

Noack, K., Wilson, A.B. \& Meyer, A. 2000. Broad taxonomic applicability of microsatellites developed for the highly polymorphic neotropical cichlid, Amphilophus citrinellum. Animal Genetics, 31, 151-151.

Noakes, D.L.G. \& Godin, J.-G.J. 1988. Ontogeny of behavior and concurrent developmental changes in sensory systems in teleost fishes. In: Fish Physiology, Vol. IIB. (Ed. by W.S. Hoar \& D.J. Randall), pp 345-395. New York: Academic Press.

Noble, G.K. \& Curtis, B. 1939. The social behavior of the jewel fish, Hemichromis bimaculatus Gill. Bulletin of the American Museum of Natural History, 76, 1-46.

Norris, K.S. \& Schilt, C.R. 1988. Cooperative societies in three-dimensional space: on the origins of aggregations, flocks, and schools, with special reference to dolphins and fish. Ethology and Sociobiology, 9, 149-179.

Öst, M., Vitikainen, E., Waldeck, P., Sundström, L. Lindström, K., Hollmén, T., Franson, J.C. \& Klip, M. 2005. Eider females form non-kin brood-rearing coalitions. Molecular Ecology, 14, 3903-3908.

Parrish, J.K. 1989. Reexamining the selfish herd: are central fish safer? Animal Behaviour, 38, 1048-1053. 
Parrish, J.K. \& Edelstein-Keshet, L. 1999. Complexity, pattern, and evolutionary trade-offs in animal aggregation. Science, 284, 99-101.

Payne, R. 1977. The ecology of brood parasitism in birds. Annual Review of Ecology and Systematics, 8, 92-94.

Pitcher, T.J. \& Parrish, J.K. 1993. Functions of shoaling behaviour in teloests. In:

Behaviour of Teleost Fishes, $2^{\text {nd }}$ edn. (Ed. by T.J. Pitcher), pp. 363-439. London: Chapman \& Hall.

Piyapong, C., Butlin, R.K., Faria, J.J., Scruton, K.J., Wang, J. \& Krause, J. 2011.

Kin assortment in juvenile shoals in wild guppy populations. Heredity, 106, 749756.

Ranta, E., Lindström, K. \& Peuhkuri, N. 1992. Size matters when three-spined sticklebacks go to school. Animal Behaviour, 43, 160-162.

R Development Core Team. 2008. R: A language and environment for statistical computing. R Foundation for Statistical Computing, Vienna, Austria. ISBN 3-900051-07-0, URL http://www.R-project.org.

Reddon, A.R. 2012. Parental effects on animal personality. Behavioral Ecology, 23, 242245.

Reddon, A.R. \& Hurd, P.L. 2009. Sex differences in the cerebral lateralization of a cichlid fish when detouring to view emotionally conditioned stimuli. Behavioral Processes, 82, 25-29.

Riedman, M.L. 1982. The evolution of alloparental care and adoption in mammals and birds. Quartely Review of Biology, 57, 405-435. 
Ruckstuhl, K.E. 2007. Sexual segregation in vertebrates: proximate and ultimate causes. Integrative and Comparative Biology, 47, 245-57.

Ruckstuhl, K.E. \& Neuhaus, P. 2005.Sexual Segregation in Vertebrates. Cambridge: Cambridge University Press.

Russell, T., Kelley, L., Graves, A. \& Magurran, E. 2004. Kin structure and shoal composition dynamics in the guppy, Poecilia reticulata. Oikos 106, 520-526.

Rohner, C. \& Krebs, C.J. 1996. Owl predation on snowshoe hares: consequences of antipredator behaviour. Oecologia, 108, 303-310.

Seghers, B.H. 1974. Schooling behavior in guppy (Poecilia reticulata) - evolutionary response to predation. Evolution, 28, 486-489.

Scott, W.B. \& Crossman, E.J. 1973. Freshwater Fishes of Canada. Fisheries Research Board Canada, Bulletin 184, 966pp.

Seppä, T., Laurila, A., Peuhkuri, N., Piironen, J. \& Lower, N. 2001. Early familiarity has fitness consequences for Arctic char (Salvelinus alpinus) juveniles. Canadian Journal of Fisheries and Aquatic Sciences, 58, 1380-1385.

Serrano, D. \& Tella, J.L. 2012. Lifetime fitness consequences of natal dispersal distance in a colonial bird. Journal Animal Ecology, 81, 97-107.

Shaw, E. 1978. Schooling fishes. American Scientist, 66, 166-175.

Simpson, J.W., Yerkes, T.J., Smith, B.D. \& Nudds, T.D. 2005. Mallard duckling survival in the Great Lakes region. The Condor, 107, 898. 
Smith, J., Kolowski, J., Graham, K., Dawes, S. \& Holekamp, K. 2008. Social and ecological determinants of fission-fusion dynamics in the spotted hyaena. Animal Behaviour, 76, 619-636.

Steck, N., Wedekind, C. \& Milinski, M. 1999. No sibling odor preference in juvenile three-spined sticklebacks. Behavioral Ecology, 10, 493-497.

Streelman, J.T. \& Karl, S.A. 1997. Reconstructing labroid evolution with single-copy nuclear DNA. Proceedings of the Royal Society of London B, 264, 1011-1020.

Sueur, C., King, A.J., Conradt, L., Kerth, G., Lusseau, D., Mettke-Hofmann, C., Schaffner, C.M., Williams, L., Zinner, D. \& Aureli, F. 2011. Collective decision-making and fission-fusion dynamics: a conceptual framework. Oikos, $120,1608-1617$.

Swaney, W., Kendal, J., Capon, H., Brown, C. \& Laland, K.N. 2001. Familiarity facilitates social learning of foraging behaviour in the guppy. Animal Behaviour, $62,591-598$.

Tang-Martinez, Z. 2001. The mechanisms of kin discrimination and the evolution of kin recognition in vertebrates: a critical re-evaluation. Behavioural Processes, 53, 2140.

Theodorakis, C.W. 1989. Size segregation and the effect of oddity on predation risk in minnow schools. Animal Behaviour, 38, 496-502.

Thiel, M. 1999. Extended parental care in marine amphipods II. Maternal protection of juveniles from predation. Journal of Experimental Marine Biology and Ecology, 234, 235-253. 
Thünken T., Bakker, T.C.M., Baldauf, S.A. \& Kullmann, H. 2007a. Active inbreeding in a cichlid fish and its adaptive significance. Current Biology, 17, $225-229$.

Thünken, T., Bakker, T.C.M., Baldauf, S.A. \& Kullmann, H. 2007b. Direct familiarity does not alter mating preferences for sisters in male Pelvicachromis taeniatus (Cichlidae). Ethology, 113, 1107-1112.

Trivers, R. 1972. Sexual selection and parental investment. In: Sexual Selection and the Descent of Man 1871-1971 (Ed. by B. Campbell), pp. 136-179. Chicago: Aldine.

Utne-Palm, A.C. \& Hart, P.J.B. 2000. The effects of familiarity on competitive interactions between three-spined sticklebacks. Oikos, 91, 225-232.

Valone, T.J. \& Templeton, J.J. 2002. Public information for the assessment of quality: a widespread social phenomenon. Proceedings of the Royal Society of London B, $357,1549-1557$.

Viscido, S.V., Parrish, J.K. \& Grunbaum, D. 2004. Individual behavior and emergent properties of fish schools: a comparison of observation and theory. Marine Ecology-Progress Series, 273, 239-249.

Vives, S. 1988. Parent choice by larval convict cichlids, Cichlasoma nigrofasciatum (Cichlidae, Pisces). Animal Behaviour, 36, 11-19.

Waldman, B. 1987. Mechanisms of kin recognition. Journal of Theoretical Biology, 128, $159-185$.

Ward, A.J.W., Axford, S. \& Krause, J. 2003. Cross-species familiarity in shoaling fishes. Proceedings of the Royal Society of London B, 270, 1157-1161. 
Ward, A.J.W., Botham, M.S., Hoare, D.J., James, R., Broom, M., Godin, J.-G.J. \& Krause, J. 2002a. Association patterns and shoal fidelity in the three-spined stickleback. Proceedings of the Royal Society of London B, 269, 2451-2455.

Ward, A.J.W. \& Hart, P.J.B. 2003. The effects of kin and familiarity on interactions between fish. Fish and Fisheries, 4, 348-358.

Ward, A.J.W. \& Hart, P.J.B. 2005. Foraging benefits of shoaling with familiars may be exploited by outsiders. Animal Behaviour, 69, 329-335.

Ward, A.J.W., Hart, P.J.B. \& Krause, J. 2004. The effects of habitat- and diet-based cues on association preferences in three-spined sticklebacks. Behavioral Ecology, $15,925-929$.

Ward, A.J.W., Hoare, D.J., Couzin, I.D., Broom, M. \& Krause, J. 2002b. The effects of parasitism and body length on positioning within wild fish shoals. Journal of Animal Ecology, 71, 10-14.

Ward, A.J.W., Holbrook, I., Krause, J. \& Hart, P.J.B. 2005. Social recognition in sticklebacks: the role of direct experience and habitat cues. Behavioral Ecology and Sociobiology, 57, 575-583.

Ward, A.J.W. \& Krause, J. 2001. Body length assortative shoaling in the European minnow, Phoxinus phoxinus. Animal Behaviour 62, 617-621.

Webster, M.M., Goldsmith, J., Ward, A.J.W. \& Hart, P.J.B. 2007. Habitat-specific chemical cues influence association preferences and shoal cohesion in fish. Behavioral Ecology and Sociobiology, 62, 273-280. 
West, S.A., Griffin, A.S. \& Gardner, A. 2007. Evolutionary explanations for cooperation. Current Biology, 17, R661-R672.

West Eberhard, M.J. 1975. The evolution of social behaviour by kin selection. Quarterly Review of Biology, 50, 1-33.

Wey, T.W. \& Blumstein, D.T. 2010. Social cohesion in yellow-bellied marmots is established through age and kin structuring. Animal Behaviour, 79, 1343-1352.

Wey, T.W., Blumstein, D.T., Shen, W. \& Jordan, F. 2008. Social network analysis of animal behaviour: a promising tool for the study of sociality. Animal Behaviour, 75, 333-344.

Whitehead, H. 2008. Analyzing Animal Societies: Quantitative Methods for Vertebrate Social Analysis. Chicago: University of Chicago Press.

Whitehead, H. 2009. SOCPROG programs: analysing animal social structures. Behavioral Ecology and Sociobiology, 63, 765-778.

Wilson, A.D.M. \& Godin, J.-G.J. 2009. Boldness and behavioral syndromes in the bluegill sunfish, Lepomis macrochirus. Behavioral Ecology, 20, 231-237.

Wisenden, B.D. 1994. Factors affecting reproductive success in free-ranging convict cichlids (Cichlasoma nigrofasciatum). Canadian Journal of Zoology, 72, 2177 2185.

Wisenden, B.D. 1995. Reproductive behaviour of free-ranging convict cichlids, Cichlasoma nigrofasciatum. Environmental Biology of Fishes, 43, 121-134.

Wisenden, B.D. 1999. Alloparental care in fishes. Reviews in Fish Biology and Fisheries, 9, 45-70. 
Wisenden, B.D. \& Dye T.P. 2009. Young convict cichlids use visual information to update olfactory homing cues. Behavioral Ecology and Sociobiology, 63, 443449.

Wisenden, B.D. \& Keenleyside, M.H.A. 1992. Intraspecific brood adoption in convict cichlids: a mutual benefit. Behavioral Ecology and Sociobiology, 31, 263-269.

Wisenden, B.D. \& Keenleyside, M.H.A. 1994. The dilution effect and differential predation following brood adoption in free-ranging convict cichlids (Cichlasoma nigrofasciatum). Ethology, 96, 203-212.

Wisenden, B., Snekser, J., Stumbo, A. \& Leese, J. 2008. Parental defence of an empty nest after catastrophic brood loss. Animal Behaviour, 76, 2059-2067.

Yanagisawa, Y. 1985. Parental strategy of the cichlid fish Perissodus microlepis, with particular reference to intraspecific brood "farming out." Environmental Biology of Fishes, 12, 241-249.

Zar, J.H. 2010. Biostatistical Analysis. $5^{\text {th }}$ edn. Upper Saddle River, New Jersey: Prentice Hall.

Zardoya, R., Vollmer, D.M., Craddock, C., Streelman, J.T., Karl, S.A. \& Meyer, A. 1996. Evolutionary conservation of microsatellite flanking regions and their use in resolving the phylogeny of cichlid fishes (Pisces: Perciformes). Proceedings of the Royal Society of London B, 263, 1589-1598. 


\section{APPENDIX 1 - Operational Definitions}

Aggregation: Organisms grouping together, can imply social or non-social groups Alloparental care: parental care of non-descendent young (Wisenden 1999) throughout this thesis, this implies unrelated young

(Shoal) Cohesiveness: the 'tightness' of individuals within a shoal, measured by interindividual distances between shoal-mates

Developmental stage: throughout this thesis this refers to different developmental periods (corresponds to body size) during the free-swimming fry stage of convict cichlid young

Familiarity: 'preferred association with certain individuals which have previously interacted' (Ward and Hart 2005, page 329).

Family unit: parents and young/brood

Fish $(p l)$ : more than one fish of the same species

Fishes $(p l)$ : more than one fish of at least two different species

Fission-fusion groups: social groups where individuals are continually joining or leaving

Free-ranging shoal: a naturally-occurring shoal in the field/wild

Fry: this term is used when referring the free-swimming larval stage of fish

Focal fish: during a choice experiment, the 'test' fish which is being observed, and whose choice is being quantified

Homing: used here as young returning to parents and brood mates (not the same meaning as homing in the migration literature) 
Kinship: being genetically related, in Part II this refers to siblings

Ontogeny: the developmental history of an organism

Phenotypic assortment: non-random grouping of individuals based on a similar phenotype (e.g. body size, colour, etc.)

School: a group of fishes which swim in a polarized and synchronised manner (i.e. all aligned and facing in the same direction)

Shoal: a group of fishes brought together by social attraction, with no implications for group structure (Pitcher and Parrish 1993)

Sibset: categorizing young into a group which are likely siblings based on genotype

Social group: typically, three or more animals occurring together, brought together by active choice (socially attracted)

Standard Length: a traditional body length measurement, from tip of the fish's nose to the end of the caudal peduncle (where the caudal fin starts)

Stimulus shoal: an experimental shoal which is used to elicit a choice response from the focal fish 


\section{APPENDIX 2}

Please see accompanying co-author permission letters (only attached to hard copies of this thesis).

\section{List of Letters:}

- Dr. Jean-Guy Godin

- Dr. Myron Smith

- Adam Densmore 


\section{Appendix 2. Co-author and journal copyright permissions}

August 1, 2012

Dear Stacey and to whomever else it may concern,

I herewith grant permission to Stacey Lee-Jenkins to include the following journal papers or manuscript, on which I am co-author with her, as individual chapters in her doctoral thesis entitled "The Behavioural Ecology of Social Associations in Fishes", as well as my permission for her to claim copyright for said thesis chapters.

Yours sincerely,

Jean-Guy J. Godin $\dot{2}$

Chancellor's Professor

Carleton University

Lee-Jenkins, S.S.Y., A.M. Densmore, J.-G.J Godin and M.L. Smith. 2011. Polymorphic microsatellite loci optimized for studies on the convict cichlid fish (Amatitlania siquia). Environmental Biology of Fishes, 92: 261-266.

Lee-Jenkins, S.S.Y. and J.-G. J. Godin. 2010. Social familiarity and shoal formation in juvenile fishes. Journal of Fish Biology, 76: 580-590.

Lee-Jenkins, S.S.Y. and J.-G.J. Godin. Concurrent effects of familiarity and kinship on social affiliations in convict cichlid (Amatitlania siquia) young. Submitted to Behaviour (under review). 


\section{Appendix 2. Co-author and journal copyright permissions}

August 1, 2012

Dear Stacey and to whomever else it may concern,

I herewith grant permission to Stacey Lee-Jenkins to include the following journal paper, on which I am co-author with her, as a chapter in her doctoral thesis entitled "The Behavioural Ecology of Social Associations in Fishes", as well as my permission for her to claim copyright for this particular thesis chapter.

Yours sincersly.

Myron L. Smith

Professor of Biology

Carleton University

Lee-Jenkins, S.S.Y., A.M. Densmore, J.-G.J Godin and M.L. Smith. 2011 . Polymorphic microsatellite loci optimized for studies on the convict cichlid fish (Amatitlania siquia). Environmental Biology of Fishes, 92: 261-266. 


\section{Appendix 2. Co-author and journal copyright permissions}

August 1, 2012

Dear Stacey and to whomever else it may concern,

I herewith grant permission to Stacey Lee-Jenkins to include the following journal paper, on which I am co-author with her, as a chapter in her doctoral thesis entitled "The Behavioural Ecology of Social Associations in Fishes", as well as my permission for her to claim copyright for this particular thesis chapter.

Yours sincerely,

Adam M. Densmore - -

Lee-Jenkins, S.S.Y., A.M. Densmore, J.-G.J Godin and M.L. Smith. 2011. Polymorphic microsatellite loci optimized for studies on the convict cichlid fish (Amatitlania siquia). Environmental Biology of Fishes, 92: 261-266. 